\title{
Small Molecule CD38 Inhibitors: Synthesis of 8-Amino-N1-inosine 5'-monophosphate, Analogues and Early Structure-Activity Relationship
}

\author{
Joanna M. Watt ${ }^{1,2}$, Richard Graeff ${ }^{3}$ and Barry V. L. Potter $1,2, * \mathbb{D}$ \\ 1 Medicinal Chemistry \& Drug Discovery, Department of Pharmacology, University of Oxford, Mansfield Road, \\ Oxford OX1 3QT, UK; js511@bath.ac.uk \\ 2 Wolfson Laboratory of Medicinal Chemistry, Department of Pharmacy and Pharmacology, University of Bath, \\ Claverton Down, Bath BA2 7AY, UK \\ 3 Department of Physiology, University of Hong Kong, Hong Kong, China; richardgraeff@gmail.com \\ * Correspondence: barry.potter@pharm.ox.ac.uk; Tel.: +44-1865-271945
}

\section{check for} updates

Citation: Watt, J.M.; Graeff, R.; Potter, B.V.L. Small Molecule CD38 Inhibitors: Synthesis of

8-Amino-N1-inosine

5'-monophosphate, Analogues and Early Structure-Activity Relationship Molecules 2021, 26, 7165. https:// doi.org/10.3390/molecules26237165

Academic Editors: Diego

Muñoz-Torrero, Helen Osborn,

Robert J. Doerksen and Silvia Socorro

Received: 8 November 2021

Accepted: 24 November 2021

Published: 26 November 2021

Publisher's Note: MDPI stays neutral with regard to jurisdictional claims in published maps and institutional affiliations.

Copyright: (c) 2021 by the authors. Licensee MDPI, Basel, Switzerland. This article is an open access article distributed under the terms and conditions of the Creative Commons Attribution (CC BY) license (https:// creativecommons.org/licenses/by/ $4.0 /)$.

\begin{abstract}
Although a monoclonal antibody targeting the multifunctional ectoenzyme CD38 is an FDA-approved drug, few small molecule inhibitors exist for this enzyme that catalyzes inter alia the formation and metabolism of the N1-ribosylated, $\mathrm{Ca}^{2+}$-mobilizing, second messenger cyclic adenosine $5^{\prime}$-diphosphoribose (cADPR). N1-Inosine $5^{\prime}$-monophosphate (N1-IMP) is a fragment directly related to cADPR. 8-Substituted-N1-IMP derivatives, prepared by degradation of cyclic parent compounds, inhibit CD38-mediated cADPR hydrolysis more efficiently than related cyclic analogues, making them attractive for inhibitor development. We report a total synthesis of the N1-IMP scaffold from adenine and a small initial compound series that facilitated early delineation of structure-activity parameters, with analogues evaluated for inhibition of CD38-mediated hydrolysis of cADPR. The $5^{\prime}$-phosphate group proved essential for useful activity, but substitution of this group by a sulfonamide bioisostere was not fruitful. $8-\mathrm{NH}_{2}-\mathrm{N} 1-\mathrm{IMP}$ is the most potent inhibitor $\left(\mathrm{IC}_{50}=7.6 \mu \mathrm{M}\right)$ and importantly HPLC studies showed this ligand to be cleaved at high CD38 concentrations, confirming its access to the $\mathrm{CD} 38$ catalytic machinery and demonstrating the potential of our fragment approach.
\end{abstract}

Keywords: synthesis; cADPR; cyclase; nucleotide; fragment

\section{Introduction}

The second messenger cyclic ADP-ribose (cADPR, 1, Figure 1) mobilizes intracellular $\mathrm{Ca}^{2+}$ in numerous cell types [1]. cADPR is synthesized enzymatically from nicotinamide adenine dinucleotide $\left(\mathrm{NAD}^{+}\right)$through ADP-ribosyl cyclases and is hydrolyzed at the N1-glycosidic linkage to give ADP-ribose (ADPR) both chemically and under physiological conditions [2-4]. cADPR chemistry and the cADPR/ $\mathrm{Ca}^{2+}$ signaling system were reviewed [5-11]. The multifunctional ectoenzyme human CD38 is primarily an $\mathrm{NAD}^{+}$glycohydrolase (NADase) and transforms NAD ${ }^{+}$into ADPR (Figure 1), but it can also produce a small amount of $\mathrm{cADPR}$ through its cyclase activity and convert cADPR into ADPR through its hydrolase activity [12,13]. It catalyzes the biosynthesis of two calcium-mobilizing second messengers cADPR and nicotinamide adenine dinucleotide phosphate (NAADP).

CD38 has relevance for a range of diseases, e.g., it is a marker of AIDS progression and a negative prognostic marker of chronic lymphocytic leukemia. A recent review categorized the enzyme as a druggable target, at least for human cancers [14]. It was also shown to be influential for social behaviour in mice [15] and plays a key role in age-related NAD ${ }^{+}$ decline. $\mathrm{NAD}^{+}$metabolism is implicated in the aging process and in the pathogenesis of several diseases. CD38 inhibition can decrease NADase activity and boost cellular 
$\mathrm{NAD}^{+}$levels and such a therapy could be used to promote increases in longevity and health span in models of aging and age-related disease [14]. Therefore, there is significant interest to identify CD38 inhibitors and provide structural clues for design of potential drug candidates.

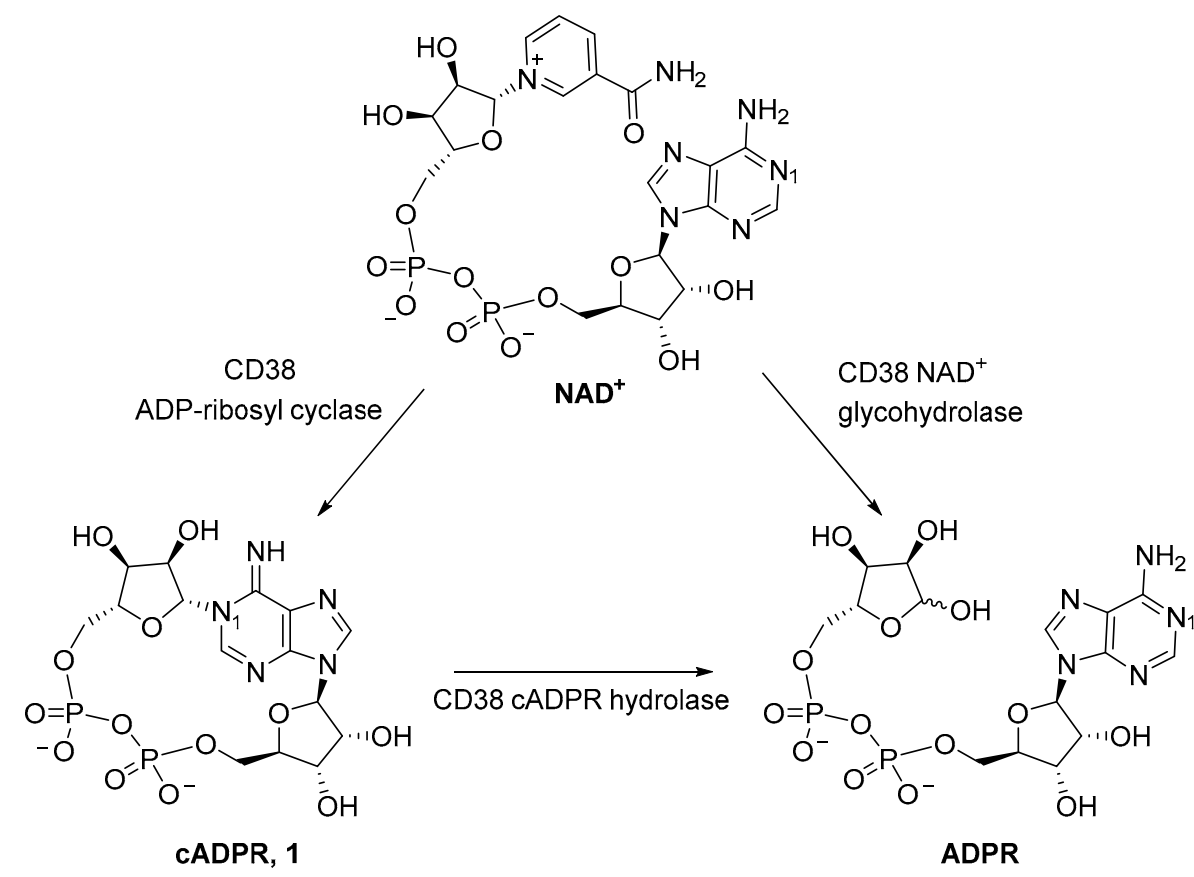

Figure 1. Conversion of $\mathrm{NAD}^{+}$into $\mathrm{CADPR}$ and ADPR.

The greatest therapeutic success so far has been in multiple myeloma using CD38 inhibitors as an antibody-based therapy to target white blood cells in the bone marrow that cause the disease and where CD38 is found on the cell surface. Darzalex (daratumumab), an FDA-approved CD38 inhibitor for mono- and combination therapy of multiple myeloma, binds to CD38, blocks the growth of the cells and induces their death. Several other antibody therapies are currently being evaluated in clinical trials, for example Isatuximab, GBR 1342, TAK - 079 and TAK - 169 [16], but relatively few small molecule CD38 inhibitors have been reported to date and there is a need to identify lead structures.

Inhibitors of the CD38 $\mathrm{NAD}^{+}$glycohydrolase activity have mainly been investigated, the best being covalent mechanism-based agents that modify the active site. For example, nicotinamide ribose derivatives derived from $\mathrm{NAD}^{+}$exhibit $\mathrm{K}_{i}$ values in the nanomolar range $[17,18]$. Metabolically stable nicotinamide-based analogues can block endogenous $\mathrm{CD} 38$ activity [19]. A non-hydrolysable $\mathrm{NAD}^{+}$analogue is a weak micromolar competitive inhibitor [19]. Membrane permeable analogues are low $\mathrm{mM}$ inhibitors and could relax agonist-induced muscle contraction [20]. NAD ${ }^{+}$analogues with ribose, nucleobase, or pyrophosphate modifications have been explored [21]. Others explored non-nucleotide compounds and non-covalent compounds via screening methodologies [22]. Screening yielded a compound that after optimization afforded a non-covalent CD38 NADase inhibitor with an $\mathrm{IC}_{50}$ of $4.7 \mu \mathrm{M}$. Low micromolar concentrations of flavonoids inhibit CD38 [23]. A recent study reported the first small molecule allosteric modulator LX102 [24]. The structure of the CD38 catalytic domain and mechanism of cADPR breakdown have recently been elucidated crystallographically using covalent inhibitors [25,26]. Glu-226 is the catalytic residue and mutation eliminates activity [27]. Glu-146 is critical to regulate the multi-functionality of CD38-mediated $\mathrm{NAD}^{+}$hydrolysis, the ADP-ribosyl cyclase and cADPR hydrolysis activities [27-29].

We previously designed the hydrolysis-resistant cADPR analogue, cyclic inosine $5^{\prime}-$ diphosphoribose (N1-CIDPR, 2, Figure 2) in which an oxo group at position 6 replaces 
the amino group [30,31]. cADPR hydrolysis by CD38 is inhibited with an $\mathrm{IC}_{50}$ of $276 \mu \mathrm{M}$ and in T-cells N1-cIDPR induces $\mathrm{Ca}^{2+}$ release almost indistinguishably to that induced by cADPR [30,32]. We also described the first total synthesis of the membrane permeant, hydrolytically stable, analogue analogue 8 bromo-cIDPR (3) via regio- and stereoselective N1-ribosylation of protected 8-bromoinosine [33]. A crystal structure of the ligand with wild-type CD38 showed N1-cIDPR to bind in the active site, close to catalytic Glu-226 with the two hydroxyl groups of the "northern" ribose forming hydrogen bonds [34]. This work facilitates, at least in principle, structure-based design of novel CD38 inhibitors using the N1-cIDPR template. In another approach to more drug-like inhibitors we deleted the pyrophosphate group of the macrocycle using a "click" approach without serious loss of activity (5, Figure 2) [35].

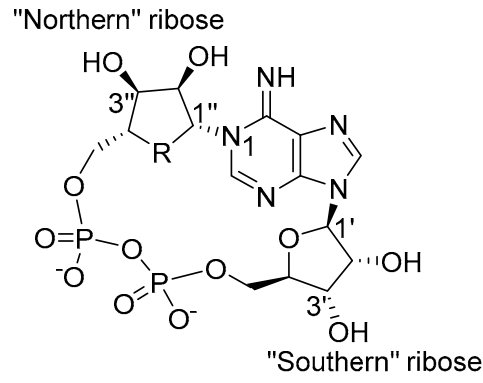

CADPR, $1 \mathrm{R}=\mathrm{O}$ CADPcR, 7, $\mathrm{R}=\mathrm{CH}_{2}$<smiles></smiles>

8- $\mathrm{NH}_{2}-\mathrm{N9}$-butyl-cIDPR, 6

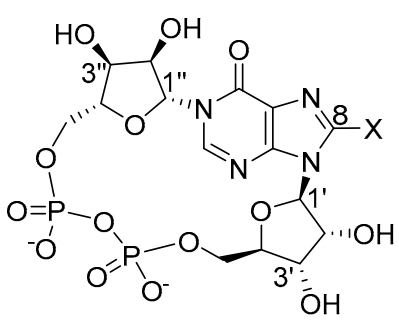

N1-CIDPR, 2, $\mathrm{X}=\mathrm{H}$ 8-Br-N1-CIDPR, 3, $\mathrm{X}=\mathrm{Br}$, 8- $\mathrm{NH}_{2}-\mathrm{N} 1$-CIDPR, $4 \mathrm{X}=\mathrm{NH}_{2}$

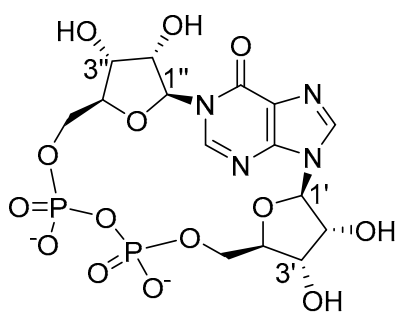

L-CIDPR, 8

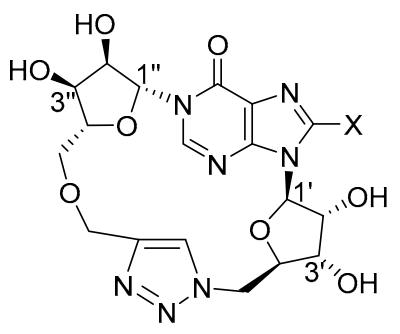

"Click" cIDPR analogues, 5 $\mathrm{X}=\mathrm{H}, \mathrm{NH}_{2}$

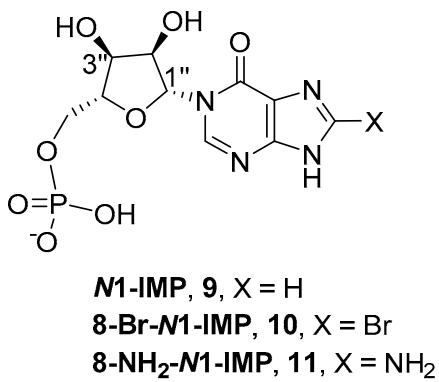

Figure 2. Structure and nomenclature of cADPR and previous analogues. NB the "northern" and "southern" riboses of the cyclic analogues are distinguished by adopting prime $\left({ }^{\prime}\right)$ and double prime $\left({ }^{\prime \prime}\right)$ notation respectively for their sugar carbons.

Analogues based on the N1-cIDPR template replaced the "southern" N9-ribose with a butyl chain, illustrating the nonessential nature of the "southern" ribose for binding [36] and 8-amino-N9-butyl-cIDPR (6) compared to the best non-covalent CD38 inhibitors $\left(\mathrm{IC}_{50}=3.3 \mu \mathrm{M}\right)$. Crystallographic analysis of the complex with CD38 unexpectedly revealed an N1-hydrolyzed ligand in the active site and ligand cleavage at high protein concentrations was confirmed. We described X-ray crystal structures of CD38 in complex with two non-hydrolysable inhibitors, an 8-substituted N1-cIDPR analogue analogue [37] and cADP carbocyclic ribose (cADPcR, 7, Figure 2) [38] and the elucidation of a preliminary SAR for inhibitors [39].

More recently, we exploited the cIDPR template to generate CD38 inhibitors via total synthesis. In the first example of a sugar hybrid cIDPR analog, L-cIDPR (8), the natural "northern" N1-linked D-ribose of cADPR was replaced by an L-ribose [40] and other work has demonstrated the existence of conformers in these macrocycles [41].

From a comparison of the N1-cIDPR and cADPcR complexes with wild-type CD38 it was clear that the "northern" ribose part of the cyclic dinucleotide (ribose and/or carbocycle) is more important in binding than the "southern" part [39]. The "northern" ribose monophosphate motif of N1-cIDPR and the carbocyclic ribose monophosphate of cADPcR overlap with the rest of the ligand accommodated more flexibly. This implied that 
perhaps non-cyclic simple fragments of the macrocycle could maintain key interactions with wild-type CD38 and might inhibit the enzyme.

A small series of N1-hypoxanthine ribose $5^{\prime}$-monophosphate fragments (N1-IMPs, 9-11), derived from careful degradation of the parent cyclic compound [39,42] were indeed inhibitors of CD38-catalyzed cADPR hydrolysis (Scheme 1). Moreover, 8-amino N1-IMP (11) showed promise, being considerably better than its cyclic counterpart $(7.6 \mu \mathrm{M}$ cf. 8- $\mathrm{NH}_{2}-\mathrm{N1}$-cIDPR $(4)$ at $\left.56 \mu \mathrm{M}\right)$ and this was explored and rationalized in a preliminary fashion through docking experiments [39]. The reduced complexity and lower molecular weight of such fragments make them attractive as a starting point for further inhibitor design. 8- $\mathrm{NH}_{2}-\mathrm{N1}$-IMP is among the best small non-covalent molecule inhibitors of CD38 activity reported so far; thus, its further development to design agents for pharmacological intervention is desirable and a straightforward synthesis is required.

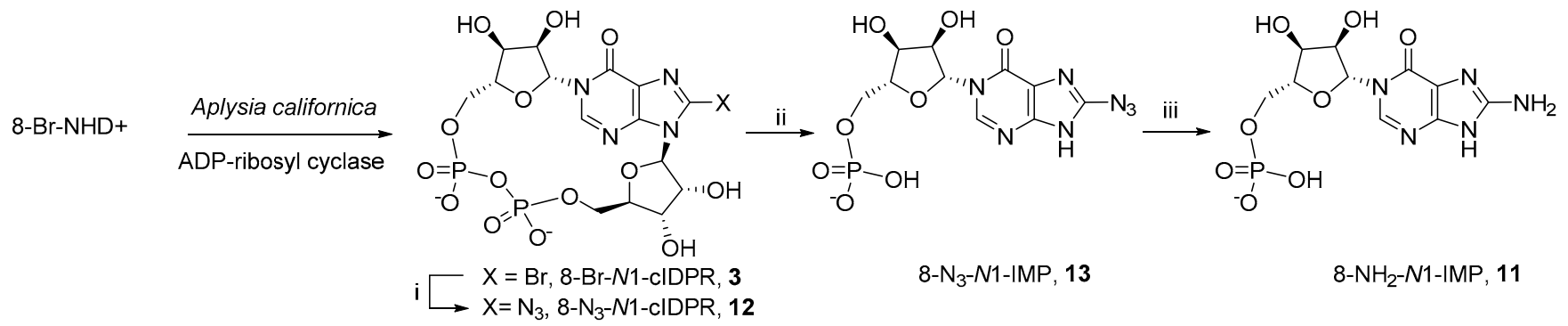

Scheme 1. Previous preparation of N1-IMP compounds. Reagents and conditions: (i) $\mathrm{NaN}_{3}$, (ii) $0.2 \mathrm{M} \mathrm{HCl}$; (iii) dithiothreitol.

We now report the synthesis of 8- $\mathrm{NH}_{2}-\mathrm{N1}$-IMP (11) and a small focused SAR study to examine obvious points of substitution and clarify the importance of the "northern" ribose phosphate group motif for cIDPR-based inhibitors (Figure 3). Analogues were evaluated for their inhibition of CD38-mediated hydrolysis of cADPR.<smiles>[X]c1nc2c(=O)n([C@H]3O[C@H](CO)[C@@H](O)[C@H]3O)cnc2n1[C@H]1O[C@H](CO)[C@@H](O)[C@H]1O</smiles>

$\mathrm{X}=\mathrm{Br}, 8-\mathrm{Br}-\mathrm{N1}$-ribosyl-inosine, 14

$\mathrm{X}=\mathrm{H}$, N1-ribosyl-inosine, 15

$\mathrm{X}=\mathrm{N}_{3}, 8-\mathrm{N}_{3}-N 1$-ribosyl-inosine, 16

$\mathrm{X}=\mathrm{NH}_{2}, 8-\mathrm{NH}_{2}-\mathrm{N} 1$-ribosyl-inosine, 17<smiles>[X]c1nc2c(=O)n([C@@H]3O[C@H](CO)[C@@H](O)[C@H]3O)cnc2n1CCCCO</smiles>

$\mathrm{X}=\mathrm{Br}, 8-\mathrm{Br}-N$ 9-butyl-N1-inosine, 18

$\mathrm{X}=\mathrm{H}$, N9-butyl-N1-inosine, 19

$\mathrm{X}=\mathrm{N}_{3}, 8-\mathrm{N}_{3}-N 9$-butyl-N1-inosine, 20

$\mathrm{X}=\mathrm{NH}_{2}, 8-\mathrm{NH}_{2}-\mathrm{N}$ - -butyl-N1-inosine, 21<smiles>[X]c1nc2c(=O)n([C@@H]3O[C@H](COP(=O)(O)O)[C@@H](O)[C@H]3O)cnc2n1CCCCO</smiles>

$\mathrm{X}=\mathrm{Br}$, 8-Br-N9-butyl-N1-IMP,

22

$\mathrm{X}=\mathrm{H}$, N9-butyl-N1-IMP, 23

$X=N_{3}, 8-N_{3}-N 9-$ butyl-N1-IMP,<smiles>[X]c1nc2c(=O)n([C@@H]3O[C@H](COP(=O)([O-])O)[C@@H](O)[C@H]3O)cnc2[nH]1</smiles>

$\mathrm{X}=\mathrm{Br}, 8-\mathrm{Br}-\mathrm{L}-\mathrm{N} 1-\mathrm{IMP}, 26$

$X=H, L-N 1-I M P, 27$

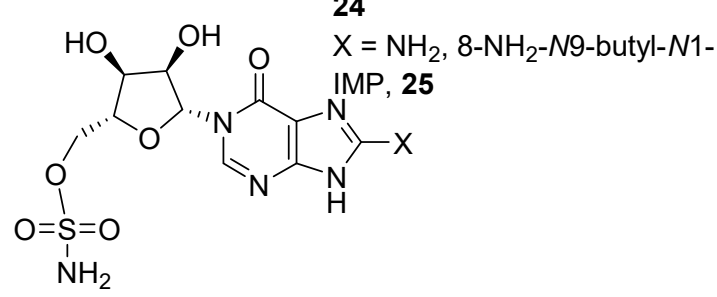

$\mathrm{X}=\mathrm{Cl}, 8-\mathrm{Cl}-\mathrm{N} 1-\mathrm{IMS}, 28$

$\mathrm{X}=\mathrm{H}, \mathrm{N} 1-\mathrm{IMS}, 29$

Figure 3. Synthetic analogues prepared in this study (IMP = Inosine $5^{\prime}$-monophosphate, IMS = Inosine $5^{\prime}$-monosulfamate). 


\section{Results and Discussion}

\subsection{Synthesis of Fragments}

Initially, fragments 14-17 were designed based on the cIDPR structure with only the pyrophosphate deleted.

Triacetyl protected 8-bromoinosine $\mathbf{3 0}$ was N1-ribosylated under standard conditions [33] to generate protected N1-ribosyl-8-bromoinosine 31 (Scheme 2). Sequential substitution with sodium azide and reduction with palladium under an atmosphere of hydrogen afforded the protected 8-azido (32) and 8-amino (33) analogues respectively. All three analogues were separately treated with methanolic ammonia to afford the corresponding N1-ribosyl-8-X-inosine analogues $(\mathbf{1 4}, \mathbf{1 6}, \mathbf{1 7})$. N1-ribosyl inosine $(\mathbf{1 5})$ was prepared directly from 31 upon treatment with palladium under an atmosphere of hydrogen.

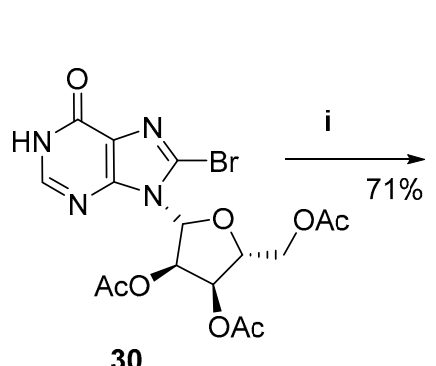

30

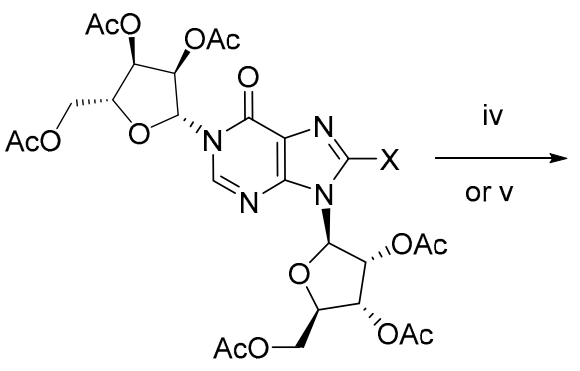

$\mathrm{AcO}$

iii, $81 \% \square \begin{aligned} 31, X & =\mathrm{Br} \\ \mathbf{3 2}, \mathrm{X} & =\mathrm{N}_{3} \\ \mathbf{3 3}, \mathrm{X} & =\mathrm{NH}_{2}\end{aligned} \quad$ ii, $56 \%$<smiles>[X]c1nc2c(=O)n(C3OC(CO)C(O)C3O)cnc2n1C1OC(CO)[C@@H](O)[C@@H]1O</smiles>

$14, \mathrm{X}=\mathrm{Br}, 100 \%$

$15, \mathrm{X}=\mathrm{H}, 50 \%$

16, $\mathrm{X}=\mathrm{N}_{3}, 47 \%$

$17, \mathrm{X}=\mathrm{NH}_{2}, 83 \%$

Scheme 2. Synthesis of N1-ribosyl inosine analogues. Reagents and conditions (i) (a) DBU, MeCN; (b) tetra-acetyl-D-ribose, TMSOTf; (ii) $\mathrm{NaN}_{3}, \mathrm{DMF}, 70{ }^{\circ} \mathrm{C}$; (iii) $\mathrm{H}_{2}, \mathrm{Pd}(\mathrm{C}), \mathrm{EtOH}$; (iv) $\mathrm{NH}_{3}$ (g), $\mathrm{MeOH}$; (v) $\mathrm{H}_{2}, \mathrm{Pd}(\mathrm{C}), \mathrm{NaHCO}_{3}, \mathrm{EtOH}$.

We next prepared fragments with an N9-butyl linker in place of the "southern" ribose (N9-hydroxybutyl-N1-inosine derivatives, 18-21, Scheme 3). This substitution in related cyclic analogues [36] showed improved inhibition of CD38-mediated hydrolysis of cADPR.

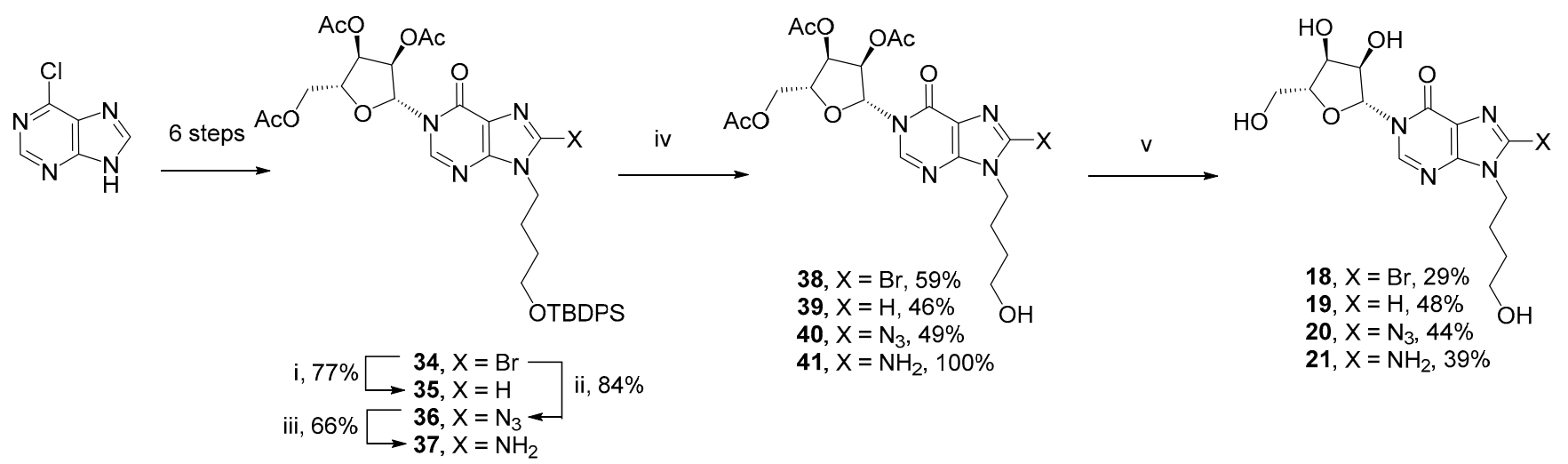

Scheme 3. Synthesis of N9-hydroxybutyl-N1-inosine analogues. Reagents and conditions(i) $\mathrm{H}_{2}, \mathrm{Pd}(\mathrm{C}), \mathrm{NaHCO}_{3}, \mathrm{EtOH}$; (ii) $\mathrm{NaN}_{3}, \mathrm{DMF}, 70{ }^{\circ} \mathrm{C}$; (iii) $\mathrm{H}_{2}, \mathrm{Pd}(\mathrm{C}), \mathrm{EtOH}$; (iv) TBAF. $3 \mathrm{H}_{2} \mathrm{O}, \mathrm{AcOH}, \mathrm{DMF}$; (v) $\mathrm{NH}_{3}$ (g), $\mathrm{MeOH}$.

8-Bromo-N9-(4-hydroxybutyl)-N1-inosine (34, Scheme3) was prepared from 6-chloropurine, as previously described [36]. Briefly, an N9-hydroxybutyl chain was introduced onto 6chloropurine that was converted in four steps to the protected 8-bromohypoxanthine. Treatment with 1,8-diazabicyclo [5.4.0]undec-7-ene (DBU) followed by trimethylsilyl triflate (TMSOTf) and 1,2,3,5-tetra-O-acetyl- $\beta$-D-ribofuranose generated the N1-ribosyl scaffold 34 . To generate three further 8-substituted analogues, 34, was treated with palladium on carbon under an atmosphere of hydrogen to generate the $8-\mathrm{H}$ analogue 35 . 8-Bromo 34 was substituted in the 
8-position using sodium azide in DMF at $70{ }^{\circ} \mathrm{C}$ to prepare 8-azido analogue 36. Finally, 8-azido analogue 36 was reduced using palladium on charcoal under an atmosphere of hydrogen to prepare 8-amino analogue 37 (Scheme 3). All four protected analogues (34-37) were deprotected in a two stage process. First the N9-hydroxybutyl was revealed by treatment with neutral TBAF in DMF to prepare 38-41, then the acetyl protecting groups were removed from the N1-ribose using saturated methanolic ammonia to prepare the final compounds $\left(8-\mathrm{Br} 18,8-\mathrm{H} 19,8-\mathrm{N}_{3} 20\right.$, 8- $\mathrm{NH}_{2}$ 21).

To determine the importance of the 5'-O-phosphate group, N9-hydroxybutyl-N1inosine derivatives (22-25) were also prepared (Scheme 4). 8-Bromo-N9-(4-hydroxybutyl)N1-inosine (34) was deprotected and reprotected as the isopropylidene ketal 42 in preparation for introduction of the protected 5-O-phosphate to afford 43. Attempts to introduce different 8-substituents to the hypoxanthine ring at this stage were not successful, presumably due to steric interference from the adjacent N9-butyl chain and bulky TBDPS group. Sequential deprotection of the TBDPS silyl ether with TBAF to afford 44, followed by deprotection of both phosphate esters and the isopropylidene ketal using aqueous TFA furnished 8-bromo-N9-hydroxybutyl-N1-IMP 22. The 8-bromo substituent was removed by hydrogenation to afford $\mathbf{2 3}$ or nucleophilic substitution with TMS- $\mathrm{N}_{3}$ to afford $\mathbf{2 4}$, followed by reduction with dithiothreitol to afford 25 .
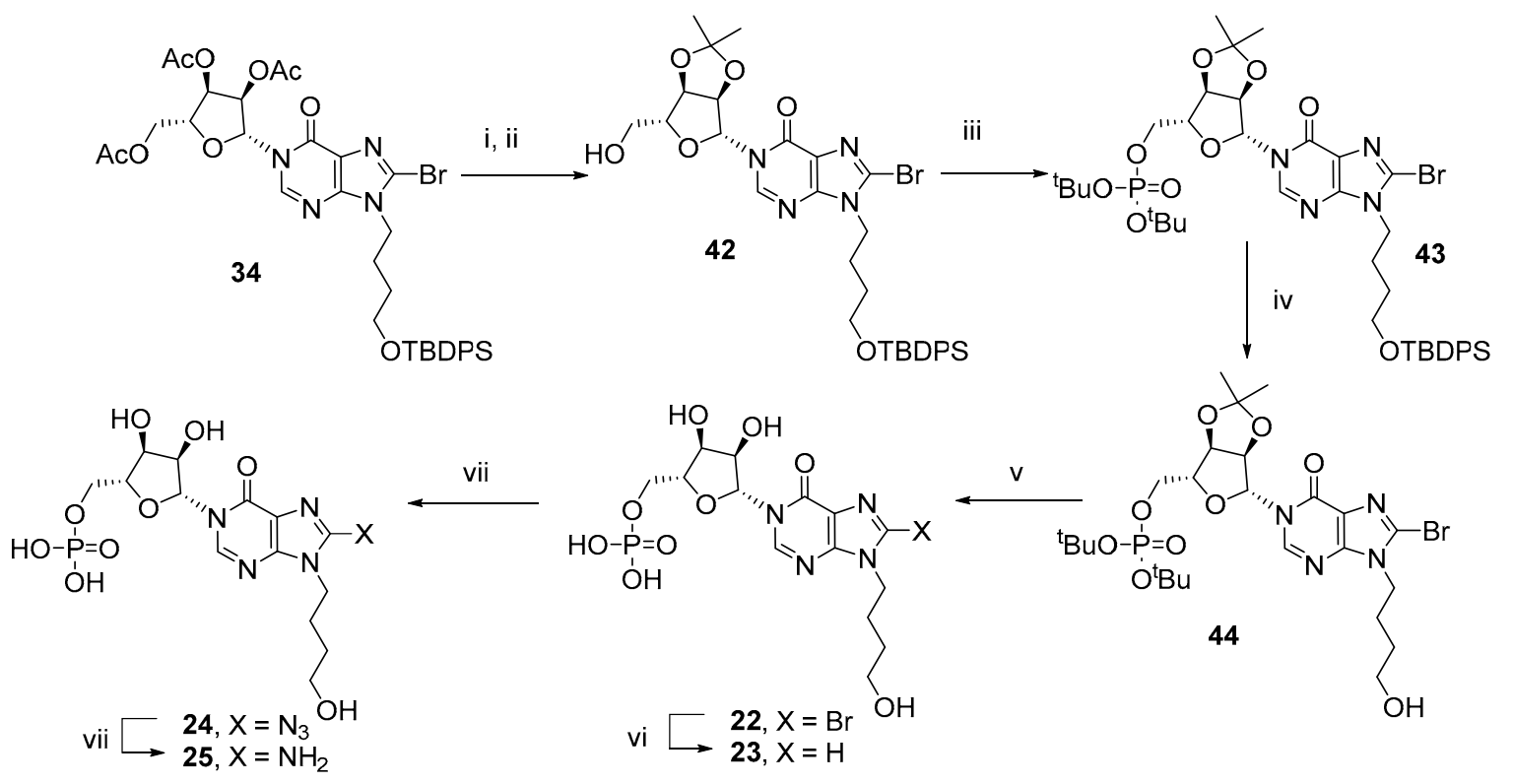

Scheme 4. Synthesis of N9-(4-hydroxybutyl)-N1-IMP analogues. Reagents and conditions (i) $\mathrm{NH}_{3}, \mathrm{MeOH}^{-}$(ii) 2,2dimethoxypropane, acetone, $p \mathrm{TsOH}$; (iii) (a) ${ }^{i} \mathrm{Pr}_{2} \mathrm{NP}\left(\mathrm{O}^{t} \mathrm{Bu}\right)_{2}, 5-\mathrm{Ph}-1 H$-tetrazole, DCM; (b) $\mathrm{H}_{2} \mathrm{O}_{2}, \mathrm{Et}_{3} \mathrm{~N}$; (iv) TBAF.3 $\mathrm{H}_{2} \mathrm{O}$, $\mathrm{AcOH}, \mathrm{DMF}$; (v) aq. TFA; (vi) $\mathrm{H}_{2}, \mathrm{Pd}(\mathrm{C}), \mathrm{NaHCO}_{3}, \mathrm{EtOH}_{-} \mathrm{H}_{2} \mathrm{O}(1: 2 \mathrm{v} / v)$; (vii) TMS-N 3 , DMF; (viii) dithiothreitol, $0.05 \mathrm{M}$ TEAB.

We previously synthesized 8- $\mathrm{NH}_{2}-\mathrm{N1}$-IMP (11) by destruction of 8- $\mathrm{N}_{3}$-CIDPR (12, Scheme 2) through acid catalyzed hydrolysis at elevated temperature [39]. However, this route is inefficient and thus we sought an alternative via total synthesis. Starting from adenine 45, the tert-butyldimethylsilyloxymethyl group [43] was introduced in a two-step procedure. In contrast to other N9 protecting groups, such as benzyl, benzoyl or acetyl, this generates an organically soluble product that is considerably easier to handle. The N9-protected adenine $\mathbf{4 6}$ was then prepared for a regio- and stereoselective N1glycosylation by introduction of a bromine group at $C 8$ to give 47 , followed by treatment with sodium nitrite to effect conversion from adenine to hypoxanthine base (48). N1glycosylation was effected by treatment of 48 with DBU, followed by TMSOTf and 1,2,3,5tetra-O-acetyl- $\beta$-D-ribofuranose to afford 49 . The three acetyl protecting groups were removed using methanolic ammonia and exchanged for a $2^{\prime}, 3^{\prime}$-O-isopropylidene group 
by treatment with 2,2-dimethoxypropane and acetone under acidic conditions to afford 50. The protected precursor $\mathbf{5 0}$ was phosphitylated at the free $5^{\prime}-\mathrm{OH}$ using di-tert-butyl protected phosphoramidite, followed by oxidation to the corresponding phosphate using hydrogen peroxide and triethylamine to afford 51. A convenient global deprotection of the tert-butyldimethylsilyloxymethyl, isopropylidene ketal and two tert-butyl phosphate esters using $50 \%$ aqueous TFA generated 10, the N1-IMP scaffold with an 8-bromo substituent. This could be conveniently manipulated to generate $8-\mathrm{NH}_{2}-\mathrm{N} 1-\mathrm{IMP} \mathbf{1 1}$ by sequential treatment with TMS- $\mathrm{N}_{3}$ and dithiothreitol (Scheme 5). Attempts to convert the 8-Br substituent to the $8-\mathrm{N}_{3}$ analogue at an earlier stage in the synthesis were unsuccessful as the N7-tert-butyldimethylsilyloxymethyl protecting group was cleaved concurrently.
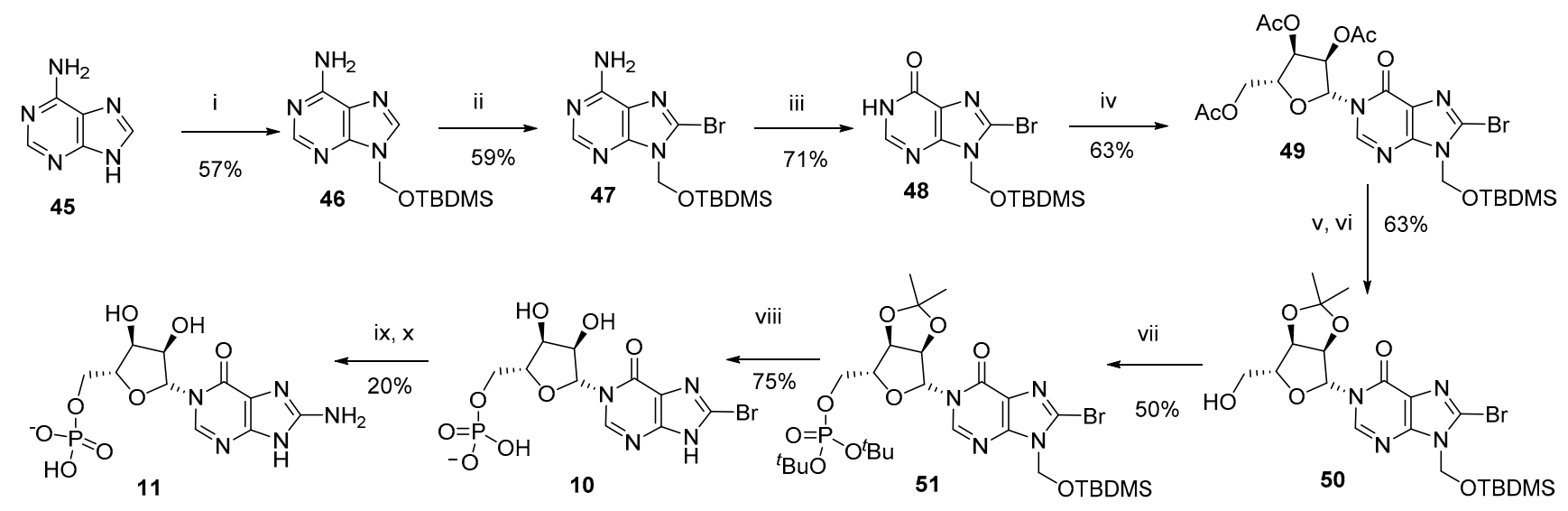

Scheme 5. Preparation of 8- $\mathrm{NH}_{2}-\mathrm{N} 1-\mathrm{IMP}$ via a total synthetic route. Reagents and conditions (i) (a) Formaldehyde,

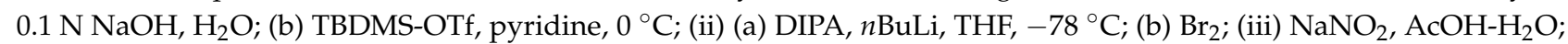
(iv) (a) DBU, DCM; (b) tetra-acetyl-D-ribose then TMS-OTf; (v) $\mathrm{NH}_{3}, \mathrm{MeOH}$; (vi) 2,2-dimethoxypropane, acetone, $p$ TsOH; (vii) (a) ${ }^{i} \mathrm{Pr}_{2} \mathrm{NP}\left(\mathrm{O}^{t} \mathrm{Bu}\right)_{2}, 5-\mathrm{Ph}-1 H$-tetrazole, DCM; (b) $\mathrm{H}_{2} \mathrm{O}_{2}, \mathrm{Et}_{3} \mathrm{~N}$; (viii) aq. TFA; (ix) TMS-N ${ }_{3}$, DMF; (x) dithiothreitol, $0.05 \mathrm{M}$ TEAB.

We next sought to explore the SAR of these more accessible, less negatively charged molecules. Following on from our earlier interesting results with inhibition of CD38 from compounds with an L-configuration "northern" ribose [40], we synthesized fragments with an L-ribose (Scheme 6). Briefly, N1-glycosylation of $\mathbf{4 8}$ was affected by treatment with DBU, TMSOTf and 1,2,3,5-tetra-O-acetyl- $\beta$-L-ribofuranose to afford 52. Treatment with methanolic ammonia removed the three acetyl groups (53), followed by introduction of a $2^{\prime}, 3^{\prime}$-O-isopropylidene ketal to afford 54 . The protected precursor was phosphitylated at the free $5^{\prime}-\mathrm{OH}$ and oxidized using the methods described above to afford 55. Global deprotection using 50\% aqueous TFA generated 26, the L-N1-IMP scaffold with an 8bromo substituent. The 8-bromo substituent was reduced to generate L-N1-IMP 27 using hydrogenation with palladium on carbon.

We next explored the potential for N1-phosphate replacement with a bioisostere (Scheme 7). Phosphate bioisosteres present binding partners without negative charge, which is more attractive for drug design [44].

N1-( $\beta$-D-Ribofuranosyl)-N9-tert-butyldimethylsilyloxymethyl-8-bromohypoxanth-ine (50) was treated with triethylamine followed by addition of sulfamoyl chloride. In addition to the desired introduction of a 5-O-sulfonamide group, the 8-bromo substituent was also substituted by an 8-chloro substituent in the reaction mixture, confirmed by MS (ES 588.13 and 590.13, 3:1) to afford 56. Deprotection of the N9-protecting group with aqueous TFA gave the 8-chloro sulfonamide analogue 28. Removal of the 8-chloro substituent by treatment with palladium on carbon under an atmosphere of hydrogen gave the N9-protected parent analogue 57, which was then deprotected using aqueous TFA to give sulfonamide analogue 29. 


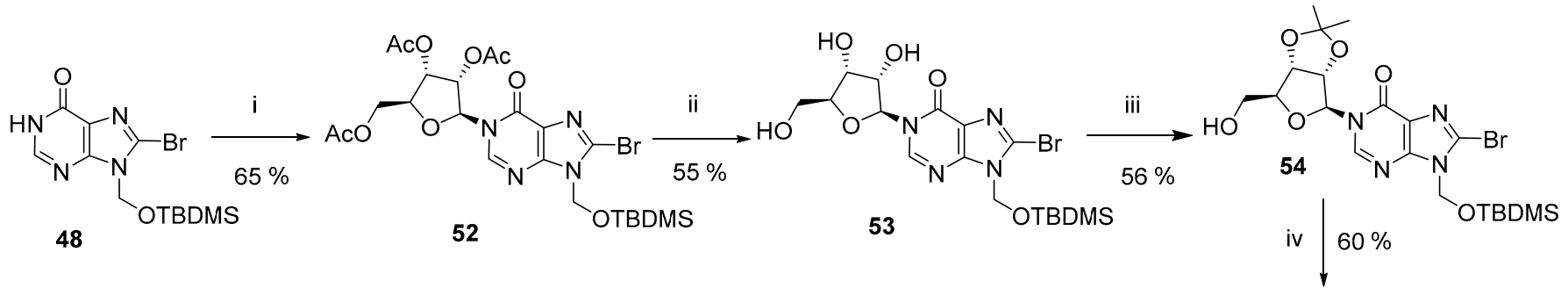

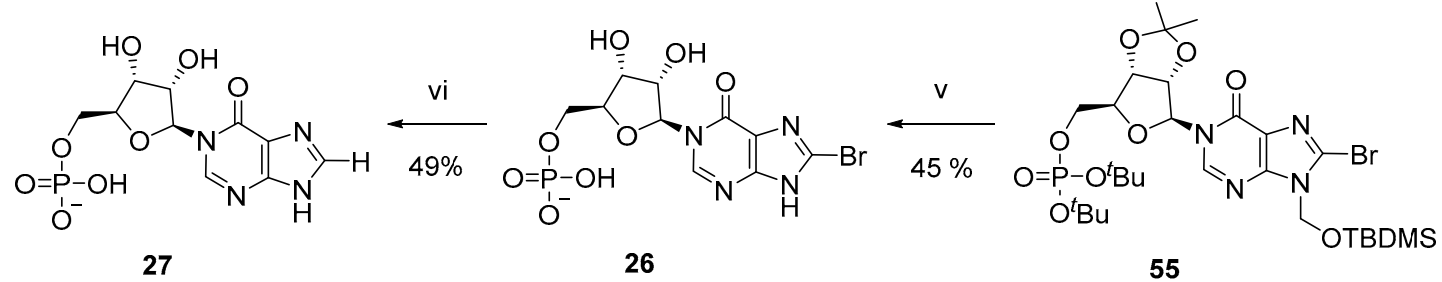

Scheme 6. Synthesis of L-ribose-N1-IMP analogues. Reagents and conditions (i) (a) DBU, DCM; (b) tetra-acetyl-L-ribose then TMS-OTf; (ii) $\mathrm{NH}_{3}, \mathrm{MeOH}$; (iii) 2,2-dimethoxypropane, acetone, $p \mathrm{TsOH}$; (iv) (a) ${ }^{i} \mathrm{Pr}_{2} \mathrm{NP}\left(\mathrm{O}^{t} \mathrm{Bu}\right)_{2}, 5-\mathrm{Ph}$ - $1 \mathrm{H}$-tetrazole, DCM; b) $\mathrm{H}_{2} \mathrm{O}_{2}, \mathrm{Et}_{3} \mathrm{~N}$; (v) aq. TFA; (vi) $\mathrm{H}_{2}, \mathrm{Pd}(\mathrm{C}), \mathrm{NaHCO}_{3}, \mathrm{EtOH}_{-} \mathrm{H}_{2} \mathrm{O}(1: 2 v / v)$.<smiles>C[C@H](OS(N)(=O)=O)C(C)(C)C</smiles>

Scheme 7. Synthesis of 5'-O-sulfonamyl- $\mathrm{N1}$-inosine analogues. Reagents and conditions (i) $\mathrm{H}_{2} \mathrm{NSO}_{2} \mathrm{Cl}$ in toluene (0.44 M), TEA, DCM; (ii) aq. TFA; (iii) $\mathrm{H}_{2}, \mathrm{Pd}(\mathrm{C}), \mathrm{NaHCO}_{3}$, EtOH.

\subsection{Fragments as Inhibitors of $c A D P R$ Hydrolysis}

All fragments were evaluated as inhibitors of CD38-catalyzed cADPR hydrolysis

(Table 1). Inhibition of cADPR hydrolysis was determined by incubating the inhibitor with CADPR and CD38 for $10 \mathrm{~min}$. and evaluating the unhydrolyzed cADPR remaining.

Table 1. Summary of inhibitory activity $\left(\mathrm{IC}_{50}, \mu \mathrm{M}\right)$ of analogues.

\begin{tabular}{cccccc}
\hline Compound & $\mathbf{8 - B r}$ & $\mathbf{8 - H}$ & $\mathbf{8 - \mathbf { N } _ { \mathbf { 3 } }}$ & $\mathbf{8 - \mathbf { N H }}$ & $\mathbf{8}-\mathbf{C l}$ \\
\hline N1-ribosyl-inosine 14-17 & No activity & 7500 & No activity & 7600 & - \\
N9-Hydroxybutyl-N1-inosine 18-21 & Insoluble & 2300 & 9500 & 3300 & - \\
N9-Hydroxybutyl-N1-IMP 22-25 & n.d & $757 \pm 122$ & $201 \pm 13$ & $332 \pm 44$ & - \\
N1-IMP 9-11 [39] & $201 \pm 41$ & $14 \pm 5$ & $n . d$ & $7.6 \pm 0.2$ & - \\
L-N1-IMP 26, 27 & $230 \pm 9$ & $460 \pm 70$ & - & - \\
N1-IMS 28, 29 & - & No activity & & No activity \\
\hline
\end{tabular}


Analogues with an N1-ribosyl group (14-17) were poor inhibitors of CD38. The 8-Br (14) and 8- $\mathrm{N}_{3}(\mathbf{1 6})$ analogues showed no activity and the $8-\mathrm{H}(\mathbf{1 5})$ and 8- $\mathrm{NH}_{2}(\mathbf{1 7})$ analogues both only showed low mM inhibitory activity. The 8-bromo analogue 18 was insoluble in the assay medium, suggesting that the combination of the N9-hydroxybutyl group and the hydrophobic 8-bromine reduced the polarity of the fragment compared to the 8- $\mathrm{H}$, $-\mathrm{N}_{3}$ and $-\mathrm{NH}_{2}$ analogues. N9-Hydroxybutyl-N1-inosines (19-21) were low $\mathrm{mM}$ inhibitors, possibly showing a marginal improvement compared to the N1-ribosyl-inosine analogues (14-17). Taken together, the poor inhibitory activity of analogues 14-21 suggests that the N1-ribose $-5^{\prime}$-phosphate group is an essential feature for inhibitory activity.

The N9-hydroxybutyl-N1-IMPs (23-25) showed improved inhibitory activity compared to their non-phosphorylated N9-hydroxybutyl counterparts (18-21), with the most active being 8- $\mathrm{N}_{3}$ analogue $24\left(\mathrm{IC}_{50}=201 \mu \mathrm{M}\right)$. N9-hydroxybutyl-N1-IMPs (23-25) showed a 40-fold reduction in activity compared to the parent N1-IMPs (9-11). This is the opposite trend observed with the cyclic analogues in previous studies [36], perhaps due to the unconstrained nature of the hydrophobic butyl chain in this case, compared to in a restricted cyclic analog.

The two analogues with an L-ribose as the N1-ribose configuration $(26,27)$ showed contrasting activity. While the activity of 8-Br analogue 26 was similar to the 8-Br N1-IMP analogue 10, the 8-H analogue 27 showed a 30 -fold reduction in activity compared to its D-ribose counterpart 9 ( $\mathrm{IC}_{50}=460$ and $14 \mu \mathrm{M}$, respectively). In other studies, where the L-ribose was constrained as part of a cyclic analog, the L-ribose substitution highlighted differences in binding activity that were attributed to likely different binding modes [40]. For fragments such as $\mathbf{2 6}$ and 27, however, there would be free rotation around the N1ribosyl bond and a smaller overall ligand to fit into the binding pocket.

CD38 is predominantly an ectoenzyme, but to a small degree its catalytic site can also face the intracellular environment, e.g., Type III CD38 has its C-terminal facing intracellularly, CD38 is present in the nucleus and mitochondrial membrane and a soluble form of CD38 is likely present in the cytoplasm [14]. Thus, approaches to neutralize the mono-phosphate charges of inhibitors could be useful for wider targeting of the enzyme. Attempted phosphate replacement with a sulfonamide bioisostere (Scheme 7), however, did not generate CD38 inhibitors, as neither of the two analogues $(\mathbf{2 8}, \mathbf{2 9})$ showed any activity. For further development there are obviously many further phosphate bioisosteres that could be explored, as well as perhaps more importantly alternative methods to mask phosphate negative charges, such as acetoxymethyl-esters and the Protide approach, using groups that may be cleaved intracellularly [44].

\subsection{Ligand Hydrolysis by CD38}

Previous studies demonstrated that CADPR analogues inhibiting CD38-mediated hydrolysis could be turned over by the high concentrations of CD38 catalytic domain (shCD38) used during crystallography [36]. Indeed, 8- $\mathrm{NH}_{2}-\mathrm{N} 9-$ butyl-cIDPR (6, Figure 2) was captured as the hydrolyzed product in the crystal structure with shCD38. Demonstration of hydrolysis by shCD38 using HPLC suggests that the fragment is indeed binding to the cADPR pocket, probably in an orientation that places the N1-ribosyl bond within reach of the catalytic residue. Incubation of 11, 8- $\mathrm{NH}_{2}-\mathrm{N} 1-\mathrm{IMP}$ (1 $\mathrm{mM}$ final concentration) with $4 \mathrm{mg} / \mathrm{mL}$ shCD38 was monitored using RP-HPLC. The peak corresponding to 8- $\mathrm{NH}_{2-}$ N1-IMP $\left(\mathrm{R}_{\mathrm{T}}=10.5 \mathrm{~min}\right.$.) reduced in intensity over time, alongside the appearance of a new peak $\left(\mathrm{R}_{\mathrm{T}}=2.0 \mathrm{~min}\right.$.) that was characteristic of an 8-amino substituted hypoxanthine analogue (See Supplementary Information, Figure S1). No change in the original peak was observed in a parallel control experiment containing no shCD38 (data not shown). 8-NH $\mathrm{NH}_{2}-\mathrm{N1}$-IMP (11) was hydrolyzed more rapidly than CIDPR (2), but more slowly than 8- $\mathrm{NH}_{2}-\mathrm{N} 9-$ butyl-cIDPR (6) (Figure 4). 


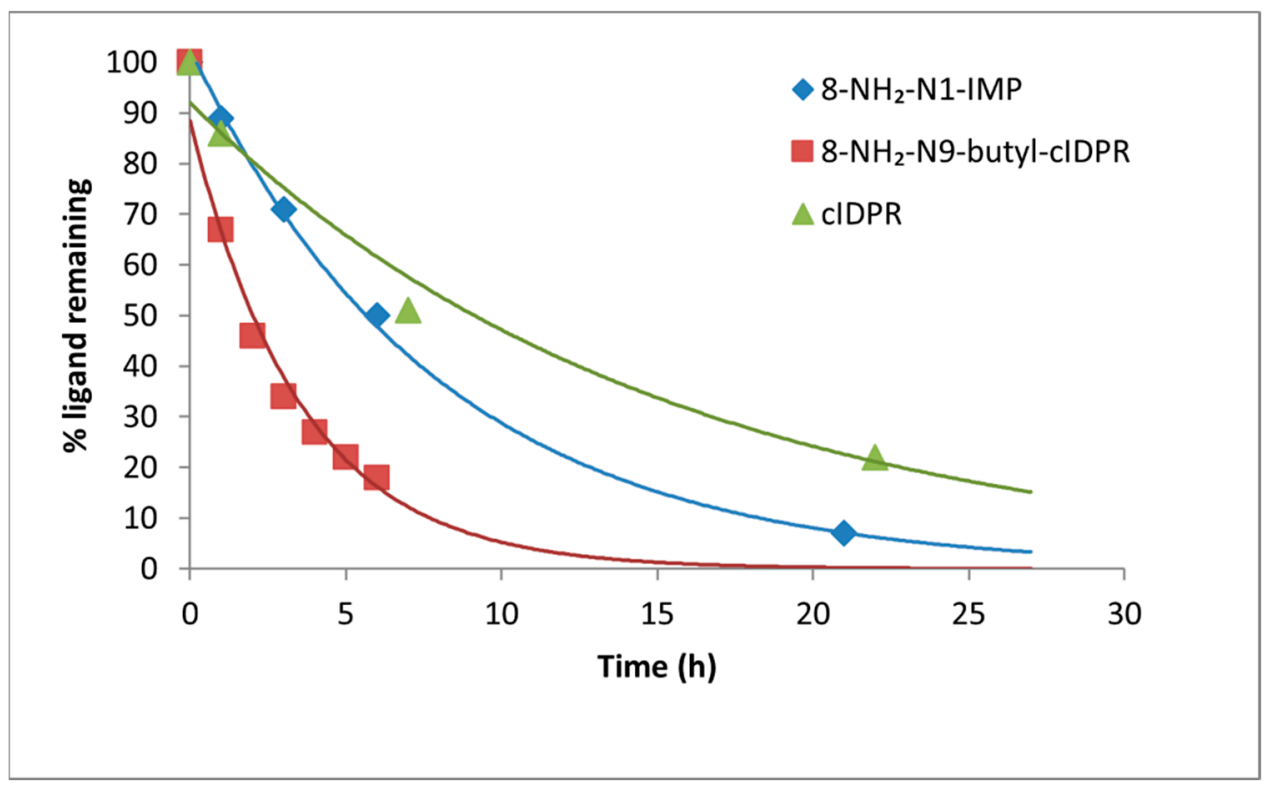

Figure 4. Hydrolysis of 8- $\mathrm{NH}_{2}-\mathrm{N} 1-\mathrm{IMP}$ by high concentrations of CD38.

Both 8- $\mathrm{NH}_{2}$-substituted analogues are more potent inhibitors of CD38-mediated hydrolysis than cIDPR (2) ( $\mathrm{IC}_{50}$ values of 7.6 and $3.3 \mu \mathrm{M}$ compared to $\left.276 \mu \mathrm{M}\right)$. Perhaps most surprising is that the small fragment, 8- $\mathrm{NH}_{2}-\mathrm{N1}$-IMP (11) is hydrolyzed at the N1ribosyl bond, suggesting that it not only binds in the active site of CD38 but also that it orientates itself to bind with the N1-ribosyl bond accessible to the catalytic residue. This would seem more likely for the larger cyclic ligands and adds further weight to the argument that the "northern" ribose makes key interactions in the CD38 binding site $[36,40]$.

\section{Materials and Methods}

\subsection{General}

All reagents and solvents were of commercial quality and were used without further purification, unless described otherwise. Unless otherwise stated, all reactions were carried out under an inert atmosphere of argon. ${ }^{1} \mathrm{H},{ }^{13} \mathrm{C}$, and ${ }^{31} \mathrm{P}$-NMR spectra were collected on a Varian Mercury $400 \mathrm{MHz}$ or Bruker Avance III $500 \mathrm{MHz}$ spectrometer. All ${ }^{1} \mathrm{H}$ and ${ }^{13} \mathrm{C}$ NMR assignments are based on gCOSY, gHMBC, gHSQC, and DEPT-135 experiments. Abbreviations for splitting patterns are as follows: br, broad; s, singlet; $d$, doublet; $t$, triplet; $\mathrm{m}$, multiplet. Coupling constants are given in hertz $(\mathrm{Hz})$. High resolution time-of-flight mass spectra were obtained on a Bruker Daltonics micrOTOF mass spectrometer using electrospray ionization (ESI). The purity of new tested compounds was determined to be $\geq 95 \%$ by analytical HPLC (see Supplementary Materials). Analytical HPLC analyses were carried out on a Waters 2695 Alliance module equipped with a Waters 2996 photodiode array detector (210-350 nm). The chromatographic system consisted of a Hichrom Guard column for HPLC and a Phenomenex Synergi $4 \mu \mathrm{m}$ MAX-RP 80A column $(150 \mathrm{~mm} \times 4.60 \mathrm{~mm})$, with elution at $1 \mathrm{~mL} / \mathrm{min}$ with either (a) isocratic ion-pair buffer: $0.17 \%(\mathrm{~m} / \mathrm{v})$ cetrimide and $45 \%(v / v)$ phosphate buffer $(\mathrm{pH} 6.4)$ in $\mathrm{MeOH}$ or $(\mathrm{b})$ a gradient of $0.05 \mathrm{M}$ Triethylammonium bicarbonate (TEAB):MeCN $(95: 5 \rightarrow 35: 65 v / v)$. TEAB was prepared by bubbling $\mathrm{CO}_{2}(\mathrm{~g})$ through a $0.05 \mathrm{M}$ solution of triethylamine in MilliQ water to $\mathrm{pH} \leq 8$. "MilliQ" water refers to purified water from a MilliQ ${ }^{\circledR}$ Reference Water Purification system, resistivity of $18.2 \mathrm{M} \Omega . \mathrm{cm}$ (at $25^{\circ} \mathrm{C}$ ). Semi-preparative HPLC was performed on a Waters 2525 pump with manual FlexInject using a Phenomenex Gemini column $(5 \mathrm{u}, \mathrm{C} 18,110 \AA$, $250 \times 10.00 \mathrm{~mm})$, eluted at $5 \mathrm{~mL} \mathrm{~min}^{-1}$ with a gradient of $0.05 \mathrm{M}$ TEAB:MeCN $(95: 5 \rightarrow$ 35:65 $\mathrm{v} / \mathrm{v}$ ). Synthetic phosphates were assayed and quantified by the Ames phosphate test [45]. Non-phosphate final compounds were quantified by quantitative ${ }^{1} \mathrm{H}-\mathrm{NMR}$. Note 
the use of $0.5 \%$ pyridine in chromatography systems with acid sensitive functional groups (e.g. phosphates protected with tert-butyl ethers) or free monophosphates. This system was used (rather than triethylamine) as it was less basic and therefore prevented decomposition of the analogues. Pyridine was evaporated from the TLC plate using a heat gun before visualization under UV light.

\subsection{Total Synthesis of 8-NH $\mathrm{H}_{2}-\mathrm{N1}-\mathrm{IMP}$ (11)}

N9-tert-Butyldimethylsilyloxymethyl-adenine (46)-Prepared from adenine following the method of Lang et al. [43].

N9-tert-Butyldimethylsilyloxymethyl-8-bromoadenine (47)-To diisopropylamine (2.93 mL, $20.94 \mathrm{mmol})$ in THF $(10 \mathrm{~mL})$ at $-78^{\circ} \mathrm{C}$ was added $n$-butyllithium $(8.55 \mathrm{~mL}, 2.5 \mathrm{M}$ solution, $21.37 \mathrm{mmol}$ ), dropwise. After $1 \mathrm{~h}$, a solution of N9-tert-Butyldimethylsilyloxymethyladenine $(46,1.17 \mathrm{~g}, 4.19 \mathrm{mmol})$ in THF $(40 \mathrm{~mL})$ was added dropwise and stirring continued for a further $1 \mathrm{~h}$. $\mathrm{Br}_{2}(837 \mu \mathrm{L}, 16.76 \mathrm{mmol})$ was added dropwise and the solution allowed to warm to rt and stirred for $16 \mathrm{~h}$. The reaction was quenched by addition of $\mathrm{NaOAc} / \mathrm{AcOH}$ ( $\mathrm{pH} 4,1 \mathrm{~N}$ aq., $2 \mathrm{~mL}$ ) and all solvents evaporated. The residue was taken up in DCM: $\mathrm{H}_{2} \mathrm{O}(1: 1$ $v / v, 100 \mathrm{~mL})$, the organic layer separated, washed with brine, dried $\left(\mathrm{Na}_{2} \mathrm{SO}_{4}\right)$ and evaporated to dryness. The crude material was purified by column chromatography on silica gel eluting with DCM:Acetone $(1: 0 \rightarrow 0: 1 \mathrm{v} / \mathrm{v})$ to afford the title compound $(879 \mathrm{mg}, 59 \%)$ as an amorphous cream solid; $R_{f}=0.59\left(\mathrm{DCM} /\right.$ Acetone 1:1 v/v); ${ }^{1} \mathrm{H}-\mathrm{NMR}\left(400 \mathrm{MHz}, \mathrm{CDCl}_{3}\right) \delta 8.32(\mathrm{~s}, 1 \mathrm{H}$, $\mathrm{H}-2$ ), 5.94 (br s, 2H, NH ), 5.71 (s, 2H, CH $\left.\mathrm{CH}_{2} \mathrm{OTBDMS}\right), 0.86$ (s, 9H) 0.10 (s, 6H) (15H, TBDMS); ${ }^{13} \mathrm{C}-\mathrm{NMR}\left(100 \mathrm{MHz}, \mathrm{CDCl}_{3}\right) \delta 154.1,153.2,151.03,127.3,119.7,67.0,25.5$ (3C), 18.0 and -5.3 (2C); HRMS $\left(\mathrm{ES}^{+}\right)$calcd for $\mathrm{C}_{12} \mathrm{H}_{21} \mathrm{~N}_{5} \mathrm{OSi}^{79} \mathrm{Br} 358.0693(\mathrm{M}+\mathrm{H})^{+}$found 358.0699 , calcd for $\mathrm{C}_{12} \mathrm{H}_{21} \mathrm{~N}_{5} \mathrm{OSi}^{81} \mathrm{Br} 360.0678(\mathrm{M}+\mathrm{H})^{+}$found 360.0691 .

N9-tert-Butyldimethylsilyloxymethyl-8-bromohypoxanthine (48)-N9-tert -Butyldimethylsilyloxymethyl-8-bromoadenine $(47,600 \mathrm{mg}, 1.67 \mathrm{mmol})$ was taken up in acetic acid-water $(46 \mathrm{~mL}, 20: 3 \mathrm{v} / \mathrm{v}) . \mathrm{NaNO}_{3}(1.39 \mathrm{~g}, 20.09 \mathrm{mmol})$ was added in one portion and the resulting solution stirred at $50{ }^{\circ} \mathrm{C}$ for $16 \mathrm{~h}$. All solvents were evaporated and the residue partitioned between DCM and $\mathrm{H}_{2} \mathrm{O}$, and the organic layer washed with $\mathrm{NaHCO}_{3}$ (sat. aq.), then brine, dried $\left(\mathrm{Na}_{2} \mathrm{SO}_{4}\right)$ and evaporated to dryness. The residue was purified by column chromatography on silica gel eluting with DCM/Acetone $(1: 0 \rightarrow$ $0: 1 \mathrm{v} / \mathrm{v})$ to afford the title compound $(430 \mathrm{mg}, 71 \%)$ as a pale orange amorphous solid; $R_{f}$ $=0.57\left(\mathrm{DCM} /\right.$ Acetone 1:1 v/v); ${ }^{1} \mathrm{H}-\mathrm{NMR}\left(400 \mathrm{MHz}, \mathrm{CDCl}_{3}\right) \delta 13.15$ (br s, 1H, NH), 8.31 (s, 1H, H-2), $5.71(\mathrm{~s}, 1 \mathrm{H}), 5.70(\mathrm{~s}, 1 \mathrm{H})\left(2 \mathrm{H}, \mathrm{CH}_{2} \mathrm{OTBDMS}\right), 0.87(\mathrm{~s}, 9 \mathrm{H}) 0.12(\mathrm{~s}, 6 \mathrm{H})(15 \mathrm{H}$, TBDMS); ${ }^{13} \mathrm{C}-\mathrm{NMR}\left(100 \mathrm{MHz} \mathrm{CDCl}_{3}\right) \delta$ 158.0, 150.2, 145.8, 126.4, 124.6, 67.5, 25.5 (3C), 18.0 and -5.3 (2C); HRMS (ES ${ }^{+}$) calcd for $\mathrm{C}_{12} \mathrm{H}_{20} \mathrm{~N}_{4} \mathrm{O}_{2} \mathrm{Si}^{79} \mathrm{Br} 359.0539(\mathrm{M}+\mathrm{H})^{+}$found 359.0544, calcd for $\mathrm{C}_{12} \mathrm{H}_{20} \mathrm{~N}_{4} \mathrm{O}_{2} \mathrm{Si}^{81} \mathrm{Br} 361.0519(\mathrm{M}+\mathrm{H})^{+}$found 361.0536.

N1-(2', $3^{\prime}, 5^{\prime}$-Tri-O-acetyl- $\beta$-D-ribofuranosyl)-N9-tert-butyldimethylsilyloxymethyl -8-bromohypoxanthine (49)-To N9-tert-butyldimethylsilyloxymethyl-8-bromohypoxanthine $(48,480 \mathrm{mg}, 1.336 \mathrm{mmol})$ in DCM $(5 \mathrm{~mL})$ was added DBU $(599 \mu \mathrm{L}, 4.008 \mathrm{mmol})$. After $30 \mathrm{~min}, 1,2,3,5$-tetra- $O$-acetyl- $\beta$-D-ribofuranose $(468 \mathrm{mg}, 1.47 \mathrm{mmol})$ was added and the solution cooled to $-78{ }^{\circ} \mathrm{C}$. Trimethylsilyl trifluoromethanesulfonate $(967 \mu \mathrm{L}, 5.344 \mathrm{mmol})$ was added dropwise and the solution stirred for a further $45 \mathrm{~min}$ before warming to rt. After $2 \mathrm{~h}, \mathrm{NaHCO}_{3}$ (satd aq) was added and the crude material extracted into DCM ( $\left.\times 3\right)$. The combined organic fractions were dried $\left(\mathrm{Na}_{2} \mathrm{SO}_{4}\right)$, and solvent was evaporated under reduced pressure. The residue was purified by column chromatography on silica gel eluting with PE/EtOAc $(1: 0 \rightarrow 0: 1 \mathrm{v} / \mathrm{v})$ to afford the title compound $(517 \mathrm{mg}, 63 \%)$ as a colourless glass; $R_{f}=0.64(\mathrm{PE}:$ EtOAc $1: 3 v / v) ;{ }^{1} \mathrm{H}-\mathrm{NMR}\left(400 \mathrm{MHz}, \mathrm{CDCl}_{3}\right) \delta 8.20(\mathrm{~s}, 1 \mathrm{H}$, $\mathrm{H}-2), 6.35\left(\mathrm{~d}, J=4.5 \mathrm{~Hz}, 1 \mathrm{H}, \mathrm{H}-\mathrm{1}^{\prime}\right), 5.64(\mathrm{~d}, J=9.8 \mathrm{~Hz}, 1 \mathrm{H}), 5.62(\mathrm{~d}, J=9.8 \mathrm{~Hz}, 1 \mathrm{H})(2 \mathrm{H}$, $\left.\mathrm{CH}_{2} \mathrm{OTBDMS}\right), 5.46-5.41\left(\mathrm{~m}, 2 \mathrm{H}, \mathrm{H}-2^{\prime}, \mathrm{H}-3^{\prime}\right), 4.43-4.33\left(\mathrm{~m}, 3 \mathrm{H}, \mathrm{H}-4^{\prime}, 2 \times \mathrm{H}-5^{\prime}\right), 2.15$ $\left(\mathrm{s}, 3 \mathrm{H}, \operatorname{AcetylC\mathrm {H}_{3}}\right), 2.10\left(\mathrm{~s}, 3 \mathrm{H}, \operatorname{Acetyl\mathrm {CH}_{3}}\right), 2.06\left(\mathrm{~s}, 3 \mathrm{H}, \operatorname{AcetylC} \underline{\mathrm{H}_{3}}\right), 0.86(\mathrm{~s}, 9 \mathrm{H}) 0.12$ (s,

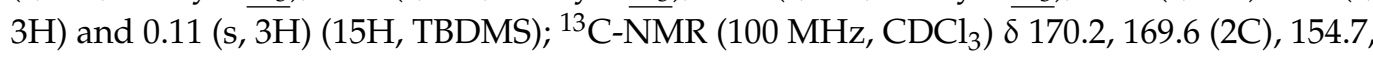
$148.4,144.5,126.1,123.9,87.4,80.4,74.2,70.1,67.3,62.9,25.4$ (3C), 20.7, 20.44, 20.38, 18.0, 
-5.2, -5.3; HRMS $\left(\right.$ ES $\left.^{+}\right)$calcd for $\mathrm{C}_{23} \mathrm{H}_{34} \mathrm{~N}_{4} \mathrm{O}_{9} \mathrm{Si}^{79} \mathrm{Br} 617.1273(\mathrm{M}+\mathrm{H})^{+}$found 617.1281, calcd for $\mathrm{C}_{23} \mathrm{H}_{34} \mathrm{~N}_{4} \mathrm{O}_{9} \mathrm{Si}^{81} \mathrm{Br} 619.1252(\mathrm{M}+\mathrm{H})^{+}$found 619.1241.

$N 1-\left(2^{\prime}, 3^{\prime}\right.$-O-Isopropylidene- $\beta$-D-ribofuranosyl)-N9-tert-butyldimethylsilyloxymethyl -8-bromohypoxanthine (50)-N1-(2', $3^{\prime}, 5^{\prime}$-Tri-O-acetyl- $\beta$-D-ribofuranosyl)- $N 9$-tert-butyldimet -hylsilyl oxymethyl-8-bromohypoxanthine $(49,370 \mathrm{mg}, 0.599 \mathrm{mmol}$ ) was taken up in $\mathrm{MeOH}$ $(5.0 \mathrm{~mL})$ in a pressure tube. The solution was cooled to $0{ }^{\circ} \mathrm{C}$ in an ice-water bath and $\mathrm{NH}_{3}$ (g) bubbled through the solution to saturation. The tube was sealed and the resulting solution stirred at rt. When complete by TLC, the solvents were removed by evaporation under reduced pressure and the residue was purified by column chromatography on silica gel eluting with DCM/Acetone (1:0 $\rightarrow$ 0:1 $v / v)$ to afford N1-( $\beta$-D-Ribofuranosyl)-N9tert-butyldimethylsilyloxymethyl-8-bromohypoxanthine as an amorphous white solid, $R_{f}$ $=0.21$ (DCM:Acetone 1:1 v/v), which was used directly in the next step. HRMS (ES+) calcd for $\mathrm{C}_{17} \mathrm{H}_{27} \mathrm{~N}_{4} \mathrm{O}_{6} \mathrm{Si}^{79} \mathrm{BrNa} 513.0775(\mathrm{M}+\mathrm{Na})^{+}$found 513.0780, calcd for $\mathrm{C}_{17} \mathrm{H}_{27} \mathrm{~N}_{4} \mathrm{O}_{6} \mathrm{Si}^{81} \mathrm{BrNa}$ $515.0755(\mathrm{M}+\mathrm{Na})^{+}$found 515.0758 .

To crude N1-( $\beta$-D-ribofuranosyl)-N9-tert-butyldimethylsilyloxymethyl-8-bromohypoxanthine in 2,2-dimethoxypropane-acetone $(1: 4 v / v, 5 \mathrm{~mL})$ was added para-toluenesulfonic acid (114 mg, $0.599 \mathrm{mmol}$ ). After $1 \mathrm{~h}, \mathrm{DCM}$ and $\mathrm{NaHCO}_{3}$ (satd. aq.) were added and the aqueous phase extracted with $\mathrm{DCM}(\times 3)$. The combined organic extracts were evaporated to dryness and purified by column chromatography on silica gel eluting with PE/EtOAc $(1: 0 \rightarrow 0: 1 \mathrm{v} / \mathrm{v})$ to afford the title compound ( $200 \mathrm{mg}$, 63\% over two steps) as a colourless glass. $R_{f}=0.65$ (PE:EtOAc 1:3 v/v); ${ }^{1} \mathrm{H}-\mathrm{NMR}\left(400 \mathrm{MHz}, \mathrm{CDCl}_{3}\right) \delta 8.05(\mathrm{~s}, 1 \mathrm{H}, \mathrm{H}-2), 5.73(\mathrm{~d}$, $\left.J=2.8 \mathrm{~Hz}, 1 \mathrm{H}, \mathrm{H}-1^{\prime}\right), 5.64(\mathrm{~d}, J=9.8 \mathrm{~Hz}, 1 \mathrm{H}), 5.62(\mathrm{~d}, J=9.8 \mathrm{~Hz}, 1 \mathrm{H})\left(2 \mathrm{H}, \mathrm{CH}_{2} \mathrm{OTBDMS}\right)$, $5.27\left(\mathrm{dd}, J=6.5,2.8 \mathrm{~Hz}, 1 \mathrm{H}, \mathrm{H}-2^{\prime}\right), 5.12\left(\mathrm{dd}, J=6.5,3.5 \mathrm{~Hz}, 1 \mathrm{H}, \mathrm{H}-3^{\prime}\right), 4.34(\mathrm{~d} d \mathrm{~d}, J=6.1$, 5.6, $\left.3.5 \mathrm{~Hz}, 1 \mathrm{H}, \mathrm{H}-4^{\prime}\right), 3.91\left(\mathrm{ddd}, J=11.9,5.6,3.3 \mathrm{~Hz}, 1 \mathrm{H}, \mathrm{H}-5^{\prime}{ }_{\mathrm{a}}\right.$ ), $3.83(\mathrm{ddd}, J=11.9,7.8$, $\left.6.1 \mathrm{~Hz}, 1 \mathrm{H}, \mathrm{H}-5^{\prime} \mathrm{b}^{2}\right), 3.40(\mathrm{dd}, J=7.8,3.3 \mathrm{~Hz}, 1 \mathrm{H}, 5-\mathrm{OH}), 1.57\left(\mathrm{~s}, 3 \mathrm{H}, \mathrm{CHCH}_{3}\right), 1.34(\mathrm{~s}, 3 \mathrm{H}$, $\left.\mathrm{CHCH}_{3}\right), 0.86(\mathrm{~s}, 9 \mathrm{H}) 0.11(\mathrm{~s}, 3 \mathrm{H})$ and $0.10(\mathrm{~s}, 3 \mathrm{H})(15 \mathrm{H}, \mathrm{TBDMS}) ;{ }^{13} \mathrm{C}-\mathrm{NMR}\left(100 \mathrm{MHz}, \mathrm{CDCl}_{3}\right)$ $\delta$ 155.2, 148.8, 146.9, 126.5, 124.6, 114.2, 96.9, 88.0, 83.5, 80.6, 67.4, 62.8, 27.2, 25.4, 25.1, 17.9, -5.2 (2C); HRMS ( $\mathrm{ES}^{+}$) calcd for $\mathrm{C}_{20} \mathrm{H}_{32} \mathrm{~N}_{4} \mathrm{O}_{6} \mathrm{Si}^{79} \mathrm{Br} 531.1269(\mathrm{M}+\mathrm{H})^{+}$found 531.1248, calcd for $\mathrm{C}_{20} \mathrm{H}_{32} \mathrm{~N}_{4} \mathrm{O}_{6} \mathrm{Si}^{81} \mathrm{Br} 533.1249(\mathrm{M}+\mathrm{H})^{+}$found 533.1246.

$N 1$-[2', $3^{\prime}$-O-Isopropylidene- $5^{\prime}$-O-(di-tert-butyl)-phosphoryl- $\beta$-D-ribofuranosyl]-N9-tertbutyldimethylsilyloxymethyl-8-bromohypoxanthine (51)-To N1-(2', $3^{\prime}$-O-isopropylidene- $\beta$ D-ribofuranosyl)-N9-tert-butyldimethylsilyloxymethyl-8-bromohypoxanthine (50,80 mg, $0.151 \mathrm{mmol})$ in DCM $(0.8 \mathrm{~mL})$ was added 5-phenyl-1H-tetrazole $(44 \mathrm{mg}, 0.301 \mathrm{mmol})$ and the solution cooled to $0{ }^{\circ} \mathrm{C}$. Di-tert-butyl $N, N$-diisopropylphosphoramidite $(71 \mu \mathrm{L}, 0.227 \mathrm{mmol})$ was added dropwise and the solution stirred at rt until phosphitylation was complete by TLC. After cooling to $0{ }^{\circ} \mathrm{C}$, triethylamine $(126 \mu \mathrm{L}, 0.906 \mathrm{mmol})$ and $\mathrm{H}_{2} \mathrm{O}_{2}\left(30 \%\right.$ in $\mathrm{H}_{2} \mathrm{O}, 33 \mu \mathrm{L}$, $0.375 \mathrm{mmol}$ ) were added and the solution stirred at rt until oxidation was complete. The reaction was diluted with DCM and washed with $\mathrm{NaHCO}_{3}$ (satd. aq.), dried over $\mathrm{Na}_{2} \mathrm{SO}_{4}$ and purified by column chromatography on silica gel eluting with PE/EtOAc (1:0 $\rightarrow$ 0:1 $v / v+0.5 \%$ pyridine in each solvent) to afford the title compound ( $55 \mathrm{mg}, 50 \%$ ) as a colourless glass; $R_{f}=0.46$ (PE:EtOAc 1:3 $v / v$ )-note there is no change in retention time compared to starting material (after oxidation); ${ }^{1} \mathrm{H}-\mathrm{NMR}\left(500 \mathrm{MHz}, \mathrm{CDCl}_{3}\right) \delta 8.00(\mathrm{~s}, 1 \mathrm{H}, \mathrm{H}-2), 5.90(\mathrm{~d}$, $\left.J=1.8 \mathrm{~Hz}, 1 \mathrm{H}, \mathrm{H}-1^{\prime}\right), 5.54(\mathrm{~d}, J=10.4 \mathrm{~Hz}, 1 \mathrm{H}), 5.52(\mathrm{~d}, J=10.4 \mathrm{~Hz}, 1 \mathrm{H})\left(2 \mathrm{H}, \mathrm{CH}_{2} \mathrm{OTBDMS}\right)$, $4.96\left(\mathrm{dd}, J=6.4,1.8 \mathrm{~Hz}, 1 \mathrm{H}, \mathrm{H}-2^{\prime}\right), 4.88\left(\mathrm{dd}, J=6.4,4.1 \mathrm{~Hz}, 1 \mathrm{H}, \mathrm{H}-3^{\prime}\right), 4.32(\mathrm{ddd}, J=6.5,5.9$, $\left.4.1 \mathrm{~Hz}, 1 \mathrm{H}, \mathrm{H}-4^{\prime}\right), 4.14\left(\mathrm{ddd}, J=11.2,6.5,4.2 \mathrm{~Hz}, 1 \mathrm{H}, \mathrm{H}-5^{\prime}{ }_{\mathrm{a}}\right), 4.08(\mathrm{ddd}, J=11.2,6.8,5.9 \mathrm{~Hz}$, $\left.1 \mathrm{H}, \mathrm{H}-5^{\prime}{ }_{\mathrm{b}}\right), 1.47\left(\mathrm{~s}, 3 \mathrm{H}, \mathrm{CHCH}_{3}\right), 1.354\left(\mathrm{~s}, 9 \mathrm{H}, \mathrm{O}^{t} \mathrm{Bu}\right), 1.346\left(\mathrm{~s}, 9 \mathrm{H}, \mathrm{O}^{t} \mathrm{Bu}\right), 1.23\left(\mathrm{~s}, 3 \mathrm{H}, \mathrm{CHCH}_{3}\right)$, $0.76(\mathrm{~s}, 9 \mathrm{H}) 0.01(\mathrm{~s}, 3 \mathrm{H})$ and $0.00(\mathrm{~s}, 3 \mathrm{H})(15 \mathrm{H}, \mathrm{TBDMS}) ;{ }^{13} \mathrm{C}-\mathrm{NMR}\left(125 \mathrm{MHz}, \mathrm{CDCl}_{3}\right) \delta 154.8$, 148.7, 146.2, 126.1, 124.4, 114.4, 94.1, $86.8(\mathrm{~d}, J=7.6 \mathrm{~Hz}), 85.1,82.7(\mathrm{~d}, J=7.5 \mathrm{~Hz}), 81.3,67.4,66.4$ $(\mathrm{d}, J=6.3), 29.84(3 \mathrm{C}, \mathrm{d}, J=4.1 \mathrm{~Hz}), 29.81(3 \mathrm{C}, \mathrm{d}, J=3.7 \mathrm{~Hz}), 27.2,25.5(3 \mathrm{C}), 25.3,18.0,-5.2$ (2C); HRMS (ES ${ }^{+}$calcd for $\mathrm{C}_{28} \mathrm{H}_{48} \mathrm{~N}_{4} \mathrm{O}_{9} \mathrm{Si}^{79} \mathrm{BrNa} 745.2004(\mathrm{M}+\mathrm{Na})^{+}$found 745.1990, calcd for $\mathrm{C}_{28} \mathrm{H}_{48} \mathrm{~N}_{4} \mathrm{O}_{9} \mathrm{Si}^{81} \mathrm{BrNa} 747.1983(\mathrm{M}+\mathrm{Na})^{+}$found 747.1964.

N1-(5'-O-Phosphoryl- $\beta$-D-ribofuranosyl) - 8-bromohypoxanthine (8-Br-N1-IMP, 10)$N 1-\left[2^{\prime}, 3^{\prime}\right.$-O-Isopropylidene- $5^{\prime}$-O-(di-tert-butyl)-phosphoryl- $\beta$-D-ribofuranosyl]-N9-tertbutyldimethylsilyloxymethyl-8-bromohypoxanthine $(51,55 \mathrm{mg}, 76 \mu \mathrm{mol})$ was treated 
with TFA (50\% aq., $4 \mathrm{~mL}$ ) for $16 \mathrm{~h}$. All solvents were evaporated and the residue evaporated from $\mathrm{MeOH} \times 3$ to give the title compound $(24 \mathrm{mg}, 75 \%)$. ${ }^{1} \mathrm{H}-\mathrm{NMR}$ and MS data were as previously described ${ }^{39}$ and it was used in the next step without further purification.

N1-(5'-O-Phosphoryl- $\beta$-D-ribofuranosyl) - 8-aminohypoxanthine (8- $\mathrm{NH}_{2}-\mathrm{N1}$-IMP, 11)To N1-(5'-O-phosphoryl- $\beta$-D-ribofuranosyl)-8-bromohypoxanthine (10, $24 \mathrm{mg}, 56 \mu \mathrm{mol})$ in DMF $(1 \mathrm{~mL})$ was added $\mathrm{TMSN}_{3}(50 \mu \mathrm{L})$ and the solution stirred at $70{ }^{\circ} \mathrm{C}$ for $16 \mathrm{~h}$. All solvents were evaporated and the crude $N 1-\left(5^{\prime}-O-P h o s p h o r y l-\beta-D-\right.$ ribofuranosyl $)-8$ azidohypoxanthine (8- $\left.\mathrm{N}_{3}-\mathrm{N} 1-\mathrm{IMP}\right)$ product used directly in the following step.

To crude N1-(5'-O-phosphoryl- $\beta$-D-ribofuranosyl)-8-azidohypoxanthine in TEAB $(0.05 \mathrm{M}, 5 \mathrm{~mL})$ was added dithiothreitol $(5 \mathrm{mg}, 32 \mu \mathrm{mol})$ and the solution stirred at rt for $16 \mathrm{~h}$ before purification by semipreparative HPLC $(1.1 \mathrm{~cm} \times 25 \mathrm{~cm}$ C18 column), eluting with acetonitrile/0.1 M TEAB $(1: 19 \rightarrow 13: 7 v / v)$ over $25 \mathrm{~min}$. Fractions were analyzed by analytical HPLC and appropriate fractions collected and evaporated under vacuum to give the title compound (5.3 mg, 20\%). ${ }^{1} \mathrm{H}-\mathrm{NMR}\left(500 \mathrm{MHz}, \mathrm{D}_{2} \mathrm{O}\right) \delta 8.42(\mathrm{~s}, 1 \mathrm{H}, \mathrm{H}-2), 6.32(\mathrm{~d}$, $\left.J=3.3 \mathrm{~Hz}, 1 \mathrm{H}, \mathrm{H}-1^{\prime}\right), 4.31-4.35\left(\mathrm{~m}, 2 \mathrm{H}, \mathrm{H}-2^{\prime}\right.$ and $\left.\mathrm{H}-3^{\prime}\right), 4.24\left(\mathrm{brs}, 1 \mathrm{H}, \mathrm{H}-4^{\prime}\right), 4.15-4.18$ $\left(\mathrm{m}, 1 \mathrm{H}, \mathrm{H}-5^{\prime}{ }_{\mathrm{a}}\right)$ and $4.07-4.03\left(\mathrm{~m}, 1 \mathrm{H}, \mathrm{H}-5^{\prime}{ }_{\mathrm{b}}\right) .{ }^{13} \mathrm{C}-\mathrm{NMR}\left(125 \mathrm{MHz}, \mathrm{D}_{2} \mathrm{O}\right) \delta 161.4(\mathrm{C}-6)$, $155.4(\mathrm{C}-4), 152.7(\mathrm{C}-5), 143.7(\mathrm{C}-2), 112.2(\mathrm{C}-8), 89.1\left(\mathrm{C}-1^{\prime}\right), 83.0\left(\mathrm{~d}, J=8.9 \mathrm{~Hz}, \mathrm{C}-4^{\prime}\right)$, $75.0\left(\mathrm{C}-2^{\prime}\right), 69.0\left(\mathrm{C}-3^{\prime}\right)$ and $63.6\left(\mathrm{~d}, J=4.5 \mathrm{~Hz}, \mathrm{C}-5^{\prime}\right) .{ }^{31} \mathrm{P}-\mathrm{NMR}\left(202 \mathrm{MHz}, \mathrm{D}_{2} \mathrm{O}\right) \delta 0.36$. HRMS $\left(\mathrm{ES}^{-}\right)$calcd for $\mathrm{C}_{10} \mathrm{H}_{13} \mathrm{~N}_{5} \mathrm{O}_{8} \mathrm{P} 362.0507(\mathrm{M}-\mathrm{H})^{-}$found 362.0516.

\subsection{N1-Ribosyl-Inosine Analogues (14-17)}

$N 1-\left(2^{\prime \prime}, 3^{\prime \prime}, 5^{\prime \prime}\right.$-Tri-O-acetyl- $\beta$-D-ribofuranosyl)-2', $3^{\prime}, 5^{\prime}$-tri-O-acetyl-8-bromoinosine (31)-2', $3^{\prime}, 5^{\prime}$-tri-O-acetyl-8-bromoinosine [33] (30, $\left.615 \mathrm{mg}, 1.30 \mathrm{mmol}\right)$ was taken up in DCM $(6 \mathrm{~mL})$ and DBU $(583 \mu \mathrm{L}, 3.90 \mathrm{mmol})$ added. After $30 \mathrm{~min}, 1,2,3,5$-tetra-O-acetyl$\beta$-D-ribofuranose $(455 \mathrm{mg}, 1.43 \mathrm{mmol})$ was added and the solution cooled to $-78{ }^{\circ} \mathrm{C}$. Trimethylsilyl trifluoromethanesulfonate $(941 \mu \mathrm{L}, 5.20 \mathrm{mmol})$ was added dropwise and the solution stirred for a further 45 min before warming to rt. After $1 \mathrm{~h}, \mathrm{NaHCO}_{3}$ (satd aq) was added and the crude material extracted into DCM $(\times 3)$. The combined organic fractions were dried $\left(\mathrm{Na}_{2} \mathrm{SO}_{4}\right)$, and solvent was evaporated under reduced pressure. The residue was purified by column chromatography on silica gel eluting with DCM/Acetone $(1: 0 \rightarrow 4: 1 \mathrm{v} / \mathrm{v})$ to afford the title compound $(678 \mathrm{mg}, 71 \%)$ as a colourless glass: $R_{f}=0.69$ (DCM:Acetone 3:1 v/v); ${ }^{1} \mathrm{H}-\mathrm{NMR}\left(400 \mathrm{MHz}, \mathrm{CDCl}_{3}\right) \delta 8.28(\mathrm{~s}, 1 \mathrm{H}, 2-\mathrm{H}), 6.38(\mathrm{~d}, J=4.6 \mathrm{~Hz}$, $1 \mathrm{H}), 6.20(\mathrm{dd}, J=6.0,4.7, \mathrm{~Hz}, 1 \mathrm{H}), 6.10(\mathrm{~d}, J=4.7 \mathrm{~Hz}, 1 \mathrm{H}), 5.79$ (app. $\mathrm{t}, J=5.8 \mathrm{~Hz}, 1 \mathrm{H})$, 5.51-5.44 (m, 2H), 4.48-4.33 (m, 6H), $2.20(\mathrm{~s}, 3 \mathrm{H}), 2.16(\mathrm{~s}, 3 \mathrm{H}), 2.14(\mathrm{~s}, 3 \mathrm{H}), 2.13(\mathrm{~s}, 3 \mathrm{H})$, 2.11 (s, 3H), 2.07 (s, 3H); ${ }^{13} \mathrm{C}-\mathrm{NMR}\left(100 \mathrm{MHz}, \mathrm{CDCl}_{3}\right) \delta 170.4,170.3,169.52,169.47,169.39$, $169.29,154.5,148.1,144.6,126.3,125.1,88.7,87.5,80.3,80.08,74.2,72.2,70.3,70.1,63.1,62.9$, 20.8, 20.6, 20.48, 20.46, 20.39, 20.37; HRMS (ES $\left.{ }^{+}\right)$calcd for $\mathrm{C}_{15} \mathrm{H}_{20} \mathrm{~N}_{4} \mathrm{O}_{9}{ }^{79} \mathrm{Br} 479.0408(\mathrm{M}+$ $\mathrm{H})^{+}$found 479.0401, calcd for $\mathrm{C}_{15} \mathrm{H}_{20} \mathrm{~N}_{4} \mathrm{O}_{9}{ }^{81} \mathrm{Br} 481.0388(\mathrm{M}+\mathrm{H})^{+}$found 481.0379 .

N1-( $\beta$-D-Ribofuranosyl) - 8-bromoinosine (8-Br-N1-ribosyl-IMP, 14)-N1-(2", 3", 5"'-TriO-acetyl- $\beta$-D-ribofuranosyl)-2',3',5'-tri-O-acetyl-8-bromoinosine (31, $107 \mathrm{mg}, 0.146 \mathrm{mmol})$ was taken up in $\mathrm{MeOH}(2.0 \mathrm{~mL})$ in a pressure tube. The solution was cooled to $0{ }^{\circ} \mathrm{C}$ in an ice-water bath and $\mathrm{NH}_{3}(\mathrm{~g})$ bubbled through the solution to saturation. The tube was sealed and the resulting solution stirred at $\mathrm{rt}$. When complete by TLC, the precipitate was removed by filtration and dried under vacuum to yield the title compound (70 $\mathrm{mg}, 100 \%)$ as a white amorphous solid; ${ }^{1} \mathrm{H}-\mathrm{NMR}\left(400 \mathrm{MHz}, \mathrm{CD}_{3} \mathrm{OD}\right) \delta 8.89(\mathrm{~s}, 1 \mathrm{H}, 2-\mathrm{H}), 6.26(\mathrm{~d}, J=2.8 \mathrm{~Hz}, 1 \mathrm{H})$, $6.10(\mathrm{~d}, J=6.4 \mathrm{~Hz}, 1 \mathrm{H}), 5.11(\mathrm{dd}, J=6.4,5.7, \mathrm{~Hz}, 1 \mathrm{H}), 4.46(\mathrm{dd}, J=5.4,2.8 \mathrm{~Hz}, 1 \mathrm{H}), 4.35-4.30$ $(\mathrm{m}, 2 \mathrm{H}), 4.20-4.16(\mathrm{~m}, 2 \mathrm{H}), 4.01(\mathrm{dd}, J=12.3,2.5 \mathrm{~Hz}, 1 \mathrm{H}), 3.91(\mathrm{dd}, J=12.4,3.3 \mathrm{~Hz}, 1 \mathrm{H}), 3.86$ $(\mathrm{dd}, J=12.3,2.8 \mathrm{~Hz}, 1 \mathrm{H}), 3.79$ (dd, $J=12.4,4.2 \mathrm{~Hz}, 1 \mathrm{H}) ;{ }^{13} \mathrm{C}-\mathrm{NMR}\left(100 \mathrm{MHz}, \mathrm{CD}_{3} \mathrm{OD}\right) \delta 156.9$,

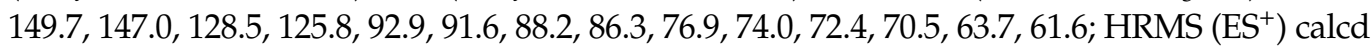
for $\mathrm{C}_{15} \mathrm{H}_{20} \mathrm{~N}_{4} \mathrm{O}_{9}{ }^{79} \mathrm{Br} 479.0408(\mathrm{M}+\mathrm{H})^{+}$found 479.0410 , calcd for $\mathrm{C}_{15} \mathrm{H}_{20} \mathrm{~N}_{4} \mathrm{O}_{9}{ }^{81} \mathrm{Br} 481.0388$ $(\mathrm{M}+\mathrm{H})^{+}$found 481.0401 .

N1-( $\beta$-D-Ribofuranosyl)-inosine (N1-ribosyl-IMP, 15)-N1-(2",3",5"-Tri-O-acetyl- $\beta$ D-ribofuranosyl)-2', 3', $5^{\prime}$-tri-O-acetyl-8-bromoinosine (31, $\left.330 \mathrm{mg}, 0.451 \mathrm{mmol}\right), \mathrm{NaHCO}_{3}$ (42 mg, $0.496 \mathrm{mmol})$ and $\mathrm{Pd} / \mathrm{C}(45 \mathrm{mg}, 45 \mu \mathrm{mol})$ were taken up in EtOH $(6 \mathrm{~mL})$ and the 
solution degassed with argon before being placed under an atmosphere of $\mathrm{H}_{2}$ for $12 \mathrm{~h}$. The catalyst was removed by filtration and the resulting solution purified by column chromatography on silica gel eluting with DCM/Acetone $(1: 0 \rightarrow 0: 1 v / v)$ to afford the title compound (90 mg, 50\%) as a clear glass; $R_{f}=0.27$ (DCM:Acetone 4:1 v/v); ${ }^{1} \mathrm{H}-\mathrm{NMR}$ $\left(500 \mathrm{MHz}, \mathrm{CD}_{3} \mathrm{OD}\right) \delta 8.82(\mathrm{~s}, 1 \mathrm{H}), 8.34(\mathrm{~s}, 1 \mathrm{H}), 6.22(\mathrm{~d}, J=3.0 \mathrm{~Hz}, 1 \mathrm{H}), 6.00(\mathrm{~d}, J=5.7 \mathrm{~Hz}$, $1 \mathrm{H}), 4.61(\mathrm{dd}, J=5.7,5.4 \mathrm{~Hz}, 1 \mathrm{H}), 4.31(\mathrm{dd}, J=5.0,3.7 \mathrm{~Hz}, 1 \mathrm{H}), 4.28-4.24(\mathrm{~m}, 2 \mathrm{H}), 4.14-4.09$ $(\mathrm{m}, 2 \mathrm{H}), 3.94(\mathrm{dd}, J=12.3,2.5 \mathrm{~Hz}, 1 \mathrm{H}), 3.85(\mathrm{dd}, J=12.4,3.0 \mathrm{~Hz}, 1 \mathrm{H}), 3.79(\mathrm{dd}, J=12.4$, $2.9 \mathrm{~Hz}, 1 \mathrm{H}), 3.74(\mathrm{dd}, J=12.3,3.3 \mathrm{~Hz}, 1 \mathrm{H}) ;{ }^{13} \mathrm{C}-\mathrm{NMR}\left(125 \mathrm{MHz}, \mathrm{CD}_{3} \mathrm{OD}\right) \delta 158.0,148.7$, 147.0, 141.4, 125.0, 91.4, 90.6, 87.6, 86.3, 76.9, 76.2, 72.1, 70.6, 63.0, 61.7; HRMS (ES ${ }^{+}$) calcd for $\mathrm{C}_{15} \mathrm{H}_{21} \mathrm{~N}_{4} \mathrm{O}_{9} 401.1303(\mathrm{M}+\mathrm{H})^{+}$found 401.1297 .

N1-(2", $3^{\prime \prime}, 5^{\prime \prime}$-Tri-O-acetyl- $\beta$-D-ribofuranosyl)-2', $3^{\prime}, 5^{\prime}$-tri-O-acetyl-8-azidoinosine (32)-To N1-(2", $3^{\prime \prime}, 5^{\prime \prime}$-tri-O-acetyl- $\beta$-D-ribofuranosyl)-2', $3^{\prime}, 5^{\prime}$-tri-O-acetyl-8-bromoinosine $(31,240 \mathrm{mg}, 0.328 \mathrm{mmol})$ in DMF $(2.4 \mathrm{~mL})$ was added $\mathrm{NaN}_{3}(68 \mathrm{mg}, 1.05 \mathrm{mmol})$ and the resulting solution stirred at $70{ }^{\circ} \mathrm{C}$ in the dark for $72 \mathrm{~h}$. The solution was evaporated to dryness and the residue taken up in DCM, washed with $\mathrm{H}_{2} \mathrm{O}$, dried over $\mathrm{Na}_{2} \mathrm{SO}_{4}$ and purified by column chromatography on silica gel eluting with PE/EtOAc $(1: 0 \rightarrow 0: 1 v / v)$ to afford the title compound $\left(128 \mathrm{mg}, 56 \%\right.$ ) as a clear glass; $R_{f}=0.53$ (PE:EtOAc 1:3 $v / v$ ); ${ }^{1} \mathrm{H}-\mathrm{NMR}\left(400 \mathrm{MHz}, \mathrm{CDCl}_{3}\right) \delta 8.16(\mathrm{~s}, 1 \mathrm{H}, 2-\mathrm{H}), 6.30(\mathrm{~d}, J=4.5 \mathrm{~Hz}, 1 \mathrm{H}), 6.02$ (dd, J = 5.8, $4.9 \mathrm{~Hz}, 1 \mathrm{H}), 5.90(\mathrm{~d}, J=4.9 \mathrm{~Hz}, 1 \mathrm{H}), 5.67$ (app. t, $J=5.8 \mathrm{~Hz}, 1 \mathrm{H}), 5.47(\mathrm{dd}, J=5.9,4.5 \mathrm{~Hz}$, $1 \mathrm{H}), 5.43(\mathrm{dd}, J=5.8,5.0 \mathrm{~Hz}, 1 \mathrm{H}), 4.42-4.22(\mathrm{~m}, 6 \mathrm{H}), 2.14(\mathrm{~s}, 3 \mathrm{H}), 2.10(\mathrm{~s}, 3 \mathrm{H}), 2.09(\mathrm{~s}, 3 \mathrm{H})$, 2.064 (s, 3H), 2.061 (s, 3H), 2.03 (s, 3H); ${ }^{13} \mathrm{C}-\mathrm{NMR}\left(100 \mathrm{MHz}, \mathrm{CDCl}_{3}\right) \delta 170.3,170.2,169.5$, $169.4,169.3,169.2,154.7,146.9,144.8,143.8,122.5,87.9,85.6,80.3,79.8,74.2,71.9,70.2,70.1$, 63.0, 62.9, 20.7, 20.6, $20.4(2 \mathrm{C}), 20.32,20.31$; HRMS (ES ${ }^{+}$) calcd for $\mathrm{C}_{27} \mathrm{H}_{31} \mathrm{~N}_{7} \mathrm{O}_{15} \mathrm{Na} 716.1770$ $(\mathrm{M}+\mathrm{Na})^{+}$found 716.1758 .

N1-( $\beta$-D-ribofuranosyl) - 8-azidoinosine (8-N 3 -N1-ribosyl-IMP, 16)-N1- $\left(2^{\prime \prime}, 3^{\prime \prime}, 5^{\prime \prime}\right.$ Tri-O-acetyl- $\beta$-D-ribofuranosyl $)-2^{\prime}, 3^{\prime}, 5^{\prime}$-tri-O-acetyl-8-azidoinosine $(32,50 \mathrm{mg}, 72 \mu \mathrm{mol})$ was taken up in $\mathrm{MeOH}(1.5 \mathrm{~mL})$ in a pressure tube. The solution was cooled to $0{ }^{\circ} \mathrm{C}$ in an ice-water bath and $\mathrm{NH}_{3}(\mathrm{~g})$ bubbled through the solution to saturation. The tube was sealed and the resulting solution stirred at rt. When complete by TLC, the solvents were removed by evaporation under reduced pressure and co-evaporation with $\mathrm{MeOH}$ $(5 \mathrm{~mL} \times 2)$. The residue was purified by column chromatography on silica gel eluting with $\mathrm{DCM} / \mathrm{MeOH}(1: 0 \rightarrow 4: 1 \mathrm{v} / \mathrm{v}+0.5 \%$ pyridine $)$ to afford the title compound $(15 \mathrm{mg}, 47 \%)$ as a clear glass; $R_{f}=0.23$ (DCM:MeOH 8:2 v/v); ${ }^{1} \mathrm{H}-\mathrm{NMR}\left(500 \mathrm{MHz}, \mathrm{D}_{2} \mathrm{O}\right) \delta 8.50(\mathrm{~s}, 1 \mathrm{H}, 2-\mathrm{H})$, $6.08(\mathrm{~d}, J=3.0 \mathrm{~Hz}, 1 \mathrm{H}), 5.80(\mathrm{~d}, J=6.2 \mathrm{~Hz}, 1 \mathrm{H}), 4.83(\mathrm{dd}, J=6.2,5.8, \mathrm{~Hz}, 1 \mathrm{H}), 4.38(\mathrm{dd}$, $J=5.8,3.6 \mathrm{~Hz}, 1 \mathrm{H}), 4.34(\mathrm{dd}, J=5.2,3.0 \mathrm{~Hz}, 1 \mathrm{H}), 4.22(\mathrm{dd}, J=7.0,5.2 \mathrm{~Hz}, 1 \mathrm{H}), 4.14-4.10$ $(\mathrm{m}, 2 \mathrm{H}), 3.93(\mathrm{dd}, J=12.9,2.7 \mathrm{~Hz}, 1 \mathrm{H}), 3.82-3.77(\mathrm{~m}, 2 \mathrm{H}), 3.75(\mathrm{dd}, J=12.7,4.6 \mathrm{~Hz}, 1 \mathrm{H})$; ${ }^{13} \mathrm{C}-\mathrm{NMR}\left(125 \mathrm{MHz}, \mathrm{D}_{2} \mathrm{O}\right) \delta 156.1,147.3,146.4,144.4,121.4,90.4,87.7,85.6,83.9,74.7,72.4$, 70.3, 68.7, 61.6, 60.2; HRMS $\left(\mathrm{ES}^{+}\right)$calcd for $\mathrm{C}_{15} \mathrm{H}_{20} \mathrm{~N}_{7} \mathrm{O}_{9} 442.1317(\mathrm{M}+\mathrm{H})^{+}$found 442.1329 .

N1-(2", $3^{\prime \prime}, 5^{\prime \prime}$-Tri-O-acetyl- $\beta$-D-ribofuranosyl)-2', $3^{\prime}, 5^{\prime}$-tri-O-acetyl-8-aminoinosine (33)-1-(2", 3", 5" $5^{\prime \prime}$-Tri-O-acetyl- $\beta$-D-ribofuranosyl)-2', $3^{\prime}, 5^{\prime}$-tri-O-acetyl-8-azidoinosine (32, $65 \mathrm{mg}, 87 \mu \mathrm{mol})$ and $\mathrm{Pd} / \mathrm{C}(9 \mathrm{mg}, 9 \mu \mathrm{mol})$ were taken up in $\mathrm{EtOH}(2 \mathrm{~mL})$ and the solution degassed with argon before being placed under an atmosphere of $\mathrm{H}_{2}$ for $12 \mathrm{~h}$. The catalyst was removed by filtration and the resulting solution purified by column chromatography on silica gel eluting with DCM/Acetone $(1: 0 \rightarrow 0: 1 v / v)$ to afford the title compound (51 mg, 81\%) as a clear glass; $R_{f}=0.48$ (DCM:Acetone 1:1 v/v); ${ }^{1} \mathrm{H}-\mathrm{NMR}\left(400 \mathrm{MHz}, \mathrm{CDCl}_{3}\right)$ $\delta 8.03(\mathrm{~s}, 1 \mathrm{H}, 2-\mathrm{H}), 6.29(\mathrm{~d}, J=4.3 \mathrm{~Hz}, 1 \mathrm{H}), 6.08(\mathrm{~d}, J=6.4 \mathrm{~Hz}, 1 \mathrm{H}), 5.84(\mathrm{dd}, J=6.4,6.2 \mathrm{~Hz}$, $1 \mathrm{H}), 5.61$ (br s, 2H, NH 2$), 5.53-5.49(\mathrm{~m}, 2 \mathrm{H}), 5.45(\mathrm{dd}, J=5.7,5.5 \mathrm{~Hz}, 1 \mathrm{H}), 4.51(\mathrm{dd}, J=$ $12.1,3.9 \mathrm{~Hz}, 1 \mathrm{H}), 4.44-4.28(\mathrm{~m}, 5 \mathrm{H}), 2.15(\mathrm{~s}, 3 \mathrm{H}), 2.12(\mathrm{~s}, 3 \mathrm{H}), 2.11(\mathrm{~s}, 3 \mathrm{H}), 2.10(\mathrm{~s}, 3 \mathrm{H})$, 2.09 (s, 3H), 2.06 (s, 3H); ${ }^{13} \mathrm{C}-\mathrm{NMR}\left(100 \mathrm{MHz}, \mathrm{CDCl}_{3}\right) \delta 170.3,170.2,169.50,169.47,169.46$, $169.41,154.9,151.0,145.9,141.7,121.4,88.0,84.8,80.5,79.9,74.2,70.9,70.2,70.0,63.0,62.9$, 20.7, 20.6, 20.5, 20.39, 20.38, 20.3; HRMS (ES ${ }^{+}$) calcd for $\mathrm{C}_{27} \mathrm{H}_{34} \mathrm{~N}_{5} \mathrm{O}_{15} 668.2046(\mathrm{M}+\mathrm{H})^{+}$ found 668.2021 .

N1-( $\beta$-D-ribofuranosyl) - 8-aminoinosine (8- $\mathrm{NH}_{2}-\mathrm{N1}$-ribosyl-IMP, 17)-N1-(2", 3", 5" Tri-O-acetyl- $\beta$-D-ribofuranosyl) - $2^{\prime}, 3^{\prime}, 5^{\prime}$-tri-O-acetyl-8-aminoinosine $(33,50 \mathrm{mg}, 69 \mu \mathrm{mol})$ 
was taken up in $\mathrm{MeOH}(2 \mathrm{~mL})$ in a pressure tube. The solution was cooled to $0{ }^{\circ} \mathrm{C}$ in an ice-water bath and $\mathrm{NH}_{3}(\mathrm{~g})$ bubbled through the solution to saturation. The tube was sealed and the resulting solution stirred at rt. When complete by TLC, the solvents were removed by evaporation under reduced pressure and co-evaporation with $\mathrm{MeOH}(5 \mathrm{~mL} \times 2$. The residue was purified by column chromatography on silica gel eluting with $\mathrm{DCM} / \mathrm{MeOH}$ $(1: 0 \rightarrow 7: 3 v / v+0.5 \%$ pyridine $)$ to afford the title compound $(24 \mathrm{mg}, 83 \%)$ as a clear glass; $R_{f}=0.38$ (DCM:MeOH 7:3 v/v + 0.5\% pyridine); ${ }^{1} \mathrm{H}-\mathrm{NMR}\left(400 \mathrm{MHz}, \mathrm{CD}_{3} \mathrm{OD}\right) \delta 8.67(\mathrm{~s}, 1 \mathrm{H}$, 2-H), $6.34(\mathrm{~d}, J=3.3 \mathrm{~Hz}, 1 \mathrm{H}), 6.09(\mathrm{~d}, J=7.3 \mathrm{~Hz}, 1 \mathrm{H}), 4.81(\mathrm{dd}, J=7.3,5.6, \mathrm{~Hz}, 1 \mathrm{H}), 4.38-4.30$ $(\mathrm{m}, 3 \mathrm{H}), 4.20-4.15(\mathrm{~m}, 2 \mathrm{H}), 4.00(\mathrm{dd}, J=12.3,2.5 \mathrm{~Hz}, 1 \mathrm{H}), 3.92-3.84(\mathrm{~m}, 3 \mathrm{H}) ;{ }^{13} \mathrm{C}-\mathrm{NMR}$ (100 MHz, CD 3 OD) $\delta 156.6,153.5,148.2,144.1,120.6,91.8,88.9,87.7,86.3,76.9,72.9,72.6$, $70.6,62.9,61.8$; HRMS (ES ${ }^{+}$) calcd for $\mathrm{C}_{15} \mathrm{H}_{21} \mathrm{~N}_{5} \mathrm{O}_{9} \mathrm{Na} 438.1231(\mathrm{M}+\mathrm{Na})^{+}$found 438.1246.

\subsection{Total Synthesis of N9-(4-Hydroxybutyl)-N1-Inosine Analogues (18-21)}

$N 1-\left(2^{\prime}, 3^{\prime}, 5^{\prime}\right.$-Tri-O-acetyl- $\beta$-D-ribofuranosyl)-N9-(4-(tert-butyldiphenylsilyl)oxybutyl) -8-bromohypoxanthine (34) was prepared as described previously [36].

$N 1-\left(2^{\prime}, 3^{\prime}, 5^{\prime}\right.$-Tri-O-acetyl- $\beta$-D-ribofuranosyl)-N9-(4-(tert-butyldiphenylsilyl)oxybutyl) -hypoxanthine (35) -N1-(2', $3^{\prime}, 5^{\prime}$-Tri-O-acetyl- $\beta$-D-ribofuranosyl)-N9-(4-(tert-butyldipheny -lsilyl)oxybutyl)-8-bromohypo-xanthine (34, 140mg, $0.179 \mathrm{mmol}), \mathrm{NaHCO}_{3}(75 \mathrm{mg}$, $0.895 \mathrm{mmol})$ and $\mathrm{Pd} / \mathrm{C}(2 \mathrm{mg}, 2 \mu \mathrm{mol})$ were taken up in $\mathrm{EtOH}(3 \mathrm{~mL})$ and the solution degassed with argon before being placed under an atmosphere of $\mathrm{H}_{2}$ for $12 \mathrm{~h}$. The catalyst was removed by filtration and the resulting solution purified by column chromatography on silica gel eluting with PE/EtOAc $(1: 0 \rightarrow 0: 1 \mathrm{v} / \mathrm{v})$ to afford the title compound $(95 \mathrm{mg}, 77 \%)$ as a clear glass; $R_{f}=0.60(\mathrm{PE}:$ EtOAc $1: 3 v / v) ;{ }^{1} \mathrm{H}-\mathrm{NMR}\left(400 \mathrm{MHz}, \mathrm{CDCl}_{3}\right) \delta 8.15(\mathrm{~s}, 1 \mathrm{H}), 7.68$ $(\mathrm{s}, 1 \mathrm{H}), 7.63-7.61(\mathrm{~m}, 4 \mathrm{H}), 7.42-7.33(\mathrm{~m}, 6 \mathrm{H})(10 \mathrm{H}, \mathrm{TBDPS}), 6.39\left(\mathrm{~d}, J=4.7 \mathrm{~Hz}, 1 \mathrm{H}, \mathrm{H}-1^{\prime}\right)$, 5.51-5.45 (m, 2H, H-2', $\left.\mathrm{H}-3^{\prime}\right), 4.44-4.36\left(\mathrm{~m}, 3 \mathrm{H}, \mathrm{H}-4^{\prime}, 2 \times \mathrm{H}-5^{\prime}\right), 4.13(\mathrm{t}, J=7.2 \mathrm{~Hz}$, $\left.2 \mathrm{H}, \mathrm{CH}_{2}\right), 3.69\left(\mathrm{t}, J=6.0 \mathrm{~Hz}, 2 \mathrm{H}, \mathrm{CH}_{2}\right), 2.14(\mathrm{~s}, 3 \mathrm{H}), 2.11(\mathrm{~s}, 3 \mathrm{H}), 2.06(\mathrm{~s}, 3 \mathrm{H})\left(3 \times \mathrm{CH}_{3}\right)$, 2.02-1.93 (m, 2H, CH $), 1.64-1.52\left(\mathrm{~m}, 2 \mathrm{H}, \mathrm{CH}_{2}\right), 1.03$ (s, 9H, TBDPS); ${ }^{13} \mathrm{C}-\mathrm{NMR}(100 \mathrm{MHz}$, $\left.\mathrm{CDCl}_{3}\right) \delta 170.2,169.53,169.51,156.0,147.4,143.8,140.0,135.5(4 \mathrm{C}), 133.6(2 \mathrm{C}), 129.6(2 \mathrm{C})$, 127.6 (4C), 123.9, 87.3, 80.1, 74.2, 70.2, 63.0, 62.9, 43.9, 29.3, 26.83, 26.80 (3C), 20.7, 20.42, 20.37, 19.1; HRMS $\left(\mathrm{ES}^{+}\right)$calcd for $\mathrm{C}_{36} \mathrm{H}_{44} \mathrm{~N}_{4} \mathrm{O}_{9} \mathrm{SiNa} 727.2770(\mathrm{M}+\mathrm{H})^{+}$found 727.2741.

N1-(2', $3^{\prime}, 5^{\prime}$-Tri-O-acetyl- $\beta$-D-ribofuranosyl)-N9-(4-hydroxybutyl)-hypoxanthine (39)-To TBAF (128 mg, $0.404 \mathrm{mmol})$ in DMF (0.5 mL) was added AcOH (24 $\mu \mathrm{L}, 0.425 \mathrm{mmol})$. After $30 \mathrm{~min}$, the solution was cooled to $0{ }^{\circ} \mathrm{C}$ and a solution of $N 1-\left(2^{\prime}, 3^{\prime}, 5^{\prime}\right.$-Tri-O-acetyl- $\beta$-Dribofuranosyl)-N9-(4-(tert-butyldiphenylsilyl)oxybutyl)-hypoxanthine (35, $95 \mathrm{mg}, 0.135 \mathrm{mmol})$ in DMF (1.0 mL) added dropwise. After 6h stirring at $\mathrm{rt}, \mathrm{NH}_{4} \mathrm{Cl}$ (satd. aq.) was added and the solution extracted with $\mathrm{DCM} \times 3$. The combined organic layers were dried over $\mathrm{Na}_{2} \mathrm{SO}_{4}$ and purified by column chromatography on silica gel eluting with $\mathrm{DCM} / \mathrm{MeOH}(1: 0 \rightarrow$ $4: 1 \mathrm{v} / \mathrm{v}$ ) to afford the title compound $\left(29 \mathrm{mg}, 46 \%\right.$ ) as a clear glass; $R_{f}=0.41$ (DCM:MeOH 9:1 v/v); ${ }^{1} \mathrm{H}-\mathrm{NMR}\left(400 \mathrm{MHz} \mathrm{CDCl}_{3}\right) \delta 8.17(\mathrm{~s}, 1 \mathrm{H}), 7.76(\mathrm{~s}, 1 \mathrm{H}), 6.36(\mathrm{~d}, J=4.6 \mathrm{~Hz}, 1 \mathrm{H}$, $\left.\mathrm{H}-1^{\prime}\right), 5.49\left(\mathrm{dd}, J=5.8,4.6 \mathrm{~Hz}, 1 \mathrm{H}, \mathrm{H}-2^{\prime}\right), 5.46\left(\mathrm{dd}, J=5.8,5.1 \mathrm{~Hz}, 1 \mathrm{H}, \mathrm{H}-3^{\prime}\right), 4.43-4.35$ $\left(\mathrm{m}, 3 \mathrm{H}, \mathrm{H}-4^{\prime}, 2 \times \mathrm{H}-5^{\prime}\right), 4.21\left(\mathrm{t}, J=7.2 \mathrm{~Hz}, 2 \mathrm{H}, \mathrm{CH}_{2}\right), 3.69\left(\mathrm{t}, J=6.1 \mathrm{~Hz}, 2 \mathrm{H}, \mathrm{CH}_{2}\right), 2.16$ $(\mathrm{s}, 3 \mathrm{H}), 2.09(\mathrm{~s}, 3 \mathrm{H}), 2.07(\mathrm{~s}, 3 \mathrm{H})\left(3 \times \mathrm{CH}_{3}\right), 2.02-1.91\left(\mathrm{~m}, 2 \mathrm{H}, \mathrm{CH}_{2}\right)$ and $1.63-1.54(\mathrm{~m}, 2 \mathrm{H}$, $\left.\mathrm{CH}_{2}\right) ;{ }^{13} \mathrm{C}-\mathrm{NMR}\left(125 \mathrm{MHz}, \mathrm{CDCl}_{3}\right) \delta 170.4,169.70,169.66,156.0,147.5,144.0,140.3,123.9$, 87.6, 80.1, 74.2, 70.2, 63.0, 61.9, 44.0, 29.2, 27.1, 20.9, 20.52, 20.49; HRMS (ES ${ }^{+}$) calcd for $\mathrm{C}_{20} \mathrm{H}_{27} \mathrm{~N}_{4} \mathrm{O}_{9} 467.1773(\mathrm{M}+\mathrm{H})^{+}$found 467.1787 .

N1-( $\beta$-D-Ribofuranosyl)-N9-(4-hydroxybutyl)-hypoxanthine (N9-hydroxybutyl-N1Inosine, 19)-N1-(2', $3^{\prime}, 5^{\prime}$-Tri-O-acetyl- $\beta$-D-ribofuranosyl)- $N 9$-(4-hydroxybutyl)-hypoxanthine $(39,25 \mathrm{mg}, 54 \mu \mathrm{mol})$ was taken up in $\mathrm{MeOH}(2.0 \mathrm{~mL})$ in a pressure tube. The solution was cooled to $0{ }^{\circ} \mathrm{C}$ in an ice-water bath and $\mathrm{NH}_{3}(\mathrm{~g})$ bubbled through the solution to saturation. The tube was sealed and the resulting solution stirred at rt. When complete by TLC, the solvents were removed by evaporation under reduced pressure and co-evaporation with $\mathrm{MeOH}(5 \mathrm{~mL} \times 2)$. The residue was purified by column chromatography on silica gel eluting with $\mathrm{DCM} / \mathrm{MeOH}(1: 0 \rightarrow 3: 1 \mathrm{v} / \mathrm{v})$ to afford the title compound $(8.7 \mathrm{mg}, 48 \%)$ as a clear glass; $R_{f}=0.19$ (DCM:MeOH 4:1 v/v); ${ }^{1} \mathrm{H}-\mathrm{NMR}\left(500 \mathrm{MHz}, \mathrm{D}_{2} \mathrm{O}\right) \delta 8.48(\mathrm{~s}, 1 \mathrm{H})$, 
$7.96(\mathrm{~s}, 1 \mathrm{H}), 6.04\left(\mathrm{~d}, J=3.3 \mathrm{~Hz}, 1 \mathrm{H}, \mathrm{H}-1^{\prime}\right), 4.28\left(\mathrm{dd}, J=5.2,3.3 \mathrm{~Hz}, 1 \mathrm{H}, \mathrm{H}-2^{\prime}\right), 4.17(\mathrm{dd}$, $\left.J=6.5,5.2 \mathrm{~Hz}, 1 \mathrm{H}, \mathrm{H}-3^{\prime}\right), 4.11\left(\mathrm{t}, J=7.1 \mathrm{~Hz}, 2 \mathrm{H}, \mathrm{CH}_{2}\right), 4.06(\mathrm{ddd}, J=6.5,4.1,2.7 \mathrm{~Hz}, 1 \mathrm{H}$, $\left.\mathrm{H}-4^{\prime}\right), 3.86\left(\mathrm{dd}, J=12.9,2.7 \mathrm{~Hz}, 1 \mathrm{H}, \mathrm{H}-5^{\prime}{ }_{\mathrm{a}}\right), 3.72\left(\mathrm{dd}, J=12.9,2.7 \mathrm{~Hz}, 1 \mathrm{H}, \mathrm{H}-5^{\prime}{ }_{\mathrm{b}}\right), 3.43$ $\left(\mathrm{t}, J=6.5 \mathrm{~Hz}, 2 \mathrm{H}, \mathrm{CH}_{2}\right), 1.76\left(\mathrm{dt}, J=7.6,7.1 \mathrm{~Hz}, 2 \mathrm{H}, \mathrm{CH}_{2}\right)$ and $1.37(\mathrm{dt}, J=7.6,6.5 \mathrm{~Hz}$, $\left.2 \mathrm{H}, \mathrm{CH}_{2}\right) ;{ }^{13} \mathrm{C}-\mathrm{NMR}\left(125 \mathrm{MHz}, \mathrm{D}_{2} \mathrm{O}\right) \delta 157.5,147.7,145.0,142.5,122.6,90.1,83.9,74.7$, $68.8,60.9,60.2,44.0,28.3,25.9$; HRMS $\left(\mathrm{ES}^{+}\right)$calcd for $\mathrm{C}_{14} \mathrm{H}_{20} \mathrm{~N}_{4} \mathrm{O}_{6} \mathrm{Na} 363.1275(\mathrm{M}+\mathrm{Na})^{+}$ found 363.1276 .

$N 1-\left(2^{\prime}, 3^{\prime}, 5^{\prime}\right.$-Tri-O-acetyl- $\beta$-D-ribofuranosyl)-N9-(4-hydroxybutyl)-8-bromohypox -anthine (38)-To TBAF $(121 \mathrm{mg}, 0.384 \mathrm{mmol})$ in DMF $(0.5 \mathrm{~mL})$ was added AcOH $(23 \mu \mathrm{L}$, $0.402 \mathrm{mmol})$. After $30 \mathrm{~min}$, the solution was cooled to $0^{\circ} \mathrm{C}$ and a solution of $\mathrm{N1}-\left(2^{\prime}, 3^{\prime}, 5^{\prime}\right.$-TriO-acetyl- $\beta$-D-ribofuranosyl)-N9-(4-(tert-butyldiphenylsilyl)oxybutyl)-8-bromohypoxanthine $(34,100 \mathrm{mg}, 0.128 \mathrm{mmol})$ in DMF $(1.0 \mathrm{~mL})$ added dropwise. After 6 h stirring at $\mathrm{rt}, \mathrm{NH}_{4} \mathrm{Cl}$ (satd. aq.) was added and the solution extracted with DCM $\times 3$. The combined organic layers were dried over $\mathrm{Na}_{2} \mathrm{SO}_{4}$ and purified by column chromatography on silica gel eluting with DCM/MeOH $(1: 0 \rightarrow 4: 1 \mathrm{v} / \mathrm{v})$ to afford the title compound $(41 \mathrm{mg}, 59 \%)$ as a clear glass; $R_{f}=0.10$ (PE:EtOAc 1:3 v/v); ${ }^{1} \mathrm{H}-\mathrm{NMR}\left(400 \mathrm{MHz}, \mathrm{CDCl}_{3}\right) \delta 8.16(\mathrm{~s}, 1 \mathrm{H}), 6.35$ $\left(\mathrm{d}, J=4.6 \mathrm{~Hz}, 1 \mathrm{H}, \mathrm{H}-1^{\prime}\right), 5.46\left(\mathrm{dd}, J=4.6,2.4 \mathrm{~Hz}, 1 \mathrm{H}, \mathrm{H}-2^{\prime}\right), 5.43(\mathrm{dd}, J=5.8,2.4 \mathrm{~Hz}$, $\left.1 \mathrm{H}, \mathrm{H}-3^{\prime}\right), 4.43-4.34\left(\mathrm{~m}, 3 \mathrm{H}, \mathrm{H}-4^{\prime}, 2 \times \mathrm{H}-5^{\prime}\right), 4.21\left(\mathrm{t}, J=7.2 \mathrm{~Hz}, 2 \mathrm{H}, \mathrm{CH}_{2}\right), 3.69(\mathrm{t}$, $\left.J=6.2 \mathrm{~Hz}, 2 \mathrm{H}, \mathrm{CH}_{2}\right), 2.15(\mathrm{~s}, 3 \mathrm{H}), 2.10(\mathrm{~s}, 3 \mathrm{H}), 2.07(\mathrm{~s}, 3 \mathrm{H})\left(3 \times \mathrm{CH}_{3}\right), 1.96-1.88(\mathrm{~m}, 2 \mathrm{H}$, $\left.\mathrm{CH}_{2}\right)$ and 1.62-1.55 (m, 2H, $\left.\mathrm{CH}_{2}\right) ;{ }^{13} \mathrm{C}-\mathrm{NMR}\left(100 \mathrm{MHz}, \mathrm{CDCl}_{3}\right) \delta 170.2,169.6,169.5,154.7$, 148.7, 144.2, 126.1, 124.0, 87.4, 80.1, 74.1, 70.1, 62.9, 62.0, 44.6, 29.1, 26.2, 20.7, 20.41, 20.35; HRMS $\left(\mathrm{ES}^{+}\right)$calcd for $\mathrm{C}_{20} \mathrm{H}_{25} \mathrm{~N}_{4} \mathrm{O}_{9} \mathrm{Na}^{79} \mathrm{Br} 567.0697(\mathrm{M}+\mathrm{Na})^{+}$found 567.0688; calcd for $\mathrm{C}_{20} \mathrm{H}_{25} \mathrm{~N}_{4} \mathrm{O}_{9} \mathrm{Na}^{81} \mathrm{Br} 569.0677(\mathrm{M}+\mathrm{Na})^{+}$found 569.0656 .

N1-( $\beta$-D-Ribofuranosyl)-N9-(4-hydroxybutyl)-8-bromohypoxanthine (8-Br-N9-hy -droxybutyl-N1-Inosine, 18)-N1-(2',3',5'-Tri-O-acetyl- $\beta$-D-ribofuranosyl)-N9-(4-hydroxy -butyl)-8-bromohypoxanthine (38, $40 \mathrm{mg}, 73 \mu \mathrm{mol})$ was taken up in $\mathrm{MeOH}(1.5 \mathrm{~mL})$ in a pressure tube. The solution was cooled to $0{ }^{\circ} \mathrm{C}$ in an ice-water bath and $\mathrm{NH}_{3}(\mathrm{~g})$ bubbled through the solution to saturation. The tube was sealed and the resulting solution stirred at rt. When complete by TLC, the solvents were removed by evaporation under reduced pressure and co-evaporation with $\mathrm{MeOH}(5 \mathrm{~mL} \times 2)$. The residue was purified by column chromatography on silica gel eluting with $\mathrm{DCM} / \mathrm{MeOH}(1: 0 \rightarrow 3: 1 v / v)$ to afford the title compound (9 mg, 29\%) as a clear glass; $R_{f}=0.12$ (DCM:MeOH 9:1 v/v); ${ }^{1} \mathrm{H}-\mathrm{NMR}\left(400 \mathrm{MHz}, \mathrm{CD}_{3} \mathrm{OD}\right) \delta$ $8.86(\mathrm{~s}, 1 \mathrm{H}), 6.26\left(\mathrm{~d}, J=3.0 \mathrm{~Hz}, 1 \mathrm{H}, \mathrm{H}-1^{\prime}\right), 4.36-4.31\left(\mathrm{~m}, 4 \mathrm{H}, \mathrm{H}-2^{\prime}, \mathrm{H}-3^{\prime}, \mathrm{CH}_{2}\right), 4.17$ (ddd, $\left.J=5.4,2.9,2.6 \mathrm{~Hz}, 1 \mathrm{H}, \mathrm{H}-4^{\prime}\right), 4.01\left(\mathrm{dd}, J=12.3,2.6 \mathrm{~Hz}, 1 \mathrm{H}, \mathrm{H}-5_{\mathrm{a}}^{\prime}\right), 3.87(\mathrm{dd}, J=12.3,2.9 \mathrm{~Hz}$, $\left.1 \mathrm{H}, \mathrm{H}-5^{\prime}{ }_{\mathrm{b}}\right), 3.65\left(\mathrm{t}, J=6.3 \mathrm{~Hz}, 2 \mathrm{H}, \mathrm{CH}_{2}\right), 1.98\left(\mathrm{dt}, J=7.5,7.1 \mathrm{~Hz}, 2 \mathrm{H}, \mathrm{CH}_{2}\right)$ and $1.62(\mathrm{dt}$, $\left.J=7.5,6.3 \mathrm{~Hz}, 2 \mathrm{H}, \mathrm{CH}_{2}\right) ;{ }^{13} \mathrm{C}-\mathrm{NMR}\left(100 \mathrm{MHz}, \mathrm{CD}_{3} \mathrm{OD}\right) \delta 157.0,150.6,147.2,127.7,124.6,91.5$, 86.3, 76.9, 70.6, 62.2, 61.7, 45.8, 30.5, 27.2; HRMS (ES ${ }^{+}$) calcd for $\mathrm{C}_{14} \mathrm{H}_{19} \mathrm{~N}_{4} \mathrm{O}_{6} \mathrm{Na}^{79} \mathrm{Br} 441.0380$ $(\mathrm{M}+\mathrm{Na})^{+}$found 441.0395; calcd for $\mathrm{C}_{14} \mathrm{H}_{19} \mathrm{~N}_{4} \mathrm{O}_{6} \mathrm{Na}^{81} \mathrm{Br} 443.0360(\mathrm{M}+\mathrm{Na})^{+}$found 443.0382 .

$N 1-\left(2^{\prime}, 3^{\prime}, 5^{\prime}\right.$-Tri-O-acetyl- $\beta$-D-ribofuranosyl)-N9-(4-(tert-butyldiphenylsilyl)oxybu -tyl)-8-azidohypoxan-thine (36)-To $N 1$ - $\left(2^{\prime}, 3^{\prime}, 5^{\prime}\right.$-tri-O-acetyl- $\beta$-D-ribofuranosyl)- $N 9$-(4-(tertbutyldiphenylsilyl)oxybutyl)-8-bromohypoxanthine (34, $400 \mathrm{mg}, 0.510 \mathrm{mmol}$ ) in DMF $(4.0 \mathrm{~mL})$ was added $\mathrm{NaN}_{3}(106 \mathrm{mg}, 1.633 \mathrm{mmol})$ and the resulting solution stirred at $70{ }^{\circ} \mathrm{C}$ in the dark for $72 \mathrm{~h}$. The solution was evaporated to dryness and the residue taken up in DCM, washed with $\mathrm{H}_{2} \mathrm{O}$, dried over $\mathrm{Na}_{2} \mathrm{SO}_{4}$ and purified by column chromatography on silica gel eluting with PE/EtOAc $(1: 0 \rightarrow 0: 1 \mathrm{v} / \mathrm{v})$ to afford the title compound $(321 \mathrm{mg}, 84 \%)$ as a clear glass; $R_{f}=0.73$ (PE:EtOAc 1:3 v/v) - note there is no change in retention time compared to the starting material; ${ }^{1} \mathrm{H}-\mathrm{NMR}\left(400 \mathrm{MHz}, \mathrm{CDCl}_{3}\right) \delta 8.09(\mathrm{~s}, 1 \mathrm{H}), 7.64-7.62(\mathrm{~m}, 4 \mathrm{H}), 7.42-7.34(\mathrm{~m}$, $6 \mathrm{H})(10 \mathrm{H}, \mathrm{TBDPS}), 6.37\left(\mathrm{~d}, J=4.4 \mathrm{~Hz}, 1 \mathrm{H}, \mathrm{H}-1^{\prime}\right), 5.50-5.45\left(\mathrm{~m}, 2 \mathrm{H}, \mathrm{H}-2^{\prime}, \mathrm{H}-3^{\prime}\right), 4.44-4.36$ $\left(\mathrm{m}, 3 \mathrm{H}, \mathrm{H}-4^{\prime}, 2 \times \mathrm{H}-5^{\prime}\right), 3.97\left(\mathrm{t}, J=7.2 \mathrm{~Hz}, 2 \mathrm{H}, \mathrm{CH}_{2}\right), 3.68\left(\mathrm{t}, J=6.1 \mathrm{~Hz}, 2 \mathrm{H}, \mathrm{CH}_{2}\right), 2.13(\mathrm{~s}$, $3 \mathrm{H}), 2.12(\mathrm{~s}, 3 \mathrm{H}), 2.08(\mathrm{~s}, 3 \mathrm{H})\left(3 \times \mathrm{CH}_{3}\right), 1.96-1.85\left(\mathrm{~m}, 2 \mathrm{H}, \mathrm{CH}_{2}\right), 1.56-1.49\left(\mathrm{~m}, 2 \mathrm{H}, \mathrm{CH}_{2}\right)$, 1.03 (s, 9H, TBDPS); ${ }^{13} \mathrm{C}-\mathrm{NMR}\left(100 \mathrm{MHz}, \mathrm{CDCl}_{3}\right) \delta 170.1,169.53,169.52,154.9,147.5,145.0$, $143.2,135.5$ (4C), 133.7 (2C), 129.6 (2C), 127.6 (4C), 121.7, 87.6, 80.2, 74.3, 70.3, 63.1, 62.8, 42.4, 29.2, 26.8 (3C), 25.9, 20.7, 20.43, 20.36, 19.1; HRMS (ES ${ }^{+}$) calcd for $\mathrm{C}_{36} \mathrm{H}_{43} \mathrm{~N}_{7} \mathrm{O}_{9} \mathrm{SiNa} 768.2784$ $(\mathrm{M}+\mathrm{H})^{+}$found 768.2761 . 
N1-(2', $3^{\prime}, 5^{\prime}$-Tri-O-acetyl- $\beta$-D-ribofuranosyl)-N9-(4-hydroxybutyl)-8-azidohypoxa -nthine (40)-To TBAF (114 mg, $0.362 \mathrm{mmol})$ in DMF $(0.5 \mathrm{~mL})$ was added AcOH $(22 \mu \mathrm{L}$, $0.380 \mathrm{mmol})$. After $30 \mathrm{~min}$, the solution was cooled to $0^{\circ} \mathrm{C}$ and a solution of $N 1-\left(2^{\prime}, 3^{\prime}, 5^{\prime}\right.$-Tri$O$-acetyl- $\beta$-D-ribofuranosyl)-N9-(4-(tert-butyldiphenylsilyl)oxybutyl)-8-azidohypoxanthine $(36,90 \mathrm{mg}, 0.121 \mathrm{mmol})$ in $\mathrm{DMF}(1.0 \mathrm{~mL})$ added dropwise. After $6 \mathrm{~h}$ stirring at $\mathrm{rt}, \mathrm{NH}_{4} \mathrm{Cl}$ (satd. aq.) was added and the solution extracted with $\mathrm{DCM} \times 3$. The combined organic layers were dried over $\mathrm{Na}_{2} \mathrm{SO}_{4}$ and purified by column chromatography on silica gel eluting with $\mathrm{DCM} / \mathrm{MeOH}(1: 0 \rightarrow 4: 1 v / v)$ to afford the title compound $(30 \mathrm{mg}, 49 \%)$ as a clear glass; $R_{f}=0.41$ (DCM:MeOH 9:1 v/v); ${ }^{1} \mathrm{H}-\mathrm{NMR}\left(400 \mathrm{MHz}, \mathrm{CDCl}_{3}\right) \delta 8.11(\mathrm{~s}, 1 \mathrm{H}), 6.34$ $\left(\mathrm{d}, J=4.5 \mathrm{~Hz}, 1 \mathrm{H}, \mathrm{H}-1^{\prime}\right), 5.48\left(\mathrm{dd}, J=5.9,4.6 \mathrm{~Hz}, 1 \mathrm{H}, \mathrm{H}-2^{\prime}\right), 5.45(\mathrm{dd}, J=5.9,4.7 \mathrm{~Hz}, 1 \mathrm{H}$, $\left.\mathrm{H}-3^{\prime}\right), 4.43-4.35\left(\mathrm{~m}, 3 \mathrm{H}, \mathrm{H}-4^{\prime}, 2 \times \mathrm{H}-5^{\prime}\right), 4.02\left(\mathrm{t}, J=7.1 \mathrm{~Hz}, 2 \mathrm{H}, \mathrm{CH}_{2}\right), 3.67(\mathrm{t}, J=6.3 \mathrm{~Hz}$, $\left.2 \mathrm{H}, \mathrm{CH}_{2}\right), 2.15(\mathrm{~s}, 3 \mathrm{H}), 2.11(\mathrm{~s}, 3 \mathrm{H}), 2.07(\mathrm{~s}, 3 \mathrm{H})\left(3 \times \mathrm{CH}_{3}\right), 1.91-1.83\left(\mathrm{~m}, 2 \mathrm{H}, \mathrm{CH}_{2}\right)$ and $1.58-1.51\left(\mathrm{~m}, 2 \mathrm{H}, \mathrm{CH}_{2}\right) ;{ }^{13} \mathrm{C}-\mathrm{NMR}\left(100 \mathrm{MHz}, \mathrm{CDCl}_{3}\right) \delta 170.2,169.6,169.5,154.9,147.5$, 145.0, 143.4, 121.7, 87.7, 80.2, 74.2, 70.2, 63.1, 62.0, 42.4, 29.1, 26.0, 20.7, 20.42, 20.36; HRMS $\left(\mathrm{ES}^{+}\right.$) calcd for $\mathrm{C}_{20} \mathrm{H}_{26} \mathrm{~N}_{7} \mathrm{O}_{9} 508.1787(\mathrm{M}+\mathrm{H})^{+}$found 508.1799.

N1-( $\beta$-D-Ribofuranosyl)-N9-(4-hydroxybutyl) - 8-azidohypoxanthine (8- $\mathrm{N}_{3}-\mathrm{N} 9$-hy -droxybutyl-N1-inosine, 20)-N1-(2', $3^{\prime}, 5^{\prime}$-Tri-O-acetyl- $\beta$-D-ribofuranosyl)-N9-(4-hydroxyb -utyl)-8-azidohypoxanthine $(40,30 \mathrm{mg}, 59 \mu \mathrm{mol})$ was taken up in $\mathrm{MeOH}(1.5 \mathrm{~mL})$ in a pressure tube. The solution was cooled to $0{ }^{\circ} \mathrm{C}$ in an ice-water bath and $\mathrm{NH}_{3}(\mathrm{~g})$ bubbled through the solution to saturation. The tube was sealed and the resulting solution stirred at rt. When complete by TLC, the solvents were removed by evaporation under reduced pressure and co-evaporation with $\mathrm{MeOH}(5 \mathrm{~mL} \times 2)$. The residue was purified by column chromatography on silica gel eluting with $\mathrm{DCM} / \mathrm{MeOH}(1: 0 \rightarrow 4: 1 v / v)$ to afford the title compound $(10 \mathrm{mg}, 44 \%)$ as a clear glass; $R_{f}=0.11(\mathrm{DCM}: \mathrm{MeOH} 9: 1 \mathrm{v} / \mathrm{v}) ;{ }^{1} \mathrm{H}-\mathrm{NMR}(400 \mathrm{MHz}$, $\left.\mathrm{CD}_{3} \mathrm{OD}\right) \delta 8.80(\mathrm{~s}, 1 \mathrm{H}), 6.27\left(\mathrm{~d}, J=3.1 \mathrm{~Hz}, 1 \mathrm{H}, \mathrm{H}-1^{\prime}\right), 4.36-4.31\left(\mathrm{~m}, 2 \mathrm{H}, \mathrm{H}-2^{\prime}, \mathrm{H}-3^{\prime}\right)$, $4.17\left(\mathrm{ddd}, J=5.5,2.9,2.3 \mathrm{~Hz}, 1 \mathrm{H}, \mathrm{H}-4^{\prime}\right), 4.13\left(\mathrm{t}, J=7.1 \mathrm{~Hz}, 2 \mathrm{H}, \mathrm{CH}_{2}\right), 4.01(\mathrm{dd}, J=12.3$, $\left.2.6 \mathrm{~Hz}, 1 \mathrm{H}, \mathrm{H}-5^{\prime}{ }_{\mathrm{a}}\right), 3.87\left(\mathrm{dd}, J=12.3,2.9 \mathrm{~Hz}, 1 \mathrm{H}, \mathrm{H}-5^{\prime}{ }_{\mathrm{b}}\right), 3.63\left(\mathrm{t}, J=6.4 \mathrm{~Hz}, 2 \mathrm{H}, \mathrm{CH}_{2}\right), 1.93$ $\left(\mathrm{dt}, J=7.3,7.1 \mathrm{~Hz}, 2 \mathrm{H}, \mathrm{CH}_{2}\right)$ and $1.58\left(\mathrm{dt}, J=7.3,6.4 \mathrm{~Hz}, 2 \mathrm{H}, \mathrm{CH}_{2}\right) ;{ }^{13} \mathrm{C}-\mathrm{NMR}(125 \mathrm{MHz}$, $\mathrm{CD}_{3} \mathrm{OD}$ ) $\delta 157.3,149.5,146.7,146.2,122.4,91.6,86.3,76.9,70.6,62.1,61.7,43.5,30.5,26.9$; HRMS $\left(\mathrm{ES}^{+}\right)$calcd for $\mathrm{C}_{14} \mathrm{H}_{19} \mathrm{~N}_{7} \mathrm{O}_{6} \mathrm{Na} 404.1289(\mathrm{M}+\mathrm{Na})^{+}$found 404.1293.

$N 1-\left(2^{\prime}, 3^{\prime}, 5^{\prime}\right.$-Tri-O-acetyl- $\beta$-D-ribofuranosyl)-N9-(4-(tert-butyldiphenylsilyl)oxybutyl) -8-aminohypoxan-thine (37)-N1-( $2^{\prime}, 3^{\prime}, 5^{\prime}$-Tri-O-acetyl- $\beta$-D-ribofuranosyl)-N9-(4-(tertbutyldiphenylsilyl)oxybutyl)-8-azidohypoxanthine (36,110 mg, $0.147 \mathrm{mmol}$ ) and $\mathrm{Pd} / \mathrm{C}$ $(9 \mathrm{mg}, 9 \mu \mathrm{mol})$ were taken up in $\mathrm{EtOH}(3 \mathrm{~mL})$ and the solution degassed with argon before being placed under an atmosphere of $\mathrm{H}_{2}$ for $12 \mathrm{~h}$. The catalyst was removed by filtration and the resulting solution purified by column chromatography on silica gel eluting with DCM/Acetone $(1: 0 \rightarrow 0: 1 \mathrm{v} / \mathrm{v})$ to afford the title compound $(70 \mathrm{mg}, 66 \%)$ as a clear glass; $R_{f}=0.60$ (DCM:Acetone 1:1 v/v); ${ }^{1} \mathrm{H}-\mathrm{NMR}\left(500 \mathrm{MHz}, \mathrm{CDCl}_{3}\right) \delta 8.03(\mathrm{~s}, 1 \mathrm{H}), 7.65-7.63$ $(\mathrm{m}, 4 \mathrm{H}), 7.44-7.36(\mathrm{~m}, 6 \mathrm{H})(10 \mathrm{H}, \mathrm{TBDPS}), 6.40\left(\mathrm{~d}, J=4.7 \mathrm{~Hz}, 1 \mathrm{H}, \mathrm{H}-1^{\prime}\right), 5.50(\mathrm{dd}, 1 \mathrm{H}$, $\left.J=5.7,4.7, \mathrm{H}-2^{\prime}\right), 5.47-5.45\left(\mathrm{~m}, 1 \mathrm{H}, \mathrm{H}-3^{\prime}\right), 4.84\left(\mathrm{brs}, 2 \mathrm{H}, \mathrm{NH}_{2}\right), 4.44-4.36\left(\mathrm{~m}, 3 \mathrm{H}, \mathrm{H}-4^{\prime}\right.$, $\left.2 \times \mathrm{H}-5^{\prime}\right), 3.98\left(\mathrm{dt}, J=7.1,1.5 \mathrm{~Hz}, 2 \mathrm{H}, \mathrm{CH}_{2}\right), 3.68\left(\mathrm{~m}, 2 \mathrm{H}, \mathrm{CH}_{2}\right), 2.15(\mathrm{~s}, 3 \mathrm{H}), 2.11(\mathrm{~s}$, $3 \mathrm{H}), 2.09(\mathrm{~s}, 3 \mathrm{H})\left(3 \times \mathrm{CH}_{3}\right), 1.92-1.88\left(\mathrm{~m}, 2 \mathrm{H}, \mathrm{CH}_{2}\right), 1.61-1.56\left(\mathrm{~m}, 2 \mathrm{H}, \mathrm{CH}_{2}\right), 1.05(\mathrm{~s}, 9 \mathrm{H}$, TBDPS); ${ }^{13} \mathrm{C}-\mathrm{NMR}\left(125 \mathrm{MHz}, \mathrm{CDCl}_{3}\right) \delta 170.3,169.63,169.61,155.1,150.7,146.7,141.4,135.5$ (4C), 133.5 (2C), 129.8 (2C), 127.7 (4C), 120.6, 87.3, 80.0, 74.3, 70.2, 64.3, 63.3, 63.1, 41.7, 29.0, 26.9 (3C), 25.9, 20.8, 20.52, 20.49, 19.2; HRMS (ES ${ }^{+}$) calcd for $\mathrm{C}_{36} \mathrm{H}_{45} \mathrm{~N}_{5} \mathrm{O}_{9} \mathrm{SiNa} 742.2879$ $(\mathrm{M}+\mathrm{Na})^{+}$found 742.2850 .

$N 1-\left(2^{\prime}, 3^{\prime}, 5^{\prime}\right.$-Tri-O-acetyl- $\beta$-D-ribofuranosyl)-N9-(4-hydroxybutyl)-8-aminohypox -anthine (41)-To TBAF $(92 \mathrm{mg}, 0.292 \mathrm{mmol})$ in DMF $(0.5 \mathrm{~mL})$ was added AcOH $(18 \mu \mathrm{L}$, $0.306 \mathrm{mmol})$. After $30 \mathrm{~min}$, the solution was cooled to $0^{\circ} \mathrm{C}$ and a solution of $N 1-\left(2^{\prime}, 3^{\prime}, 5^{\prime}\right.$-Tri$\mathrm{O}$-acetyl- $\beta$-D-ribofuranosyl)-N9-(4-(tert-butyldiphenylsilyl)oxybutyl)-8-aminohypoxanthine $(37,70 \mathrm{mg}, 0.0972 \mathrm{mmol})$ in DMF $(0.5 \mathrm{~mL})$ added dropwise. After $6 \mathrm{~h}$ stirring at $\mathrm{rt}, \mathrm{NH}_{4} \mathrm{Cl}$ (satd. aq.) was added and the solution extracted with $\mathrm{DCM} \times 3$. The combined organic layers were dried over $\mathrm{Na}_{2} \mathrm{SO}_{4}$ and purified by column chromatography on silica gel eluting with $\mathrm{DCM} / \mathrm{MeOH}(1: 0 \rightarrow 4: 1 \mathrm{v} / \mathrm{v})$ to afford the title compound $(47 \mathrm{mg}, 100 \%)$ as 
a clear glass; $R_{f}=0.47$ (DCM:MeOH 9:1 v/v); ${ }^{1} \mathrm{H}-\mathrm{NMR}\left(400 \mathrm{MHz}, \mathrm{CDCl}_{3}\right) \delta 7.99(\mathrm{~s}, 1 \mathrm{H})$, $6.24\left(\mathrm{~d}, J=4.0 \mathrm{~Hz}, 1 \mathrm{H}, \mathrm{H}-1^{\prime}\right), 6.16\left(\right.$ br s, $\left.2 \mathrm{H}, \mathrm{NH}_{2}\right), 5.55\left(\mathrm{dd}, J=5.8,4.0 \mathrm{~Hz}, 1 \mathrm{H}, \mathrm{H}-2^{\prime}\right)$, $5.45\left(\mathrm{dd}, J=5.8,5.7 \mathrm{~Hz}, 1 \mathrm{H}, \mathrm{H}-3^{\prime}\right), 4.43-4.31\left(\mathrm{~m}, 3 \mathrm{H}, \mathrm{H}-4^{\prime}, 2 \times \mathrm{H}-5^{\prime}\right), 4.03(\mathrm{t}, J=7.0 \mathrm{~Hz}$, $\left.2 \mathrm{H}, \mathrm{CH}_{2}\right), 3.69\left(\mathrm{t}, J=5.8 \mathrm{~Hz}, 2 \mathrm{H}, \mathrm{CH}_{2}\right), 2.12(\mathrm{~s}, 3 \mathrm{H}), 2.08(\mathrm{~s}, 6 \mathrm{H})\left(3 \times \mathrm{CH}_{3}\right), 1.91-1.82(\mathrm{~m}$, $\left.2 \mathrm{H}, \mathrm{CH}_{2}\right)$ and $1.58-1.51\left(\mathrm{~m}, 2 \mathrm{H}, \mathrm{CH}_{2}\right) ;{ }^{13} \mathrm{C}-\mathrm{NMR}\left(100 \mathrm{MHz}_{2} \mathrm{CDCl}_{3}\right) \delta 170.4,169.61,169.59$, $154.9,152.4,146.8,141.1,120.5,88.4,79.7,74.1,70.0,62.9,62.0,41.5,28.4,26.1,20.7,20.41$ (2C); HRMS (ES ${ }^{+}$) calcd for $\mathrm{C}_{20} \mathrm{H}_{28} \mathrm{~N}_{5} \mathrm{O}_{9} 482.1882(\mathrm{M}+\mathrm{H})^{+}$found 482.1891 .

N1-( $\beta$-D-Ribofuranosyl)-N9-(4-hydroxybutyl) - 8-aminohypoxanthine (8- $\mathrm{NH}_{2}-\mathrm{N9}$ hydroxybutyl-N1-inosine, 21)-N1-(2', $3^{\prime}, 5^{\prime}$-Tri-O-acetyl- $\beta$-D-ribofuranosyl)- $N 9$-(4-hydrox -ybutyl)-8-aminohypoxanthine $(41,45 \mathrm{mg}, 93 \mu \mathrm{mol})$ was taken up in $\mathrm{MeOH}(1.5 \mathrm{~mL})$ in a pressure tube. The solution was cooled to $0{ }^{\circ} \mathrm{C}$ in an ice-water bath and $\mathrm{NH}_{3}(\mathrm{~g})$ bubbled through the solution to saturation. The tube was sealed and the resulting solution stirred at $\mathrm{rt}$. When complete by TLC, the solvents were removed by evaporation under reduced pressure and co-evaporation with $\mathrm{MeOH}(5 \mathrm{~mL} \times 2)$. The residue was purified by column chromatography on silica gel eluting with $\mathrm{DCM} / \mathrm{MeOH}(1: 0 \rightarrow 4: 1 v / v+0.5 \%$ pyridine $)$ to afford the title compound (13 mg, 39\%) as a clear glass; $R_{f}=0.47$ (DCM:MeOH 7:3 v/v); ${ }^{1} \mathrm{H}-\mathrm{NMR}\left(400 \mathrm{MHz}, \mathrm{CD}_{3} \mathrm{OD}\right) \delta 8.63(\mathrm{~s}, 1 \mathrm{H}), 6.25\left(\mathrm{~d}, J=3.4 \mathrm{~Hz}, 1 \mathrm{H}, \mathrm{H}-1^{\prime}\right), 4.37(\mathrm{dd}, J=5.2$, $\left.3.4 \mathrm{~Hz}, 1 \mathrm{H}, \mathrm{H}-2^{\prime}\right), 4.33\left(\mathrm{dd}, J=5.7,5.2 \mathrm{~Hz}, 1 \mathrm{H}, \mathrm{H}-3^{\prime}\right), 4.16(\mathrm{ddd}, J=5.7,3.0,2.5 \mathrm{~Hz}, 1 \mathrm{H}$, $\left.\mathrm{H}-4^{\prime}\right), 4.12\left(\mathrm{t}, J=7.2 \mathrm{~Hz}, 2 \mathrm{H}, \mathrm{CH}_{2}\right), 4.00\left(\mathrm{dd}, J=12.3,2.5 \mathrm{~Hz}, 1 \mathrm{H}, \mathrm{H}-5^{\prime}{ }_{\mathrm{a}}\right), 3.86(\mathrm{dd}, J=12.3$, $\left.3.0 \mathrm{~Hz}, 1 \mathrm{H}, \mathrm{H}-5^{\prime}{ }_{\mathrm{b}}\right), 3.65\left(\mathrm{t}, J=6.4 \mathrm{~Hz}, 2 \mathrm{H}, \mathrm{CH}_{2}\right), 1.90\left(\mathrm{dt}, J=7.5,7.2 \mathrm{~Hz}, 2 \mathrm{H}, \mathrm{CH}_{2}\right)$ and $1.61\left(\mathrm{dt}, J=7.5,6.4 \mathrm{~Hz}, 2 \mathrm{H}, \mathrm{CH}_{2}\right) ;{ }^{13} \mathrm{C}-\mathrm{NMR}\left(125 \mathrm{MHz}, \mathrm{CD}_{3} \mathrm{OD}\right) \delta 156.9,154.1,148.6,143.8$, 121.2, 91.7, 86.2, 76.8, 70.7, 62.4, 61.9, 42.4, 30.4, 26.5; HRMS (ES ${ }^{+}$) calcd for $\mathrm{C}_{14} \mathrm{H}_{22} \mathrm{~N}_{5} \mathrm{O}_{6}$ $356.1565(\mathrm{M}+\mathrm{H})^{+}$found 356.1561 .

\subsection{Total Synthesis of N9-(4-Hydroxybutyl)-N1-IMP Analogues (22-25)}

$\mathrm{N1} 1-\left[2^{\prime}, 3^{\prime}\right.$-O-Isopropylidine-5'-O-(di-tert-butyl)-phosphoryl- $\beta$-D-ribofuranosyl]N9-(4-hydroxybutyl)-8-bromohypoxanthine (44) was prepared in 10 steps from 6chloropurine as described previously [36].

N1-(5'-O-Phosphoryl- $\beta$-D-ribofuranosyl)-N9-(4-hydroxybutyl)-8-bromohypoxan -thine (22)-N1-[2', 3'-O-Isopropylidine- $5^{\prime}$-O-(di-tert-butyl)-phosphoryl- $\beta$-D-ribofuranosyl] -N9-(4-hydroxybutyl)-8-bromohypoxanthine $(44,50 \mathrm{mg}, 77 \mu \mathrm{mol})$ was stirred at $0{ }^{\circ} \mathrm{C}$ in TFA (50\% aq., $2 \mathrm{~mL})$. Solvents were evaporated to dryness and the residue evaporated with $\mathrm{MeOH}(\times 3)$ before purification by semipreparative HPLC $(1.1 \mathrm{~cm} \times 25 \mathrm{~cm}$ C18 column), eluting with acetonitrile/0.1 $\operatorname{M~TEAB~}(1: 19 \rightarrow 13: 7 v / v)$ over $25 \mathrm{~min}$. Fractions were analyzed by analytical HPLC and appropriate fractions collected and evaporated under vacuum to give the title compound $(33 \mathrm{mg}, 87 \%) ; \mathrm{UV}\left(\mathrm{H}_{2} \mathrm{O}, \mathrm{pH} 7\right), \lambda \max =257 \mathrm{~nm}$ $(\varepsilon=14700) ;{ }^{1} \mathrm{H}-\mathrm{NMR}\left(500 \mathrm{MHz}, \mathrm{D}_{2} \mathrm{O}\right) \delta 8.64(\mathrm{~s}, 1 \mathrm{H}, \mathrm{H}-2), 6.10\left(\mathrm{~d}, J=2.4 \mathrm{~Hz}, 1 \mathrm{H}, \mathrm{H}-1^{\prime}\right)$, 4.31-4.27 (m, 2H, H-2' and $\left.\mathrm{H}-3^{\prime}\right), 4.21-4.18\left(\mathrm{~m}, 1 \mathrm{H}, \mathrm{H}-4^{\prime}\right), 4.11-4.06\left(\mathrm{~m}, 3 \mathrm{H}, \mathrm{H}-5^{\prime}{ }_{\mathrm{a}}\right.$, $\left.\mathrm{CH}_{2}\right), 3.95-3.92\left(\mathrm{~m}, 1 \mathrm{H}, \mathrm{H}-5^{\prime}{ }_{\mathrm{b}}\right), 3.45\left(\mathrm{t}, J=6.5 \mathrm{~Hz}, 2 \mathrm{H}, \mathrm{CH}_{2}\right), 1.72(\mathrm{dt}, J=7.6,7.3 \mathrm{~Hz}$, $\left.2 \mathrm{H}, \mathrm{CH}_{2}\right)$ and $1.41\left(\mathrm{dt}, J=8.3,6.5 \mathrm{~Hz}, 2 \mathrm{H}, \mathrm{CH}_{2}\right) ;{ }^{13} \mathrm{C}-\mathrm{NMR}\left(125 \mathrm{MHz}, \mathrm{D}_{2} \mathrm{O}\right) \delta 156.1,148.7$, 145.3, 128.2, 122.8, 89.1 (C-1'), $83.4\left(\mathrm{~d}, \mathrm{~J}=8.9 \mathrm{~Hz}, \mathrm{C}-4^{\prime}\right), 75.2\left(\mathrm{C}-2^{\prime}\right), 68.8\left(\mathrm{C}-3^{\prime}\right), 62.7$ $\left(\mathrm{d}, J=3.8 \mathrm{~Hz}, \mathrm{C}-5^{\prime}\right), 60.9,44.8,28.3,25.3\left(4 \times \mathrm{CH}_{2}\right) ;{ }^{31} \mathrm{P}-\mathrm{NMR}\left(202 \mathrm{MHz}, \mathrm{D}_{2} \mathrm{O}\right) \delta 2.49$. HRMS (ES ${ }^{-}$) calcd for $\mathrm{C}_{14} \mathrm{H}_{19} \mathrm{~N}_{4} \mathrm{O}_{9} \mathrm{P}^{79} \mathrm{Br} 497.0079(\mathrm{M}-\mathrm{H})^{-}$found 497.0073, calcd for $\mathrm{C}_{14} \mathrm{H}_{19} \mathrm{~N}_{4} \mathrm{O}_{9} \mathrm{P}^{81} \mathrm{Br} 499.0058(\mathrm{M}-\mathrm{H})^{-}$found 499.0072.

N1-(5'-O-Phosphoryl- $\beta$-D-ribofuranosyl)-N9-(4-hydroxybutyl)hypoxanthine (23)N1-(5'-O-Phosphoryl- $\beta$-D-ribofuranosyl)-N9-(4-hydroxybutyl)-8-bromohypoxanthine (22, $38 \mathrm{mg}, 77 \mu \mathrm{mol}), \mathrm{NaHCO}_{3}(20 \mathrm{mg}, 0.23 \mathrm{mmol})$ and $\mathrm{Pd} / \mathrm{C}(5 \mathrm{mg})$ were taken up in MilliQ$\mathrm{EtOH}(2: 1 v / v, 3 \mathrm{~mL})$ and the solution degassed with argon before being placed under an atmosphere of $\mathrm{H}_{2}$ for $12 \mathrm{~h}$. The catalyst was removed by filtration and the resulting solution purified by semipreparative HPLC $(1.1 \mathrm{~cm} \times 25 \mathrm{~cm}$ C18 column), eluting with acetonitrile/0.1 M TEAB $(1: 19 \rightarrow 13: 7 v / v)$ over $25 \mathrm{~min}$. Fractions were analyzed by analytical HPLC and appropriate fractions collected and evaporated under vacuum to give the title compound (25 mg, 78\%); UV ( $\left.\mathrm{H}_{2} \mathrm{O}, \mathrm{pH} 7\right), \lambda \max =252 \mathrm{~nm}(\varepsilon=10300) ;{ }^{1} \mathrm{H}-\mathrm{NMR}$ $\left(500 \mathrm{MHz}, \mathrm{D}_{2} \mathrm{O}\right) \delta 8.52(\mathrm{~s}, 1 \mathrm{H}, \mathrm{H}-2), 7.96(\mathrm{~s}, 1 \mathrm{H}, \mathrm{H}-8), 6.11\left(\mathrm{~d}, J=2.3 \mathrm{~Hz}, 1 \mathrm{H}, \mathrm{H}-1^{\prime}\right)$, 
4.30-4.27 (m, 2H, H-2' and $\left.\mathrm{H}-3^{\prime}\right), 4.22-4.19\left(\mathrm{~m}, 1 \mathrm{H}, \mathrm{H}-4^{\prime}\right), 4.13-4.16\left(\mathrm{~m}, 1 \mathrm{H}, \mathrm{H}-5^{\prime}{ }_{\mathrm{a}}\right)$, $4.10\left(\mathrm{t}, J=7.1 \mathrm{~Hz}, 2 \mathrm{H}, \mathrm{CH}_{2}\right), 4.02-3.98\left(\mathrm{~m}, 1 \mathrm{H}, \mathrm{H}-5^{\prime}{ }_{\mathrm{b}}\right), 3.44\left(\mathrm{t}, J=6.5 \mathrm{~Hz}, 2 \mathrm{H}, \mathrm{CH}_{2}\right), 1.76$ $\left(\mathrm{dt}, J=7.6,7.1 \mathrm{~Hz}, 2 \mathrm{H}, \mathrm{CH}_{2}\right)$ and $1.38\left(\mathrm{dt}, J=8.1,6.5 \mathrm{~Hz}, 2 \mathrm{H}, \mathrm{CH}_{2}\right) ;{ }^{13} \mathrm{C}-\mathrm{NMR}(125 \mathrm{MHz}$, $\left.\mathrm{D}_{2} \mathrm{O}\right) \delta 157.4,147.5,144.7,142.4,122.3,89.1\left(\mathrm{C}-1^{\prime}\right), 82.9\left(\mathrm{~d}, J=8.8 \mathrm{~Hz}, \mathrm{C}-4^{\prime}\right), 75.1\left(\mathrm{C}-2^{\prime}\right)$, $68.8\left(\mathrm{C}-3^{\prime}\right), 63.4\left(\mathrm{~d}, \mathrm{~J}=4.1 \mathrm{~Hz}, \mathrm{C}-5^{\prime}\right), 60.9,44.0,28.3,25.9\left(4 \times \mathrm{CH}_{2}\right){ }^{31} \mathrm{P}-\mathrm{NMR}(202 \mathrm{MHz}$, $\left.\mathrm{D}_{2} \mathrm{O}\right) \delta$ 0.49. HRMS (ES ${ }^{-}$) calcd for $\mathrm{C}_{14} \mathrm{H}_{20} \mathrm{~N}_{4} \mathrm{O}_{9} \mathrm{P} 419.0973(\mathrm{M}-\mathrm{H})^{-}$found 419.0958 .

N1-(5'-O-Phosphoryl- $\beta$-D-ribofuranosyl)-N9-(4-hydroxybutyl)-8-azidohypoxanthine (24)-N1-(5'-O-phosphoryl- $\beta$-D-ribofuranosyl)-N9-(4-hydroxybutyl)-8-bromohypoxanthine (22, $20 \mathrm{mg}, 40 \mu \mathrm{mol})$ was evaporated from DMF $(2 \times 2 \mathrm{~mL})$, taken up in DMF $(1 \mathrm{~mL})$ and $\mathrm{TMSN}_{3}(53 \mu \mathrm{L}, 401 \mu \mathrm{L})$ added. After $16 \mathrm{~h}$ at $70{ }^{\circ} \mathrm{C}$ in the dark, all solvents were evaporated and the residue purified by semi preparative $\mathrm{HPLC}(1.1 \mathrm{~cm} \times 25 \mathrm{~cm}$ C18 column), eluting with acetonitrile/0.1 M TEAB $(1: 19 \rightarrow 13: 7 v / v)$ over $25 \mathrm{~min}$. Fractions were analyzed by analytical HPLC and appropriate fractions collected and evaporated under vacuum to give the title compound (5.2 mg, 28\%); UV $\left(\mathrm{H}_{2} \mathrm{O}, \mathrm{pH} 7\right), \lambda \max =277 \mathrm{~nm}(\varepsilon=15,600) ;{ }^{1} \mathrm{H}-\mathrm{NMR}$ $\left(500 \mathrm{MHz}, \mathrm{D}_{2} \mathrm{O}\right) \delta 8.59$ (s, 1H, H-2), $6.18\left(\mathrm{~d}, J=2.2 \mathrm{~Hz}, 1 \mathrm{H}, \mathrm{H}-1^{\prime}\right), 4.35-4.31$ (m, 2H, H-2' and $\left.\mathrm{H}-3^{\prime}\right), 4.27-4.24\left(\mathrm{~m}, 1 \mathrm{H}, \mathrm{H}-4^{\prime}\right), 4.19-4.15\left(\mathrm{~m}, 1 \mathrm{H}, \mathrm{H}-5^{\prime}{ }_{\mathrm{a}}\right), 4.06-4.03\left(\mathrm{~m}, 1 \mathrm{H}, \mathrm{H}-5^{\prime}{ }_{\mathrm{b}}\right)$, $3.96\left(\mathrm{t}, J=7.0 \mathrm{~Hz}, 2 \mathrm{H}, \mathrm{CH}_{2}\right), 3.50\left(\mathrm{t}, J=6.6 \mathrm{~Hz}, 2 \mathrm{H}, \mathrm{CH}_{2}\right), 1.74\left(\mathrm{dt}, J=7.5,7.0 \mathrm{~Hz}, 2 \mathrm{H}, \mathrm{CH}_{2}\right)$ and $1.43\left(\mathrm{dt}, J=8.1,6.6 \mathrm{~Hz}, 2 \mathrm{H}, \mathrm{CH}_{2}\right) ;{ }^{13} \mathrm{C}-\mathrm{NMR}\left(125 \mathrm{MHz}, \mathrm{D}_{2} \mathrm{O}\right) \delta 156.2,147.7,146.6,144.2$, 120.5, $89.2\left(\mathrm{C}-1^{\prime}\right), 83.0\left(\mathrm{~d}, J=8.9 \mathrm{~Hz}, \mathrm{C}-4^{\prime}\right), 75.2\left(\mathrm{C}-2^{\prime}\right), 68.7\left(\mathrm{C}-3^{\prime}\right), 63.2(\mathrm{~d}, J=4.6 \mathrm{~Hz}$, $\left.\mathrm{C}^{-} 5^{\prime}\right), 60.9,42.4,28.3,25.0\left(4 \times \mathrm{CH}_{2}\right){ }^{31} \mathrm{P}-\mathrm{NMR}\left(202 \mathrm{MHz}, \mathrm{D}_{2} \mathrm{O}\right) \delta 0.97$. HRMS $\left(\mathrm{ES}^{-}\right)$calcd for $\mathrm{C}_{14} \mathrm{H}_{19} \mathrm{~N}_{7} \mathrm{O}_{9} \mathrm{P} 460.0987(\mathrm{M}-\mathrm{H})^{-}$found 460.0969 .

N1-(5'-O-Phosphoryl- $\beta$-D-ribofuranosyl)-N9-(4-hydroxybutyl)-8-aminohypoxanthine (25)-To N1-(5'-O-phosphoryl- $\beta$-D-ribofuranosyl)-N9-(4-hydroxybutyl)-8-azidohypoxanthine $(24,18 \mathrm{mg}, 39 \mu \mathrm{mol})$ in TEAB $(0.05 \mathrm{M}, 5 \mathrm{~mL})$ was added dithiothreitol $(5 \mathrm{mg}, 32 \mu \mathrm{mol})$. After $16 \mathrm{~h}$, the reaction was complete by HPLC $\left(\lambda_{\max } 277 \rightarrow 262\right)$ and was purified by semipreparative HPLC $(1.1 \mathrm{~cm} \times 25 \mathrm{~cm}$ C18 column), eluting with acetonitrile/0.1 M TEAB $(1: 19 \rightarrow 13: 7 v / v)$ over $25 \mathrm{~min}$. Fractions were analyzed by analytical HPLC and appropriate fractions collected and evaporated under vacuum to give the title compound (9.6 mg, 57\%); UV ( $\left.\mathrm{H}_{2} \mathrm{O}, \mathrm{pH} 7\right), \lambda \max =265 \mathrm{~nm}(\varepsilon=25,400) ; \mathrm{H}-\mathrm{NMR}\left(500 \mathrm{MHz}, \mathrm{D}_{2} \mathrm{O}\right) \delta 8.46$ $(\mathrm{s}, 1 \mathrm{H}, \mathrm{H}-2), 6.12\left(\mathrm{~d}, J=2.4 \mathrm{~Hz}, 1 \mathrm{H}, \mathrm{H}-1^{\prime}\right), 4.29-4.26\left(\mathrm{~m}, 2 \mathrm{H}, \mathrm{H}-2^{\prime}\right.$ and $\left.\mathrm{H}-3^{\prime}\right), 4.18-4.16$ $\left(\mathrm{m}, 1 \mathrm{H}, \mathrm{H}-4^{\prime}\right), 4.09-4.06\left(\mathrm{~m}, 1 \mathrm{H}, \mathrm{H}-5^{\prime}{ }_{\mathrm{a}}\right), 3.96-3.93\left(\mathrm{~m}, 1 \mathrm{H}, \mathrm{H}-5^{\prime}{ }_{\mathrm{b}}\right), 3.87(\mathrm{t}, J=7.0 \mathrm{~Hz}, 2 \mathrm{H}$, $\left.\mathrm{CH}_{2}\right), 3.42\left(\mathrm{t}, J=6.4 \mathrm{~Hz}, 2 \mathrm{H}, \mathrm{CH}_{2}\right), 1.65\left(\mathrm{dt}, J=7.5,7.0 \mathrm{~Hz}, 2 \mathrm{H}, \mathrm{CH}_{2}\right)$ and $1.38(\mathrm{dt}, J=8.1$, $\left.6.4 \mathrm{~Hz}, 2 \mathrm{H}, \mathrm{CH}_{2}\right) ;{ }^{13} \mathrm{C}-\mathrm{NMR}\left(125 \mathrm{MHz}, \mathrm{D}_{2} \mathrm{O}\right) \delta 155.8,152.9,147.3,142.3,119.3,89.1\left(\mathrm{C}-1^{\prime}\right)$, $83.1\left(\mathrm{~d}, J=8.8 \mathrm{~Hz}, \mathrm{C}-4^{\prime}\right), 75.2\left(\mathrm{C}-2^{\prime}\right), 68.8\left(\mathrm{C}-3^{\prime}\right), 62.8\left(\mathrm{~d}, J=4.3 \mathrm{~Hz}, \mathrm{C}-5^{\prime}\right), 61.1,41.5,28.4$, $24.5\left(4 \times \mathrm{CH}_{2}\right) ;{ }^{31} \mathrm{P}-\mathrm{NMR}\left(202 \mathrm{MHz}, \mathrm{D}_{2} \mathrm{O}\right) \delta 2.03$; HRMS $\left(\mathrm{ES}^{-}\right)$calcd for $\mathrm{C}_{14} \mathrm{H}_{21} \mathrm{~N}_{5} \mathrm{O}_{9} \mathrm{P}$ $434.1082(\mathrm{M}-\mathrm{H})^{-}$found 434.1063.

\subsection{Total Synthesis of L-N1-IMP Analogues (26-27)}

$N 1-\left(2^{\prime}, 3^{\prime}, 5^{\prime}\right.$-Tri-O-acetyl- $\beta$-L-ribofuranosyl)-N9-tert-butyldimethylsilyloxymethyl -8-bromohypoxanthine (52)-To N9-tert-butyldimethylsilyloxymethyl-8-bromohypoxan thine $(48,430 \mathrm{mg}, 1.197 \mathrm{mmol})$ in DCM $(4.5 \mathrm{~mL})$ was added DBU $(537 \mu \mathrm{L}, 3.590 \mathrm{mmol})$. After $30 \mathrm{~min}, 1,2,3,5$-tetra- $O$-acetyl- $\beta$-L-ribofuranose $(419 \mathrm{mg}, 1.317 \mathrm{mmol}$ ) was added and the solution cooled to $-78{ }^{\circ} \mathrm{C}$. Trimethylsilyl trifluoromethanesulfonate $(867 \mu \mathrm{L}, 4.788 \mathrm{mmol})$ was added dropwise and the solution stirred for a further $45 \mathrm{~min}$ before warming to rt. After $2 \mathrm{~h}, \mathrm{NaHCO}_{3}$ (satd aq) was added and the crude material extracted into DCM $(\times 3)$. The combined organic fractions were dried $\left(\mathrm{Na}_{2} \mathrm{SO}_{4}\right)$, and solvent was evaporated under reduced pressure. The residue was purified by column chromatography on silica gel eluting with PE/EtOAc $(1: 0 \rightarrow 0: 1 \mathrm{v} / v)$ to afford the title compound $(481 \mathrm{mg}, 65 \%)$ as acolourless glass; $R_{f}=0.48$ (PE:EtOAc 1:3 v/v); ${ }^{1} \mathrm{H}-\mathrm{NMR}\left(400 \mathrm{MHz}, \mathrm{CDCl}_{3}\right) \delta 8.20(\mathrm{~s}$, $1 \mathrm{H}, \mathrm{H}-2), 6.35\left(\mathrm{~d}, J=4.6 \mathrm{~Hz}, 1 \mathrm{H}, \mathrm{H}-1^{\prime}\right), 5.64(\mathrm{~d}, J=9.8 \mathrm{~Hz}, 1 \mathrm{H}), 5.61(\mathrm{~d}, J=9.8 \mathrm{~Hz}, 1 \mathrm{H})$ (2H, $\left.\mathrm{CH}_{2} \mathrm{OTBDMS}\right), 5.46-5.40\left(\mathrm{~m}, 2 \mathrm{H}, \mathrm{H}-2^{\prime}, \mathrm{H}-3^{\prime}\right), 4.43-4.32\left(\mathrm{~m}, 3 \mathrm{H}, \mathrm{H}-4^{\prime}, 2 \times \mathrm{H}-5^{\prime}\right)$, $2.13\left(\mathrm{~s}, 3 \mathrm{H}, \operatorname{AcetylC\mathrm {H}_{3}}\right), 2.09$ (s, 3H, Acetyl $\left.\mathrm{CH}_{3}\right), 2.05\left(\mathrm{~s}, 3 \mathrm{H}, \operatorname{AcetylCH}_{3}\right), 0.85(\mathrm{~s}, 9 \mathrm{H}) 0.11$ $(\mathrm{s}, 3 \mathrm{H})$ and $0.10(\mathrm{~s}, \overline{3 \mathrm{H}})(15 \mathrm{H}, \mathrm{TBDMS}) ;{ }^{13} \mathrm{C}-\overline{\mathrm{NMR}}\left(100 \mathrm{MHz}, \mathrm{CDCl}_{3} \overline{) \delta} 170.2,169.5(2 \mathrm{C})\right.$, $154.7,148.4,144.5,126.1,123.9,87.4,80.1,74.2,70.1,67.3,62.9,25.5$ (3C), 20.7, 20.43, 20.37, 
18.0, -5.26 and -5.27; HRMS (ES ${ }^{+}$) calcd for $\mathrm{C}_{23} \mathrm{H}_{34} \mathrm{~N}_{4} \mathrm{O}_{9} \mathrm{Si}^{79} \mathrm{Br} 617.1273(\mathrm{M}+\mathrm{H})^{+}$found 617.1298, calcd for $\mathrm{C}_{23} \mathrm{H}_{34} \mathrm{~N}_{4} \mathrm{O}_{9} \mathrm{Si}^{81} \mathrm{Br} 619.1252(\mathrm{M}+\mathrm{H})^{+}$found 619.1298 .

$N 1-\left(2^{\prime}, 3^{\prime}\right.$-O-Isopropylidene- $\beta$-L-ribofuranosyl)-N9-tert-butyldimethylsilyloxymet

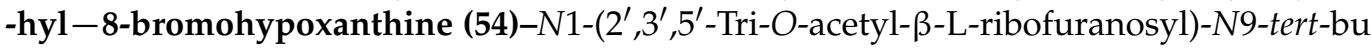
-tyldimethylsilyloxy-methyl-8-bromohypoxanthine $(\mathbf{5 2}, 470 \mathrm{mg}, 0.761 \mathrm{mmol})$ was taken up in $\mathrm{MeOH}(5.0 \mathrm{~mL})$ in a pressure tube. The solution was cooled to $0{ }^{\circ} \mathrm{C}$ in an ice-water bath and $\mathrm{NH}_{3}(\mathrm{~g})$ bubbled through the solution to saturation. The tube was sealed and the resulting solution stirred at rt. When complete by TLC, the solvents were removed by evaporation under reduced pressure and the residue was purified by column chromatography on silica gel eluting with DCM/Acetone $(1: 0 \rightarrow 0: 1 v / v)$ to afford the deacetylated intermediate 53 (205 mg, 55\%) as an amorphous white solid, $R_{f}=0.34$ (EtOAc), which was used directly in the next step.

To N1-( $\beta$-L-ribofuranosyl)-N9-tert-butyldimethylsilyloxymethyl-8-bromohypoxanthine $(53,170 \mathrm{mg}, 0.346 \mathrm{mmol})$ in 2,2-dimethoxypropane-acetone $(1: 4 v / v, 10 \mathrm{~mL})$ was added paratoluenesulfonic acid $(66 \mathrm{mg}, 0.346 \mathrm{mmol})$. After $1 \mathrm{~h}, \mathrm{DCM}$ and $\mathrm{NaHCO}_{3}$ (satd. aq.) were added and the aqueous phase extracted with $\mathrm{DCM}(\times 3)$. The combined organic extracts were evaporated to dryness, taken up in $\mathrm{MeOH}(5 \mathrm{~mL})$ and treated with pre-washed DOWEX ${ }^{\circledR} \mathrm{H}^{+}$resin (50WX8, 100-200 mesh, ion-exchange resin) for $30 \mathrm{~min}$. Note - the Dowex ${ }^{\circledR} \mathrm{H}^{+}$resin was used as a source of cations to remove the unwanted partial 5'-O-[2methoxypropyl] protecting group, while leaving the desired $2^{\prime}, 3^{\prime}$-O-isopropylidene in tact. The resin was removed by filtration and the filtrate purified by column chromatography on silica gel eluting with PE/EtOAc $(1: 0 \rightarrow 0: 1 v / v)$ to afford the title compound (103 mg, 56\%) as acolourless glass; $R_{f}=0.71(\mathrm{EtOAc}) ;{ }^{1} \mathrm{H}-\mathrm{NMR}\left(500 \mathrm{MHz}, \mathrm{CDCl}_{3}\right) \delta 8.03(\mathrm{~s}, 1 \mathrm{H}, 2-\mathrm{H}), 5.71$ $\left(\mathrm{d}, J=2.9 \mathrm{~Hz}, 1 \mathrm{H}, \mathrm{H}-1^{\prime}\right), 5.66(\mathrm{~d}, J=9.9 \mathrm{~Hz}, 1 \mathrm{H}), 5.63(\mathrm{~d}, J=9.9 \mathrm{~Hz}, 1 \mathrm{H})\left(2 \mathrm{H}, \mathrm{CH}_{2} \mathrm{OTBDMS}\right)$, $5.31\left(\mathrm{dd}, J=6.5,2.9 \mathrm{~Hz}, 1 \mathrm{H}, \mathrm{H}-2^{\prime}\right), 5.15\left(\mathrm{dd}, J=6.5,3.6 \mathrm{~Hz}, 1 \mathrm{H}, \mathrm{H}-3^{\prime}\right), 4.36 \overline{(\mathrm{d} d \mathrm{~d},} J=6.0$, 3.7, $\left.3.6 \mathrm{~Hz}, 1 \mathrm{H}, \mathrm{H}-4^{\prime}\right), 3.93\left(\mathrm{ddd}, J=12.0,6.0,3.1 \mathrm{~Hz}, 1 \mathrm{H}, \mathrm{H}-5^{\prime}{ }_{\mathrm{a}}\right.$ ), 3.84 (ddd, $J=12.0$, 8.2, $\left.3.7 \mathrm{~Hz}, 1 \mathrm{H}, \mathrm{H}-5^{\prime}{ }_{\mathrm{b}}\right), 3.31\left(\mathrm{dd}, \mathrm{J}=8.2,3.1,5^{\prime}-\mathrm{OH}\right), 1.59\left(\mathrm{~s}, 3 \mathrm{H}, \mathrm{CCH}_{3}\right), 1.36\left(\mathrm{~s}, 3 \mathrm{H}, \mathrm{CCH}_{3}\right)$, $0.87(\mathrm{~s}, 9 \mathrm{H}), 0.12(\mathrm{~s}, 3 \mathrm{H}), 0.11(\mathrm{~s}, 3 \mathrm{H})(15 \mathrm{H}, \mathrm{TBDMS}) ;{ }^{13} \mathrm{C}-\mathrm{NMR}\left(125 \mathrm{MHz}, \mathrm{CDCl}_{3}\right) \delta 1 \overline{55.3}$

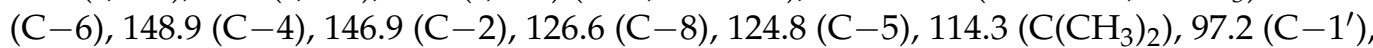
$88.1\left(\mathrm{C}-4^{\prime}\right), 83.5\left(\mathrm{C}-2^{\prime}\right), 80.7\left(\mathrm{C}-3^{\prime}\right), 67.5\left(\mathrm{CH}_{2} \mathrm{OTBDMS}\right), 62.9\left(\mathrm{C}-5^{\prime}\right), 27.3\left(\mathrm{CCH}_{3}\right), 25.5$ (3C, $\left.\mathrm{SiC}\left(\mathrm{CH}_{3}\right)_{3}\right), 25.2\left(\mathrm{CCH}_{3}\right), 18.1\left(\mathrm{SiC}\left(\mathrm{CH}_{3}\right)_{3}\right),-5.2\left(2 \mathrm{C}, \mathrm{Si}\left(\mathrm{CH}_{3}\right)_{2}\right) ; \mathrm{HRMS}\left(\mathrm{ES}^{+}\right)$calcd for $\mathrm{C}_{20} \mathrm{H}_{32} \mathrm{~N}_{4} \mathrm{O}_{6}{ }^{79} \mathrm{BrSi} 531.1275(\mathrm{M}+\mathrm{H})^{+}$found 531.1288, calcd for $\mathrm{C}_{20} \mathrm{H}_{32} \mathrm{~N}_{4} \mathrm{O}_{6}{ }^{79} \mathrm{BrSi} 533.1254$ $(\mathrm{M}+\mathrm{H})^{+}$found 533.1249 .

$N 1$-[2', $3^{\prime}$-O-Isopropylidene- $5^{\prime}$-O-(di-tert-butyl)-phosphoryl- $\beta$-L-ribofuranosyl]N9-tert-butyldimethyl-silyloxymethyl-8-bromohypoxanthine (55)-To N1-(2', $3^{\prime}$-O-isop -ropylidene- $\beta$-L-ribofuranosyl)- $N 9$-tert-butyldimethylsilyloxymethyl-8-bromohypoxanthine $(54,100 \mathrm{mg}, 0.188 \mathrm{mmol})$ in DCM $(1.0 \mathrm{~mL})$ was added 5-phenyl-1H-tetrazole $(55 \mathrm{mg}$, $0.376 \mathrm{mmol}$ ) and the solution cooled to $0{ }^{\circ} \mathrm{C}$. Di-tert-butyl $\mathrm{N}, \mathrm{N}$-diisopropylphosphoramidite $(89 \mu \mathrm{L}, 0.282 \mathrm{mmol})$ was added dropwise and the solution stirred at rt until phosphitylation was complete by TLC. After cooling to $0{ }^{\circ} \mathrm{C}$, triethylamine $(157 \mu \mathrm{L}, 1.128 \mathrm{mmol})$ and $\mathrm{H}_{2} \mathrm{O}_{2}$ ( $30 \%$ in $\mathrm{H}_{2} \mathrm{O}, 48 \mu \mathrm{L}, 0.470 \mathrm{mmol}$ ) were added and the solution stirred at $\mathrm{rt}$ until oxidation was complete. The reaction was diluted with DCM and washed with $\mathrm{NaHCO}_{3}$ (satd. aq.), dried over $\mathrm{Na}_{2} \mathrm{SO}_{4}$ and purified by column chromatography on silica gel eluting with $\mathrm{PE} /$ EtOAc $(1: 0 \rightarrow 0: 1 v / v+0.5 \%$ pyridine in each solvent) to afford the title compound $(82 \mathrm{mg}, 60 \%)$ as a colourless glass; $R_{f}=0.37$ (PE:EtOAc 1:3 v/v); ${ }^{1} \mathrm{H}-\mathrm{NMR}(500 \mathrm{MHz}$, $\left.\mathrm{CDCl}_{3}\right) \delta 8.10(\mathrm{~s}, 1 \mathrm{H}, 2-\mathrm{H}), 6.01\left(\mathrm{~d}, J=2.0 \mathrm{~Hz}, 1 \mathrm{H}, \mathrm{H}-1^{\prime}\right), 5.65(\mathrm{~d}, J=9.9 \mathrm{~Hz}, 1 \mathrm{H}), 5.63$ $(\mathrm{d}, J=9.9 \mathrm{~Hz}, 1 \mathrm{H})\left(2 \mathrm{H}, \mathrm{CH}_{2} \mathrm{OTBDMS}\right), 5.07\left(\mathrm{dd}, J=6.4,2.0 \mathrm{~Hz}, 1 \mathrm{H}, \mathrm{H}-2^{\prime}\right), 4.99(\mathrm{dd}$, $\left.J=6.4,4.0 \mathrm{~Hz}, 1 \mathrm{H}, \mathrm{H}-3^{\prime}\right), 4.42\left(\mathrm{ddd}, J=5.8,4.1,4.0 \mathrm{~Hz}, 1 \mathrm{H}, \mathrm{H}-4^{\prime}\right), 4.25(\mathrm{ddd}, J=12.9$, 6.5, $\left.4.1 \mathrm{~Hz}, 1 \mathrm{H}, \mathrm{H}-5^{\prime}{ }_{\mathrm{a}}\right), 4.18\left(\mathrm{ddd}, J=12.9,7.2,5.8 \mathrm{~Hz}, 1 \mathrm{H}, \mathrm{H}-5^{\prime}{ }_{\mathrm{b}}\right), 1.58\left(\mathrm{~s}, 3 \mathrm{H}, \mathrm{CCH}_{3}\right)$, $1.47\left(\mathrm{~s}, 9 \mathrm{H}, \mathrm{O}^{t} \mathrm{Bu}\right), 1.46\left(\mathrm{~s}, 9 \mathrm{H}, \mathrm{O}^{t} \mathrm{Bu}\right), 1.34\left(\mathrm{~s}, 3 \mathrm{H}, \mathrm{CCH}_{3}\right), 0.87(\mathrm{~s}, 9 \mathrm{H}), 0.12(\mathrm{~s}, 3 \mathrm{H}), 0.1 \overline{1}(\mathrm{~s}$,

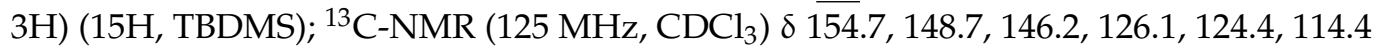

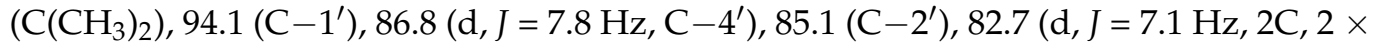
POC $\left.\left(\mathrm{CH}_{3}\right)_{3}\right), 81.3\left(\mathrm{C}-3^{\prime}\right), 67.3\left(\mathrm{CH}_{2} \mathrm{OTBDMS}\right), 66.4\left(\mathrm{~d}, J=6.3 \mathrm{~Hz}, \mathrm{C}-5^{\prime}\right), 29.81(\mathrm{~d}, J=4.3 \mathrm{~Hz}$, $\left.3 \mathrm{C}, \mathrm{POC}\left(\mathrm{CH}_{3}\right)_{3}\right), 29.78\left(\mathrm{~d}, \mathrm{~J}=4.2 \mathrm{~Hz}, 3 \mathrm{C}, \mathrm{POC}\left(\mathrm{CH}_{3}\right)_{3}\right), 27.1\left(\mathrm{CCH}_{3}\right), 25.5\left(3 \mathrm{C}, \mathrm{SiC}\left(\mathrm{CH}_{3}\right)_{3}\right)$, 
$25.3\left(\mathrm{CCH}_{3}\right), 18.0\left(\mathrm{SiC}\left(\mathrm{CH}_{3}\right)_{3}\right),-5.2\left(2 \mathrm{C}, \mathrm{Si}\left(\mathrm{CH}_{3}\right)_{2}\right) ;{ }^{31} \mathrm{P}-\mathrm{NMR}\left(202 \mathrm{MHz}, \mathrm{CDCl}_{3}\right) \delta-10.10$; HRMS $\left(\mathrm{ES}^{+}\right.$) calcd for $\mathrm{C}_{28} \mathrm{H}_{48} \mathrm{~N}_{4} \mathrm{O}_{9} \mathrm{P}^{79} \mathrm{BrSiNa} 745.2010(\mathrm{M}+\mathrm{Na})^{+}$found 745.2040 , calcd for $\mathrm{C}_{28} \mathrm{H}_{48} \mathrm{~N}_{4} \mathrm{O}_{9} \mathrm{P}^{81} \mathrm{BrSiNa}$ 747.1989 $(\mathrm{M}+\mathrm{Na})^{+}$found 747.2045.

N1-(5'-O-Phosphoryl- $\beta$-L-ribofuranosyl) - 8-bromohypoxanthine (8-Br-L-N1-IMP, 26)-N1-[2', 3'-O-Isopropylidene- $5^{\prime}$-O-(di-tert-butyl)-phosphoryl- $\beta$-L-ribofuranosyl]-N9-tertbutyldimethylsilyloxymethyl-8-bromohypoxanthine $(55,55 \mathrm{mg}, 76 \mu \mathrm{mol})$ was treated with TFA ( $50 \%$ aq., $4 \mathrm{~mL}$ ) for $16 \mathrm{~h}$. All solvents were evaporated and the residue evaporated from $\mathrm{MeOH} \times 3$ before purification by semipreparative HPLC $(1.1 \mathrm{~cm} \times 25 \mathrm{~cm}$ C18 column), eluting with acetonitrile/0.1 M TEAB $(1: 19 \rightarrow 13: 7 v / v)$ over 25 min. Fractions were analyzed by analytical HPLC and appropriate fractions collected and evaporated under vacuum to give the title compound (14.4 mg, 45\%); $\mathrm{UV}\left(\mathrm{H}_{2} \mathrm{O}, \mathrm{pH} 7\right), \lambda \max =261 \mathrm{~nm}$ $(\varepsilon=15,900) ;{ }^{1} \mathrm{H}-\mathrm{NMR}\left(500 \mathrm{MHz}, \mathrm{D}_{2} \mathrm{O}\right) \delta 8.49(\mathrm{~s}, 1 \mathrm{H}, 2-\mathrm{H}), 6.22\left(\mathrm{~d}, J=4.2 \mathrm{~Hz}, 1 \mathrm{H}, \mathrm{H}-1^{\prime}\right)$, $4.39\left(\mathrm{dd}, J=5.3,4.4 \mathrm{~Hz}, 1 \mathrm{H}, \mathrm{H}-2^{\prime}\right), 4.35\left(\mathrm{dd}, J=5.3,5,2 \mathrm{~Hz}, 1 \mathrm{H}, \mathrm{H}-3^{\prime}\right), 4.27-4.21(\mathrm{~m}$, $\left.1 \mathrm{H}, \mathrm{H}-4^{\prime}\right), 4.07-4.03\left(\mathrm{~m}, 1 \mathrm{H}, \mathrm{H}-5^{\prime} \mathrm{a}\right)$ and $3.99-3.94\left(\mathrm{~m}, 1 \mathrm{H}, \mathrm{H}-5^{\prime}{ }_{\mathrm{b}}\right) ;{ }^{13} \mathrm{C}-\mathrm{NMR}(125 \mathrm{MHz}$, $\left.\mathrm{D}_{2} \mathrm{O}\right) \delta 157.3,156.4,142.5,136.3,123.8,88.4\left(\mathrm{C}-1^{\prime}\right), 83.5\left(\mathrm{~d}, J=8.5 \mathrm{~Hz}, \mathrm{C}-4^{\prime}\right), 75.0\left(\mathrm{C}-2^{\prime}\right)$, $69.4\left(\mathrm{C}-3^{\prime}\right)$ and $63.1\left(\mathrm{~d}, J=4.4 \mathrm{~Hz}, \mathrm{C}-5^{\prime}\right) ;{ }^{31} \mathrm{P}-\mathrm{NMR}\left(202 \mathrm{MHz}, \mathrm{D}_{2} \mathrm{O}\right) \delta 2.82 ; \mathrm{HRMS}\left(\mathrm{ES}^{-}\right)$ calcd for $\mathrm{C}_{10} \mathrm{H}_{11} \mathrm{~N}_{4} \mathrm{O}_{8} \mathrm{P}^{79} \mathrm{Br} 424.9503(\mathrm{M}-\mathrm{H})^{-}$found 424.9524, calcd for $\mathrm{C}_{10} \mathrm{H}_{11} \mathrm{~N}_{4} \mathrm{O}_{8} \mathrm{P}^{81} \mathrm{Br}$ $426.9478(\mathrm{M}-\mathrm{H})^{-}$found 426.9503.

N1-(5'-O-Phosphoryl- $\beta$-L-ribofuranosyl)-hypoxanthine (L-N1-IMP, 27)-N1-(5'-OPhosphoryl- $\beta$-L-ribofuranosyl)-8-bromohypoxanthine (26, $5.3 \mathrm{mg}, 14 \mu \mathrm{mol}), \mathrm{NaHCO}_{3}$ $(12 \mathrm{mg}, 0.14 \mathrm{mmol})$ and Pd/C (5 mg) were taken up in MilliQ-EtOH $(2: 1 v / v, 3 \mathrm{~mL})$ and the solution degassed with argon before being placed under an atmosphere of $\mathrm{H}_{2}$ for $16 \mathrm{~h}$. The catalyst was removed by filtration through celite and the resulting solution purified by semipreparative HPLC $(1.1 \mathrm{~cm} \times 25 \mathrm{~cm}$ C18 column), eluting with acetonitrile $/ 0.1 \mathrm{M}$ TEAB $(1: 19 \rightarrow 13: 7 v / v)$ over $25 \mathrm{~min}$. Fractions were analyzed by analytical HPLC and appropriate fractions collected and evaporated under vacuum to give the title compound $(2.1 \mathrm{mg}, 49 \%)$; UV $\left(\mathrm{H}_{2} \mathrm{O}, \mathrm{pH} 7\right), \lambda \max =251 \mathrm{~nm}(\varepsilon=11,500) ;{ }^{1} \mathrm{H}-\mathrm{NMR}\left(500 \mathrm{MHz}, \mathrm{D}_{2} \mathrm{O}\right) \delta$ $8.65(\mathrm{~s}, 1 \mathrm{H}), 8.10(\mathrm{~s}, 1 \mathrm{H}), 6.22\left(\mathrm{~d}, J=3.8 \mathrm{~Hz}, 1 \mathrm{H}, \mathrm{H}-1^{\prime}\right), 4.39\left(\mathrm{dd}, J=5.3,3.8 \mathrm{~Hz}, 1 \mathrm{H}, \mathrm{H}-2^{\prime}\right)$, $4.36\left(\mathrm{dd}, J=5.5,5,3 \mathrm{~Hz}, 1 \mathrm{H}, \mathrm{H}-3^{\prime}\right), 4.27-4.23\left(\mathrm{~m}, 1 \mathrm{H}, \mathrm{H}-4^{\prime}\right), 4.16-4.10\left(\mathrm{~m}, 1 \mathrm{H}, \mathrm{H}-5^{\prime}{ }_{\mathrm{a}}\right)$ and $4.04-4.00\left(\mathrm{~m}, 1 \mathrm{H}, \mathrm{H}-5^{\prime}{ }_{\mathrm{b}}\right) ;{ }^{13} \mathrm{C}-\mathrm{NMR}\left(125 \mathrm{MHz}, \mathrm{D}_{2} \mathrm{O}\right) \delta 156.3,(147), 144.7,141.8,(122)^{*}$, $88.9\left(\mathrm{C}-1^{\prime}\right), 83.2\left(\mathrm{~d}, J=8.4 \mathrm{~Hz}, \mathrm{C}-4^{\prime}\right), 75.0\left(\mathrm{C}-2^{\prime}\right), 68.9\left(\mathrm{C}-3^{\prime}\right)$ and $63.0(\mathrm{~d}, J=3.4 \mathrm{~Hz}$, C- $\left.5^{\prime}\right) ;{ }^{31} \mathrm{P}-\mathrm{NMR}\left(202 \mathrm{MHz}, \mathrm{D}_{2} \mathrm{O}\right) \delta 1.71$. HRMS $\left(\right.$ ES $\left.^{-}\right)$calcd for $\mathrm{C}_{10} \mathrm{H}_{12} \mathrm{~N}_{4} \mathrm{O}_{8} \mathrm{P} 347.0398$ $(\mathrm{M}-\mathrm{H})^{-}$found 347.0409 . ${ }^{*}$ Only three of 5 hypoxanthine $\mathrm{C}$ visible in ${ }^{13} \mathrm{C}$, the values in parenthesis are estimates.

\subsection{Total Synthesis of Pyrophosphate Bioisostere Analogues (28-29)}

$N 1-\left(2^{\prime}, 3^{\prime}\right.$-O-Isopropylidene- $5^{\prime}$-O-sulfonamide- $\beta$-D-ribofuranosyl)- $N 9$-tert-butyl -dimethylsilyloxymethyl-8-chlorohypoxanthine (56)-N1-(2',3'-O-Isopropylidene- $\beta$-Dribofuranosyl)-N9-tert-butyldimethylsilyl-oxymethyl-8-bromohypoxanthine (50,150mg, $0.28 \mathrm{mmol})$ was taken up in DCM $(1.5 \mathrm{~mL})$ and cooled to $0{ }^{\circ} \mathrm{C}$. Triethylamine $(47 \mu \mathrm{L}$, $0.34 \mathrm{mmol}$ ) was added and the solution stirred for $30 \mathrm{~min}$ before dropwise addition of sulfamoyl chloride in toluene $(1.28 \mathrm{~mL}, 0.56 \mathrm{mmol}, 0.44 \mathrm{M}$ solution). After $16 \mathrm{~h}$ at $\mathrm{rt}, \mathrm{MeOH}$ $(1 \mathrm{~mL})$ was added and all solvent evaporated under reduced pressure. The residue was purified by column chromatography on silica gel eluting with PE/EtOAc $(1: 0 \rightarrow 0: 1 v / v)$ to afford the title compound (102 mg, 64\%) as acolourless glass; $R_{f}=0.68$ (PE:EtOAc 1:3 $v / v) ;{ }^{1} \mathrm{H}-\mathrm{NMR}\left(400 \mathrm{MHz}, \mathrm{CDCl}_{3}\right) \delta 8.02(\mathrm{~s}, 1 \mathrm{H}, 2-\mathrm{H}), 5.77\left(\mathrm{~d}, J=1.4 \mathrm{~Hz}, 1 \mathrm{H}, \mathrm{H}-1^{\prime}\right), 5.67(\mathrm{~d}$, $J=9.8 \mathrm{~Hz}, 1 \mathrm{H}), 5.64(\mathrm{~d}, J=9.8 \mathrm{~Hz}, 1 \mathrm{H})\left(2 \mathrm{H}, \mathrm{CH}_{2} \mathrm{OTBDMS}\right), 5.40\left(\mathrm{br} \mathrm{s}, 2 \mathrm{H}, \mathrm{NH}_{2}\right), 5.25(\mathrm{dd}$, $\left.J=6.5,1.4 \mathrm{~Hz}, 1 \mathrm{H}, \mathrm{H}-2^{\prime}\right), 5.08-5.05\left(\mathrm{~m}, 1 \mathrm{H}, \overline{\mathrm{H}}-3^{\prime}\right), 4.51-4.44\left(\mathrm{~m}, 3 \mathrm{H}, \mathrm{H}-4^{\prime}, 2 \times \mathrm{H}-5^{\prime}\right)$, $1.56\left(\mathrm{~s}, 3 \mathrm{H}, \mathrm{CCH}_{3}\right), 1.34\left(\mathrm{~s}, 3 \mathrm{H}, \mathrm{CCH}_{3}\right), 0.88(\mathrm{~s}, 9 \mathrm{H}), 0.14(\mathrm{~s}, 3 \mathrm{H}), 0.12(\mathrm{~s}, 3 \mathrm{H})(15 \mathrm{H}, \mathrm{TBDMS}) ;$ ${ }^{13} \mathrm{C}-\mathrm{NMR}\left(100 \overline{\mathrm{MHz}}, \mathrm{CDCl}_{3}\right) \delta 155 . \overline{2}, 148.4,147.0,138.2,123.0,114.5\left(\mathrm{C}_{\left.\left(\mathrm{CH}_{3}\right)_{2}\right),}, 66.7\left(\mathrm{C}-1^{\prime}\right)\right.$, $86.7\left(\mathrm{C}-4^{\prime}\right), 84.5\left(\mathrm{C}-2^{\prime}\right), 81.8\left(\mathrm{C}-3^{\prime}\right), 69.8\left(\mathrm{C}-5^{\prime}\right), 66.8\left(\mathrm{CH}_{2} \mathrm{OTBDMS}\right), 27.0\left(\mathrm{CCH}_{3}\right), 25.5$ $\left(3 \mathrm{C}, \mathrm{SiC}\left(\mathrm{CH}_{3}\right)_{3}\right), 25.1\left(\mathrm{CCH}_{3}\right), 18.0\left(\mathrm{SiC}\left(\mathrm{CH}_{3}\right)_{3}\right),-5.3\left(2 \mathrm{C}, \mathrm{Si}\left(\mathrm{CH}_{3}\right)_{2}\right)$; HRMS $\left(\mathrm{ES}^{+}\right)$calcd for $\mathrm{C}_{20} \mathrm{H}_{32} \mathrm{~N}_{5} \mathrm{O}_{8} \mathrm{SSi}^{35} \mathrm{ClNa} 588.1322(\mathrm{M}+\mathrm{Na})^{+}$found 588.1317, calcd for $\mathrm{C}_{20} \mathrm{H}_{32} \mathrm{~N}_{5} \mathrm{O}_{8} \mathrm{Ssi}^{37} \mathrm{ClNa}$ $590.1294(\mathrm{M}+\mathrm{Na})^{+}$found 590.1347. 
N1-(5'-O-sulfonamide- $\beta$-D-ribofuranosyl)-8-chlorohypoxanthine (8-Cl-N1-IMS, 28)-N1-(2', $3^{\prime}$-O-Isopropylidene- $5^{\prime}$-O-sulfonamide- $\beta$-D-ribofuranosyl)-N9-tert-butyldime -thylsilyloxymethyl-8-chlorohypo-xanthine $(56,15 \mathrm{mg}, 25 \mu \mathrm{mol})$ was cooled to $0{ }^{\circ} \mathrm{C}$ and $\mathrm{H}_{2} \mathrm{O}(1 \mathrm{~mL})$ then TFA $(1 \mathrm{~mL})$ added. The solution was allowed to warm to $\mathrm{rt}$ and stirred for $3 \mathrm{~h}$. All solvent was evaporated and the residue co-evaporated with $\mathrm{MeOH}(\times 3)$. The residue was purified by column chromatography on silica gel eluting with $\mathrm{DCM} / \mathrm{MeOH}$ $(1: 0 \rightarrow 4: 1 \mathrm{v} / \mathrm{v})$ to afford the title compound $(7 \mathrm{mg}, 69 \%)$ as a colourless glass. The final compound was further purified by semipreparative HPLC ( $1.1 \mathrm{~cm} \times 25 \mathrm{~cm} \mathrm{C18} \mathrm{column),}$ eluting with acetonitrile/0.1 M TEAB $(1: 19 \rightarrow 13: 7 v / v)$ over 25 min. Fractions were analyzed by analytical HPLC and appropriate fractions collected and evaporated under vacuum; $R_{f}=0.59$ (DCM:MeOH 9:1 v/v); ${ }^{1} \mathrm{H}-\mathrm{NMR}\left(500 \mathrm{MHz}, \mathrm{D}_{2} \mathrm{O}\right) \delta 8.13(\mathrm{~s}, 1 \mathrm{H}, \mathrm{H}-2)$, $6.05\left(\mathrm{~d}, J=2.2 \mathrm{~Hz}, 1 \mathrm{H}, \mathrm{H}-1^{\prime}\right), 4.47-4.44\left(\mathrm{~m}, 1 \mathrm{H}, \mathrm{H}-2^{\prime}\right), 4.36-4.33\left(\mathrm{~m}, 2 \mathrm{H}, \mathrm{H}-3^{\prime}, \mathrm{H}-4^{\prime}\right)$ and $4.29-4.26(\mathrm{~m}, 2 \mathrm{H}, 2 \times \mathrm{H}-5) ;{ }^{13} \mathrm{C}-\mathrm{NMR}\left(125 \mathrm{MHz}, \mathrm{D}_{2} \mathrm{O}\right) \delta 156.2,150.1,142.3,142.1$, 123.4, 90.2, 80.9, 74.2, 68.9 and 68.5; HRMS (ES ${ }^{-}$) calcd for $\mathrm{C}_{10} \mathrm{H}_{11}{ }^{35} \mathrm{Cl} \mathrm{N}_{5} \mathrm{O}_{7} \mathrm{~S} 380.0062$ $(\mathrm{M}-\mathrm{H})^{-}$found 380.0099 , calcd for $\mathrm{C}_{10} \mathrm{H}_{11}{ }^{37} \mathrm{Cl} \mathrm{N}_{5} \mathrm{O}_{7} \mathrm{~S} 382.0033(\mathrm{M}-\mathrm{H})^{-}$found 382.0076 .

$N 1-\left(2^{\prime}, 3^{\prime}\right.$-O-Isopropylidene- $5^{\prime}$ - $O$-sulfonamide- $\beta$-D-ribofuranosyl)- $N 9$-tert-butyl -dimethylsilyloxymethyl-hypoxanthine (57)-N1-(2', $3^{\prime}-\mathrm{O}$-Isopropylidene- $5^{\prime}$-O-sulfonamide$\beta$-D-ribofuranosyl)-N9-tert-butyldimethylsilyloxymethyl-8-chlorohypoxanthine (56,15 mg, $25 \mu \mathrm{mol})$ was taken up in $\mathrm{EtOH}(1 \mathrm{~mL}) . \mathrm{Pd} / \mathrm{C}(<1 \mathrm{mg}, 10 \mathrm{~mol} \%)$ and $\mathrm{NaHCO}_{3}(11 \mathrm{mg}$, $0.125 \mathrm{mmol})$ were added and the flask evacuated and purged with Argon $(\times 3)$ before placing under an atmosphere of $\mathrm{H}_{2}$. After stirring for $16 \mathrm{~h}$, the suspension was filtered through cotton wool to remove the catalyst and all solvent evaporated under reduced pressure. The residue was purified by column chromatography on silica gel eluting with $\mathrm{DCM} / \mathrm{MeOH}(1: 0 \rightarrow 4: 1 \mathrm{v} / \mathrm{v})$ to afford the title compound $(7 \mathrm{mg}, 54 \%)$ as a colourless glass; $R_{f}=0.32\left(\right.$ PE:EtOAc 1:3 v/v); ${ }^{1} \mathrm{H}-\mathrm{NMR}\left(400 \mathrm{MHz}, \mathrm{CDCl}_{3}\right) \delta 8.00(\mathrm{~s}, 1 \mathrm{H}, 2-\mathrm{H}), 7.93(\mathrm{~s}, 1 \mathrm{H}$, $8-\mathrm{H}), 5.78\left(\mathrm{~d}, J=1.3 \mathrm{~Hz}, 1 \mathrm{H}, \mathrm{H}-1^{\prime}\right), 5.69(\mathrm{~d}, J=9.6 \mathrm{~Hz}, 1 \mathrm{H}), 5.66(\mathrm{~d}, J=9.6 \mathrm{~Hz}, 1 \mathrm{H})(2 \mathrm{H}$, $\mathrm{CH}_{2} \mathrm{OTBDMS}$ ), 5.43 (br s, $\left.2 \mathrm{H}, \mathrm{NH}_{2}\right), 5.29\left(\mathrm{dd}, J=6.4,1.3 \mathrm{~Hz}, 1 \mathrm{H}, \mathrm{H}-2^{\prime}\right), 5.10(\mathrm{dd}, J=6.4$, $\left.2 . \overline{\mathrm{Hz}}, 1 \mathrm{H}, \mathrm{H}-3^{\prime}\right), 4.53-4.46\left(\mathrm{~m}, 3 \mathrm{H}, \mathrm{H}-4^{\prime}, 2 \times \mathrm{H}-5^{\prime}\right), 1.57\left(\mathrm{~s}, 3 \mathrm{H}, \mathrm{CCH}_{3}\right), 1.35(\mathrm{~s}, 3 \mathrm{H}$, $\left.\mathrm{CCH}_{3}\right), 0.88(\mathrm{~s}, 9 \mathrm{H}), 0.12(\mathrm{~s}, 3 \mathrm{H}), 0.11(\mathrm{~s}, 3 \mathrm{H})(15 \mathrm{H}, \mathrm{TBDMS}) ;{ }^{13} \mathrm{C}-\mathrm{NMR}\left(125 \overline{\mathrm{MHz}}, \mathrm{CDCl}_{3}\right) \delta$ $156.4,147.4,146.8,140.4,124.2,114.5\left(\mathrm{C}\left(\mathrm{CH}_{3}\right)_{2}\right), 96.8\left(\mathrm{C}-1^{\prime}\right), 86.8\left(\mathrm{C}-4^{\prime}\right), 84.6\left(\mathrm{C}-2^{\prime}\right), 81.9$ $\left(\mathrm{C}-3^{\prime}\right), 69.9\left(\mathrm{C}-5^{\prime}\right), 67.7\left(\mathrm{CH}_{2} \mathrm{OTBDMS}\right), 27.0\left(\mathrm{CCH}_{3}\right), 25.5\left(3 \mathrm{C}, \mathrm{SiC}\left(\mathrm{CH}_{3}\right)_{3}\right), 25.2\left(\mathrm{CCH}_{3}\right)$, $18.0\left(\mathrm{SiC}\left(\mathrm{CH}_{3}\right)_{3}\right),-5.2\left(2 \mathrm{C}, \mathrm{Si}\left(\mathrm{CH}_{3}\right)_{2}\right)$; HRMS $\left(\mathrm{ES}^{+}\right)$calcd for $\mathrm{C}_{20} \mathrm{H}_{34} \mathrm{~N}_{5} \mathrm{O}_{8} \mathrm{SSi} 532.1892$ $(\mathrm{M}+\mathrm{Na})^{+}$found 532.1909 .

$N 1-\left(5^{\prime}\right.$-O-sulfonamide- $\beta$-D-ribofuranosyl)-hypoxanthine (N1-IMS, 29)-N1-(2', $3^{\prime}-\mathrm{O}-$ Isopropylidene- $5^{\prime}$-O-sulfonamide- $\beta$-D-ribofuranosyl)- $N$ 9-tert-butyldimethylsilyloxymethylhypoxanthine $(57,5.5 \mathrm{mg}, 10 \mu \mathrm{mol})$ was cooled to $0{ }^{\circ} \mathrm{C}$ and $\mathrm{H}_{2} \mathrm{O}(1 \mathrm{~mL})$ then TFA ( $1 \mathrm{~mL})$ added. The solution was allowed to warm to $\mathrm{rt}$ and stirred for $3 \mathrm{~h}$. All solvent was evaporated and the residue co-evaporated with $\mathrm{MeOH}(\times 3)$. The residue was purified by column chromatography on silica gel eluting with $\mathrm{DCM} / \mathrm{MeOH}(1: 0 \rightarrow 4: 1 v / v)$ to afford the title compound ( $3 \mathrm{mg}, 84 \%)$ as a colourless glass; ${ }^{1} \mathrm{H}-\mathrm{NMR}\left(500 \mathrm{MHz}, \mathrm{D}_{2} \mathrm{O}\right) \delta$ $8.32(\mathrm{~s}, 1 \mathrm{H}), 8.18(\mathrm{br} \mathrm{s}, 1 \mathrm{H}), 6.06(\mathrm{~d}, J=3.3 \mathrm{~Hz}, 1 \mathrm{H}), 4.48(\mathrm{dd}, J=11.4,1.9 \mathrm{~Hz}, 1 \mathrm{H}), 4.36$ $(\mathrm{dd}, J=11.4,3.3 \mathrm{~Hz}, 1 \mathrm{H}), 4.33(\mathrm{dd}, J=4.6,3.5 \mathrm{~Hz}, 1 \mathrm{H})$ and $4.29-4.25(\mathrm{~m}, 2 \mathrm{H}) ;{ }^{13} \mathrm{C}-\mathrm{NMR}$ $\left(125 \mathrm{MHz}, \mathrm{D}_{2} \mathrm{O}\right) \delta 155.7,151.2,145.0,141.9,117.7,90.4,81.1,74.2,68.8$ and 68.3; HRMS $\left(\right.$ ES $^{-}$) calcd for $\mathrm{C}_{10} \mathrm{H}_{13} \mathrm{~N}_{5} \mathrm{O}_{7} \mathrm{SNa} 370.0428(\mathrm{M}-\mathrm{H})^{-}$found 370.0437.

\subsection{Enzymatic Assay for cADPR Hydrolysis}

The inhibition of cADPR hydrolysis by various concentrations of inhibitor $(0-1 \mathrm{mM})$ was determined by incubating $1 \mu \mathrm{M}$ cADPR with $1 \mu \mathrm{g} / \mathrm{mL}$ of CD38 for $10 \mathrm{~min}$ at $20-24^{\circ} \mathrm{C}$ in $25 \mathrm{mM}$ sodium acetate, $\mathrm{pH}$ 4.5. The reaction was stopped by the addition of $150 \mathrm{mM}$ $\mathrm{HCl}$. The precipitated protein was filtered, and the $\mathrm{pH}$ was neutralized with Tris base. After diluting the mixture 20-fold, the concentration of the unhydrolyzed cADPR present in the diluted reaction mixture was assayed by the fluorimetric cycling assay as previously described [46]. 


\subsection{HPLC Studies}

HPLC studies were carried out as previously described [36]. Briefly, the solution containing shCD38 was adjusted to the desired concentration $(4 \mathrm{mg} / \mathrm{mL})$ using Tris- $\mathrm{HCl}$ buffer $(20 \mathrm{mM}, \mathrm{pH})$ and $50 \mu \mathrm{L}$ was added to the inhibitor $(0.05 \mu$ mole in MilliQ $(2 \mathrm{~mL})$ $1 \mathrm{mM}$ final concentration) in an Eppendorf tube at room temperature $(\mathrm{T}=0)$. At a given time point, a sample of $5 \mu \mathrm{L}$ was removed and diluted with $95 \mu \mathrm{L}$ MilliQ water. $10 \mu \mathrm{L}$ Of this sample was injected directly into the analytical HPLC system (see General Experimental), eluting at $1 \mathrm{~mL} / \mathrm{min}$ with an isocratic ion-pair buffer: $0.17 \%(\mathrm{~m} / \mathrm{v})$ cetrimide and $45 \%(v / v)$ phosphate buffer (pH 6.4) in $\mathrm{MeOH}$.

\section{Conclusions}

Five fragment scaffolds were prepared, each with multiple 8-substitutions. N1-ribosylinosine derivatives 14-17 and N9-Hydroxybutyl-N1-inosine derivatives 18-21 are nonphosphorylated analogues that retain the key "northern" ribose motif. These analogues illustrate the importance of the $5^{\prime}$-phosphate group on the "northern" ribose for CD38 inhibitory activity. Introduction of the $5^{\prime}$-phosphate group to in N9-hydroxybutyl-N1-IMP analogues 22-25 shows some improvement in activity; however, the unconstrained N9butyl chain appeared to be detrimental, compared to its effect in cyclic analogues [36]. The promising fragment 8- $\mathrm{NH}_{2}-\mathrm{N} 1-\mathrm{IMP}(\mathbf{1 1})$ was prepared via total synthesis for the first time, which affords a route to generate this analogue in more significant amounts (compared alternatively to the previously reported degradation of the cyclic parent analog) and to access other related analogues for SAR studies. To illustrate the utility of this new synthetic route, L-ribose (26-27) and sulphonamide (28-29) analogues were prepared. In summary, this work illustrates the potential for design of much simpler and mono-phosphorylated CD38 inhibitors, through a key structural motif derived from its macrocyclic pyrophosphate ligand that could be worthy of future optimization and development. Importantly, their continuing, albeit weak, substrate activity implies that such compounds bind closely mimicking the relevant part of the natural ligand, which should aid structure-based design strategies. CD38 while generally an ectoenzyme, does also exist inside cells, so the reduction of the inhibitor class to a simple monophosphate derivative as here makes available wellestablished prodrug strategies that should improve inhibitor access.

Supplementary Materials: The following are available online, Figure S1: Hydrolysis of 8- $\mathrm{NH}_{2-}$ N1-IMP by high concentrations of shCD $38 ;{ }^{1} \mathrm{H},{ }^{13} \mathrm{C}$ and ${ }^{31} \mathrm{P}$ spectral data and HPLC profiles for novel compounds.

Author Contributions: Conceptualization, B.V.L.P. and J.M.W.; methodology (synthesis of compounds), J.M.W.; methodology (biological evaluation), R.G.; writing—original draft preparation, review and editing, B.V.L.P. and J.M.W.; All authors have read and agreed to the published version of the manuscript.

Funding: This research was funded by The Wellcome Trust, grant number 101010. B.V.L.P. is a Wellcome Trust Senior Investigator. APC was funded by MDPI. For the purpose of Open Access, the authors have applied a CC BY public copyright license to any Author Accepted Manuscript version arising from this submission.

Institutional Review Board Statement: Not applicable.

Informed Consent Statement: Not applicable.

Data Availability Statement: All relevant data are presented within the body of this paper or in the Supplementary Information.

Conflicts of Interest: The authors declare no conflict of interest.

Sample Availability: Samples of some compounds may be available from the authors. 


\section{References}

1. Clapper, D.L.; Walseth, T.F.; Dargie, P.J.; Lee, H.C. Pyridine-nucleotide metabolites stimulate calcium release from sea-urchin egg microsomes desensitized to inositol trisphosphate. J. Biol. Chem. 1987, 262, 9561-9568. [CrossRef]

2. Ashamu, G.A.; Sethi, J.K.; Galione, A.; Potter, B.V.L. Roles for adenosine ribose hydroxyl groups in cyclic adenosine $5^{\prime}$-diphosphate ribose-mediated $\mathrm{Ca}^{2+}$-release. Biochemistry 1997, 36, 9509-9517. [CrossRef] [PubMed]

3. Guse, A.H.; Cakir-Kiefer, C.; Fukuoka, M.; Shuto, S.; Weber, K.; Bailey, V.C.; Matsuda, A.; Mayr, G.W.; Oppenheimer, N.; Schuber, F.; et al. Novel hydrolysis-resistant analogues of cyclic ADP-ribose: Modification of the "northern" ribose and calcium release activity. Biochemistry 2002, 41, 6744-6751. [CrossRef] [PubMed]

4. Bailey, V.C.; Fortt, S.M.; Summerhill, R.J.; Galione, A.; Potter, B.V.L. Cyclic aristeromycin diphosphate ribose: A potent and poorly hydrolysable $\mathrm{Ca}^{2+}$-mobilising mimic of cyclic adenosine diphosphate ribose. FEBS Lett. 1996, 379, 227-230. [CrossRef]

5. Zhang, F.J.; Gu, Q.M.; Sih, C.J. Bioorganic chemistry of cyclic ADP-ribose (cADPR). Bioorg. Med. Chem. 1999, 7, 653-664. [CrossRef]

6. Lee, H.C. Multiplicity of $\mathrm{Ca}^{2+}$ messengers and $\mathrm{Ca}^{2+}$ stores: A perspective from cyclic ADP-ribose and NAADP. Curr. Mol. Med. 2004, 4, 227-237. [CrossRef]

7. Guse, A.H. Biochemistry, biology, and pharmacology of cyclic adenosine diphosphoribose (cADPR). Curr. Med. Chem. 2004, 11, 847-855. [CrossRef] [PubMed]

8. Guse, A.H. Regulation of calcium signaling by the second messenger cyclic adenosine diphosphoribose (cADPR). Curr. Mol. Med. 2004, 4, 239-248. [CrossRef] [PubMed]

9. Guse, A.H. Second messenger function and the structure-activity relationship of cyclic adenosine diphosphoribose (cADPR). FEBS J. 2005, 272, 4590-4597. [CrossRef] [PubMed]

10. Potter, B.V.L.; Walseth, T.F. Medicinal chemistry and pharmacology of cyclic ADP-ribose. Curr. Mol. Med. $2004,4,303-311$. [CrossRef]

11. Shuto, S.; Matsuda, A. Chemistry of cyclic ADP-ribose and its analogs. Curr. Med. Chem. 2004, 11, 827-845. [CrossRef]

12. Howard, M.; Grimaldi, J.C.; Bazan, J.F.; Lund, F.E.; Santosargumedo, L.; Parkhouse, R.M.E.; Walseth, T.F.; Lee, H.C. Formation and hydrolysis of cyclic ADP-ribose catalyzed by lymphocyte antigen CD38. Science 1993, 262, 1056-1059. [CrossRef]

13. Kim, H.; Jacobson, E.L.; Jacobson, M.K. Synthesis and degradation of cyclic ADP-ribose by NAD glycohydrolases. Science 1993, 261, 1330-1333. [CrossRef]

14. Chini, E.N.; Chini, C.C.S.; Netto, J.M.E.; de Oliveira, G.C.; van Schooten, W. The Pharmacology of CD38/NADase: An Emerging Target in Cancer and Diseases of Aging. Trends Pharmacol. Sci. 2018, 39, 424-436. [CrossRef]

15. Jin, D.; Liu, H.X.; Hirai, H.; Torashima, T.; Nagai, T.; Lopatina, O.; Shnayder, N.A.; Yamada, K.; Noda, M.; Seike, T.; et al. CD38 is critical for social behaviour by regulating oxytocin secretion. Nature 2007, 446, 41-45. [CrossRef] [PubMed]

16. Martin, T.G.; Corzo, K.; Chiron, M.; van de Velde, H.; Abbadessa, G.; Campana, F.; Solanki, M.; Meng, R.; Lee, H.; Wiederschain, D.; et al. Therapeutic Opportunities with Pharmacological Inhibition of CD38 with Isatuximab. Cells 2019, 8, 1522. [CrossRef]

17. Sauve, A.A.; Deng, H.T.; Angeletti, R.H.; Schramm, V.L. A covalent intermediate in CD38 in responsible for ADP-ribosylation and cyclisation reactions. J. Am. Chem. Soc. 2000, 122, 7855-7859. [CrossRef]

18. Sauve, A.A.; Schramm, V.L. Mechanism-based inhibitors of CD38: A mammalian cyclic ADP-ribose synthetase. Biochemistry 2002, 41, 8455-8463. [CrossRef]

19. Wall, K.A.; Klis, M.; Kornet, J.; Coyle, D.; Ame, J.C.; Jacobson, M.K.; Slama, J.T. Inhibition of the intrinsic NAD ${ }^{+}$glycohydrolase activity of CD38 by carbocyclic NAD analogues. Biochem. J. 1998, 335, 631-636. [CrossRef]

20. Dong, M.; Si, Y.-Q.; Sun, S.-Y.; Pu, X.-P.; Yang, Z.-J.; Zhang, L.-R.; Zhang, L.-H.; Leung, F.P.; Lam, C.M.C.; Kwong, A.K.Y.; et al. Design, synthesis and biological characterization of novel inhibitors of CD38. Org. Biomol. Chem. 2011, 9, 3246-3257. [CrossRef] [PubMed]

21. Wang, S.; Zhu, W.; Wang, X.; Li, J.; Zhang, K.; Zhang, L.; Zhao, Y.-J.; Lee, H.C.; Zhang, L. Design, synthesis and SAR studies of NAD analogues as potent inhibitors towards CD38 NADase. Molecules 2014, 19, 15754-15767. [CrossRef]

22. Zhou, Y.; Ting, K.Y.; Lam, C.M.C.; Kwong, A.K.Y.; Xia, J.; Jin, H.; Liu, Z.; Zhang, L.; Lee, H.C.; Zhang, L. Design, synthesis and biological evaluation of noncovalent inhibitors of human CD38 NADase. ChemMedChem 2012, 7, 223-228. [CrossRef]

23. Kellenberger, E.; Kuhn, I.; Schuber, F.; Müller-Steffner, H. Flavonoids as inhibitors of human CD38. Bioorg. Med. Chem. Lett. 2011, 21, 3939-3942. [CrossRef]

24. Yang, L.; Li, T.; Li, S.; Wu, Y.; Shi, X.; Jin, H.; Liu, Z.; Zhao, Y.; Zhang, L.; Lee, H.C.; et al. Rational Design and Identification of Small-Molecule Allosteric Inhibitors of CD38. ChemBioChem 2019, 20, 2485-2493. [CrossRef] [PubMed]

25. Liu, Q.; Kriksunov, I.A.; Graeff, R.; Munshi, C.; Lee, H.C.; Hao, Q. Crystal structure of human CD38 extracellular domain. Structure 2005, 13, 1331-1339. [CrossRef]

26. Graeff, R.; Liu, Q.; Kriksunov, I.A.; Kotaka, M.; Oppenheimer, N.; Hao, Q.; Lee, H.C. Mechanism of cyclizing NAD to cyclic ADP-ribose by ADP-ribosyl cyclase and CD38. J. Biol. Chem. 2009, 284, 27629-27636. [CrossRef] [PubMed]

27. Graeff, R.; Liu, Q.; Kriksunov, I.A.; Hao, Q.; Lee, H.C. Acidic residues at the active sites of CD38 and ADP-ribosyl cyclase determine nicotinic acid adenine dinucleotide phosphate (NAADP) synthesis and hydrolysis activities. J. Biol. Chem. 2006, 281, 28951-28957. [CrossRef]

28. Liu, Q.; Kriksunov, I.A.; Graeff, R.; Lee, H.C.; Hao, Q. Structural basis for formation and hydrolysis of the calcium messenger cyclic ADP-ribose by human CD38. J. Biol. Chem. 2007, 282, 5853-5861. [CrossRef] 
29. Liu, Q.; Graeff, R.; Kriksunov, I.A.; Jiang, H.; Zhang, B.; Oppenheimer, N.; Lin, H.N.; Potter, B.V.L.; Lee, H.C.; Hao, Q. Structural basis for enzymatic evolution from a dedicated ADP-ribosyl cyclase to a multifunctional NAD hydrolase. J. Biol. Chem. 2009, 284, 27637-27645. [CrossRef] [PubMed]

30. Wagner, G.K.; Black, S.; Guse, A.H.; Potter, B.V.L. First enzymatic synthesis of an N1-cyclised cADPR (cyclic ADP-ribose) analogue with a hypoxanthine partial structure: Discovery of a membrane permeant cADPR agonist. Chem. Commun. 2003, 1944-1945. [CrossRef] [PubMed]

31. Wagner, G.K.; Guse, A.H.; Potter, B.V.L. Rapid synthetic route toward structurally modified derivatives of cyclic adenosine 5'-diphosphate ribose. J. Org. Chem. 2005, 70, 4810-4819. [CrossRef]

32. Kirchberger, T.; Wagner, G.K.; Xu, J.; Cordiglieri, C.; Wang, P.; Gasser, A.; Fliegert, R.; Bruhn, S.; Flugel, A.; Lund, F.E.; et al. Cellular effects and metabolic stability of N1-cyclic inosine diphosphoribose and its derivatives. Br. J. Pharmacol. 2006, 149, 337-344. [CrossRef]

33. Swarbrick, J.M.; Potter, B.V.L. Total synthesis of a cyclic adenosine 5'-diphosphate ribose receptor agonist. J. Org. Chem. 2012, 77, 4191-4197. [CrossRef]

34. Liu, Q.; Kriksunov, I.A.; Moreau, C.; Graeff, R.; Potter, B.V.L.; Lee, H.C.; Hao, Q. Catalysis associated conformational changes revealed by human CD38 complexed with a non-hydrolysable substrate analog. J. Biol. Chem. 2007, 282, 24825-24832. [CrossRef]

35. Swarbrick, J.M.; Graeff, R.; Garnham, C.; Thomas, M.P.; Galione, A.; Potter, B.V.L. "Click cyclic ADP-ribose": A neutral second messenger mimic. Chem. Commun. 2014, 50, 2458-2461. [CrossRef]

36. Swarbrick, J.M.; Graeff, R.; Zhang, H.; Thomas, M.P.; Hao, Q.; Potter, B.V.L. Cyclic adenosine 5'-diphosphate ribose analogs without a "southern" ribose inhibit ADP ribosyl cyclase-hydrolase CD38. J. Med. Chem. 2014, 57, 8517-8529. [CrossRef]

37. Moreau, C.; Wagner, G.K.; Weber, K.; Guse, A.H.; Potter, B.V.L. Structural determinants for N1/N7 cyclization of nicotinamide hypoxanthine dinucleotide derivatives by ADP-ribosyl cyclase from Aplysia californica: $\mathrm{Ca}^{2+}$-mobilizing activity of 8-substituted cyclic inosine 5'-diphosphoribose analogs in T-lymphocytes. J. Med. Chem. 2006, 49, 5162-5176. [CrossRef]

38. Shuto, S.; Fukuoka, M.; Manikowsky, A.; Ueno, Y.; Nakano, T.; Kuroda, R.; Kuroda, H.; Matsuda, A. Total synthesis of cyclic ADP-carbocyclic ribose, a stable mimic of the $\mathrm{Ca}^{2+}$-mobilizing second messenger cyclic ADP-ribose. J. Am. Chem. Soc. 2001, 123, 8750-8759. [CrossRef]

39. Moreau, C.; Liu, Q.; Graeff, R.; Wagner, G.K.; Swarbrick, J.M.; Thomas, M.P.; Shuto, S.; Lee, H.-C.; Hao, Q.; Potter, B.V.L. CD38 Structure-Based Inhibitor Design using the N1-Cyclic Inosine 5'-Diphosphate Ribose Template. PLoS ONE 2013, 8, e66247. [CrossRef]

40. Watt, J.M.; Graeff, R.; Thomas, M.P.; Potter, B.V.L. Second messenger analogues highlight unexpected substrate sensitivity of CD38: Total synthesis of the hybrid "L-cyclic inosine 5'-diphosphate ribose". Sci. Rep. 2017, 7, 16100. [CrossRef]

41. Watt, J.M.; Thomas, M.P.; Potter, B.V.L. Synthetic cADPR analogues may form only one of two possible conformational diastereoisomers. Sci. Rep. 2018, 8, 15268. [CrossRef]

42. Moreau, C.; Woodman, T.J.; Potter, B.V.L. Unusual entry to the novel 8-halo-N1-ribosyl hypoxanthine system by degradation of a cyclic adenosine 5'-diphosphate ribose analogue. Chem. Commun. 2006, 1127-1129. [CrossRef] [PubMed]

43. Lang, P.; Magnin, G.; Mathis, G.; Burger, A.; Biellmann, J.-F. Synthesis of 8-( $\omega$-Hydroxyalkyl)-, 8-( $\omega$-Hydroxyalk-1-enyl)-, and 8-( $\omega$-Hydroxyalk-1-ynyl)adenines Using the tert-Butyldimethylsilyl-oxymethyl Group, a New and Versatile Protecting Group of Adenine. J. Org. Chem. 2000, 65, 7825-7832. [CrossRef] [PubMed]

44. Elliott, T.S.; Slowey, A.; Yeb, Y.; Conway, S.J. The use of phosphate bioisosteres in medicinal chemistry and chemical biology. Med. Chem. Commun. 2012, 3, 735-751. [CrossRef]

45. Ames, B.N.; Dubin, D.T. The role of polyamines in the neutralization of bacteriophage deoxyribonucleic acid. J. Biol. Chem. 1960, 235, 769-775. [CrossRef]

46. Graeff, R.M.; Lee, H.C. A novel cycling assay for cellular cADP-ribose with nanomolar sensitivity. Biochem. J. 2002, 361, 379-384. [CrossRef] 